\title{
A role for gene-environment interactions in Autism Spectrum Disorder is suggested by variants in genes regulating exposure to environmental factors
}

\author{
João Xavier Santos ${ }^{1,2}$, Célia Rasga ${ }^{1,2}$, Ana Rita Marques ${ }^{1,2}$, Hugo F. M. C. Martiniano ${ }^{1,2}$, \\ Muhammad Asif ${ }^{1,2}$, Joana Vilela ${ }^{1,2}$, Guiomar Oliveira ${ }^{3,4,5}$, Astrid Moura Vicente ${ }^{1,2^{*}}$ \\ * Correspondence: Astrid M. Vicente, Instituto Nacional de Saúde Doutor Ricardo Jorge, Avenida \\ Padre Cruz, 1649-016 Lisboa, Portugal. Email: astrid.vicente@insa.min-saude.pt \\ ${ }^{1}$ Instituto Nacional de Saúde Doutor Ricardo Jorge, Avenida Padre Cruz, 1649-016 Lisboa, Portugal \\ ${ }^{2}$ BioISI: Biosystems \& Integrative Sciences Institute, Faculdade de Ciências, Universidade de Lisboa, \\ Lisboa, Portugal \\ ${ }^{3}$ Unidade de Neurodesenvolvimento e Autismo (UNDA), Serviço do Centro de Desenvolvimento da \\ Criança, Centro de Investigação e Formação Clínica, Hospital Pediátrico, Centro Hospitalar e \\ Universitário de Coimbra, Coimbra, Portugal \\ ${ }^{4}$ Institute for Biomedical Imaging and Life Sciences, Faculty of Medicine, Universidade de Coimbra, \\ Coimbra, Portugal \\ ${ }^{5}$ University Clinic of Pediatrics, Faculty of Medicine, University of Coimbra, Portugal
}

\begin{abstract}
Introduction: Autism Spectrum Disorder (ASD) is a clinically heterogeneous neurodevelopmental disorder defined by deficits in social communication and interaction and repetitive and stereotyped interests and behaviors. ASD heritability estimates of 50-83\% support a strong role of genetics in its onset, with large sequencing studies reporting a high burden of rare potentially pathogenic copy number variants (CNVs) and single nucleotide variants (SNVs) in affected subjects. Recent data strongly suggests that prenatal to postnatal exposure to ubiquitous environmental factors (e.g. environmental toxins, medications and nutritional factors) contribute to ASD risk. Detoxification processes and physiological permeability barriers (i.e. blood-brain barrier, placenta and respiratory cilia) are crucial in regulating exposure and response to external agents during early development. Thus, the objectives of this study were: 1) to find genes involved in detoxification and regulation of barriers permeability with a high load of relevant CNVs and SNVs in ASD subjects; 2) to explore interactions between the identified genes and environmental factors relevant for the disorder.

Material and Methods: Through literature and databases review we searched for genes involved in detoxification and regulation of barriers permeability processes. Genetic data collected from large datasets of subjects with ASD (Autism Genome Project (AGP), Simmons Simplex Collection (SSC), and Autism Sequencing Consortium (ASC)) was used to identify potentially pathogenic variants targeting detoxification and barrier genes. Data from control subjects without neuropsychiatric disorder history was used for comparison purposes. The Comparative Toxicogenomics Database (CTD) was interrogated to identify putatively relevant gene-environment interactions reported in humans throughout the literature.
\end{abstract}

Results: We compiled a list of 519 genes involved in detoxification and regulation of permeability barriers. The analysis of AGP and SSC data resulted in the identification of 7 genes more-frequently targeted by CNVs in ASD subjects from both datasets, after Bonferroni correction for multiple testing 
(AGP: $\mathrm{P}<3.5211 \times 10^{-4}$; SSC: $\mathrm{P}<4.587 \times 10^{-4}$ ). Moreover, 8 genes were exclusively targeted by CNVs from ASD subjects. Regarding SNVs analyses using the ASC dataset, we found 40 genes targeted by potentially pathogenic loss-of-function and/or missense SNVs exclusive to 6 or more cases. The CTD was interrogated for interactions between 55 identified genes and 54 terms for unique chemicals associated with the disorder. A total of 212 gene-environment interaction pairs, between 51/55 (92.7\%) genes and 38/54 (70.4\%) chemicals, putatively relevant for ASD, were discovered. ABCB1, $A B C G 2, C Y P 2 C 19$, GSTM1, CYP2D6, and SLC3A2 were the genes that interacted with more chemicals, while valproic acid, benzo(a)pyrene $(\mathrm{b}(\mathrm{a}) \mathrm{p})$, bisphenol A, particulate matter and perfluorooctane sulfonic acid (PFOS) were the top chemicals.

Discussion: The identified genes code for functionally diverse proteins, ranging from enzymes that increase the degradability of xenobiotics (CYP450s, UGTs and GSTs), to transporters (ABCs and SLCs), proteins that regulate the correct function of barriers (claudins and dyneins) and placental hormones. The identified gene-environment interactions may reflect the fact that some genes and chemicals are understudied and that the potential neurotoxicity of many substances is unreported. We suggest that environmental factors can have pathogenic effects when individuals carry variants targeting these genes and discuss the potential mechanisms by which these genes can influence ASD risk.

Conclusion: We reinforce the hypothesis that gene-environment interactions are relevant, at least, for a subset of ASD cases. Given that no treatment exists for the pathology, the identification of relevant modifiable exposures can contribute to the development of preventive strategies for health management policies in ASD.

\section{Introduction}

Autism spectrum disorder (ASD) is an early onset neurodevelopmental disorder characterized by deficits on social communication and interaction and repetitive and stereotyped interests and behaviors $(1,2)$. These two core features often appear associated with other symptoms, such as intellectual disability, speech delays and attention deficits (2), originating a phenotypically heterogeneous spectrum. In recent years, ASD prevalence estimates have been on the rise, with values of $1-5 \%$ being reported in developed countries $(3,4)$. Regarding gender distribution, a male skewness in consistently reported, with a male-to-female ratio of $4: 1$ to $3: 1$ being assumed $(5,6)$.

The advent of high-throughput sequencing platforms has identified multiple rare de novo or inherited high-effect copy number variants (CNVs) (7-11) and gene-disrupting single nucleotide variants (SNVs) (12-14) associated with pathology. Low-effect common variants are also relevant (15). ASD onset can also happen in a syndromic context, comorbid to pathologies like Fragile $\mathrm{X}$ syndrome, Rett Syndrome and Tuberous sclerosis (16). Despite this, most cases of the disorder remain idiopathic. Moreover, family studies, particularly monozygotic and dizygotic twin studies, report ASD heritability estimates of 50-83\% (17-19), which clearly leave space for a role of non-genetic factors in the disorder. Current research suggests that ASD is likely explained by a multifactorial etiology that includes genetic and non-genetic risk factors, which interact in a cumulative way to reach a threshold for onset $(15,17,18,20)$.

Since the beginning of the 2000 s, studies started to focus on prenatal to postnatal exposure to environmental agents as non-genetic risk factors. Early development is a recognized window of susceptibility to external cues, which can have detrimental effects, potentially modulating the neuropathological events that lead to the onset of the disorder (21). To infer associations between 
early exposures and ASD risk, studies either adopt prospective or retrospective designs, resorting to one of four different strategies to measure the exposures: 1) collection of biological samples (blood (22), urine (23) and naturally-shed deciduous teeth (24)) from the pregnant women and/or their offspring to quantify multiple analytes; 2) application of questionnaires answered by the mothers of the children to evaluate self-reported exposures $(25,26) ; 3)$ geo-referencing studies for the mapping of sources of environmental toxins (e.g. landfill sites (27) and agricultural fields (28)) or understanding of air-quality patterns $(29,30) ; 4)$ analysis of medical and prescription records to evaluate medications and supplements intake (31).

Multiple associations between environmental exposures and ASD have been reported and, while some, such as vaccination and thimerosal exposure, have been contradicted (32), others warrant further investigation. Meta-analyses, as the ones published by Rossignol et al (33) and Modabbernia et al (34), are excellent tools to identify environmental factors more consistently associated with the disorder. In this paper we divide these putatively relevant environmental factors into three major classes: 1) environmental toxins; 2) medications; 3) nutritional factors. Environmental toxins include air pollutants (nitrogen dioxide $\left(\mathrm{NO}_{2}\right)$, ozone $\left(\mathrm{O}_{3}\right)$, particulate matter $(\mathrm{PM})$ and polycyclic aromatic hydrocarbons (PAHs)) $(29,30,35,36)$, bisphenol A (BPA) $(37,38)$, heavy metals (lead, manganese and mercury) $(24,39)$ pesticides $(28,40)$, phthalates $(41,42)$, polybrominated diphenyl ethers (PBDEs) $(22,26)$, polychlorinated biphenyls (PCBs) $(22,26,43)$ and perfluorinated compounds (PFCs) $(22,44)$. Medications include teratogens (valproic acid $(45,46)$ and thalidomide $(47,48)$ ) and antidepressants $(49,50)$. Nutritional factors include folic acid $(51,52)$ and vitamin D.

Exposure to most of the referred toxins is ubiquitous, since they are present in environment, everyday household and industrial products and food. PBDEs, PCBs, PFCs and some heavy metals and pesticides are persistent organic pollutants (POPs), being resistant to degradation through chemical or biological processes (53), which increases their risk of bioaccumulation. Contrary, BPA and phthalates are non-POPs and are, thus, rapidly metabolized (53). Nonetheless, given the virtually ubiquitous exposure, they are still relevant. Most of these toxins have neurotoxic properties (63) and many (e.g. BPA, phthalates, pesticides, PCBs, PBDEs and lead) are recognized endocrine-disrupting chemicals (EDCs) (53-55). EDCs, when ingested or absorbed, can mimic estrogens, androgens and thyroid hormones, acting as agonists or antagonists to hormone receptors, potentially leading to endocrine dysregulations. Regarding medications, thalidomide, primarily sold as a sedative, was widely used to alleviate morning sickness in pregnant women during the 50s, while valproate is prescribed for epilepsy and bipolar disorder. Periods of critical vulnerability these two teratogens are proposed to occur early in pregnancy, concomitant with neural tube closure at $28^{\text {th }}$ day of pregnancy (47). Antidepressants are frequently used to treat maternal depression, with selective serotonin reuptake inhibitors (SSRIs) being the most prescribed ones. Contrary to the other factors, it is deficient gestational or at birth levels of nutritional factors that seem to increase the risk of developing ASD. This is not unexpected, since folic acid is used as a supplement by pregnant women in order to prevent neural tube defects in the developing fetus, and vitamin D is a steroid hormone that plays a crucial role in calcium and phosphorous metabolism. Circulatory levels of 25-hydroxyvitamin D $25(\mathrm{OH}) \mathrm{D}$ - the precursor of the active form of vitamin $\mathrm{D}$, are usually quantified to assess vitamin $\mathrm{D}$ deficiency.

Physiological permeability barriers, such as the placenta, the blood-brain barrier (BBB) and the motile cilia of the human airway epithelia are crucial in limiting the exposure of the organism to chemicals. The BBB, which is formed by brain endothelial cells, functions as a semipermeable 
membrane to various neurotoxins, thanks to the tight junctions between these cells (56). The placenta establishes an interface between the mother and the developing fetus that, among other functions, regulates transfer of nutrients and waste products between maternal and fetal plasma (57). Finally, the respiratory epithelium serves as a barrier to potential xenobiotics by the action of mucociliary clearance carried by the cilia (58). Most of the referred environmental factors are able to cross these structures (59-64). Meanwhile, detoxification pathways involve a series of enzymatic reactions that act to detoxify xenobiotics and remove them from cells. Thus, these structures and processes are of crucial importance during neurodevelopment, when the organism is particularly vulnerable to exogenous influences.

The objectives of this study were: 1) to identify if genes involved in detoxification and regulation of barriers permeability are targeted by potentially pathogenic CNVs and SNVs in subjects with ASD; 2) to understand if such genes interact with environmental factors relevant for the disorder. We hypothesize that environmental factors can have pathogenic effects in genetically susceptible individuals. For such, we questioned large population datasets composed by individuals with ASD for the presence of variants targeting genes involved in detoxification and regulation of barriers permeability, and compared the results with control populations without history of neuropsychiatric disorder. We further explored interactions between such genes and the environmental factors potentially relevant for ASD.

\section{Materials and Methods}

\section{Population datasets}

The primary ASD dataset used for CNVs identification was obtained from the Autism Genome Project (AGP) consortium (N=2446 ASD cases) $(8,9)$ (table 1). As control, data from two population cohorts (Cooper et al (65) and Shaikh et al (66)) composed by subjects without clinical history of neuropsychiatric disease was used (N=9649). From Shaikh et al, 694 African-American and 12 Asian-American individuals were not considered (table 1). We had no access to the ethnicity of Cooper et al subjects, and thus all individuals were analyzed. CNV data from these control datasets are publicly available through the Database of Genomic Variants (DGV) (67). Additionally, for results validation, data from the Simons Simplex Collection (SSC) (N=1124 ASD cases), a resource of the Simons Foundation Autism Research (SFARI), was used (table 1) (10). All these populations were genotyped through various Illumina platforms. AGP population was genotyped using Illumina 1M SNP arrays, control populations were genotyped using 550k to 1.2 platforms and SSC population was genotyped using $1 \mathrm{Mv} 3$ or $1 \mathrm{Mv} 1$ arrays.

For SNVs identification we used data from 3426 subjects (2674 cases and 752 controls) with, at least, 80\% Caucasian ethnicity, genotyped through the Autism Sequencing Consortium (ASC) (68). ASC exome-sequencing data was obtained from dbGaP portal (accession code: phs000294.v4.p3). Samples were sequenced at the Broad Institute.

The Autism Diagnostic Interview-Revised (ADI-R) and Autism Diagnostic Observation Schedule (ADOS) tools were applied for assessment of ASD diagnosis in AGP, SSC and ASC datasets. 
Table 1: Data regarding characteristics of the ASD- and control population datasets used in this study. AGP - Autism Genome Project; SSC - Simons Simplex Collection; ASC - Autism Sequencing Consortium

\begin{tabular}{|c|c|c|c|c|}
\hline Dataset & $\begin{array}{c}\text { Population } \\
\text { type }\end{array}$ & $\begin{array}{c}\text { Number of } \\
\text { analyzed subjects }\end{array}$ & Ethnicity (\%) & References \\
\hline AGP & $\begin{array}{l}\text { Simplex and } \\
\text { multiplex } \\
\text { families }\end{array}$ & $\begin{array}{l}2446 \text { subjects } \\
\text { diagnosed with } \\
\text { ASD }\end{array}$ & $\begin{array}{l}\text { Caucasians (87.8\%); African- } \\
\text { Americans (3.1\%); Latin-Americans } \\
(6.3 \%) ; \text { Asians (2.8\%); Mixed (0.1\%) }\end{array}$ & $(8,9)$ \\
\hline SSC & $\begin{array}{l}\text { Simplex } \\
\text { families }\end{array}$ & $\begin{array}{l}1124 \text { subjects } \\
\text { diagnosed with } \\
\text { ASD }\end{array}$ & $\begin{array}{l}\text { Caucasians (78.6\%); African-Americans } \\
(3.8 \%) ; \text { Latin-Americans (4\%); Asians } \\
(4.3 \%) ; \text { Mixed }(9.3 \%)\end{array}$ & (10) \\
\hline $\begin{array}{l}\text { Cooper } \text { et al } \\
2011 \text { control } \\
\text { cohort }\end{array}$ & $\begin{array}{l}\text { Unrelated } \\
\text { subjects }\end{array}$ & $\begin{array}{l}8329 \text { subjects } \\
\text { without history of } \\
\text { neurological } \\
\text { disease }\end{array}$ & $\begin{array}{l}\text { Caucasians }(81.2 \%) \text {; African-Americans } \\
(2 \%) \text {; individuals of other or unknown } \\
\text { ancestry }(16.5 \%)\end{array}$ & (65) \\
\hline $\begin{array}{l}\text { Shaikh et al } \\
2009 \text { control } \\
\text { cohort }\end{array}$ & $\begin{array}{l}\text { Unrelated } \\
\text { subjects }\end{array}$ & $\begin{array}{l}1320 \text { subjects } \\
\text { without history of } \\
\text { neurological } \\
\text { disease }\end{array}$ & $\begin{array}{l}\text { Caucasians }(100 \%) \text { ( } 706 \text { African- or } \\
\text { Asian-Americans were not considered) }\end{array}$ & (66) \\
\hline ASC & $\begin{array}{l}\text { ASD-families } \\
\text { and unrelated } \\
\text { control subjects }\end{array}$ & $\begin{array}{l}2674 \text { subjects with } \\
\text { ASD and } 752 \\
\text { controls }\end{array}$ & Caucasians (100\%) & (68) \\
\hline
\end{tabular}

\section{Identification of genes involved in detoxification and regulation of barriers permeability processes}

To define a list of genes involved in detoxification processes and regulation of blood-brain barrier, placenta or respiratory cilia permeability we performed a literature review, by querying PubMed with the following terms: "detoxification", "placenta", "blood-brain barrier" and "respiratory cilia". To perform this list we limited our query output to reviews, as these offer an excellent compendium for information regarding pathways organization. Additionally, publicly available databases, such as The Human Protein Atlas (69) and Toxin and Toxin-Target Database (T3DB) $(70,71)$ were also used. The Human Protein Atlas contains protein expression data derived from the annotation of immunohistochemical staining of specific cell populations in human tissues and organs, including brain and placenta, allowing for the detection of genes expressed in these organs. $T 3 D B$ provides mechanisms of toxicity and target proteins for a wide variety of toxins, allowing us select genes that code for proteins targeted by relevant environmental factors.

\section{CNVs quality control and characterization}

For this study, only genic variants were considered. Variants from the AGP project were initially predicted using three different algorithms (QuantiSNP, PennCNV and iPattern) (8). As a quality control, variants predicted by only one algorithm or that corresponded to amplification artifacts resultant from the used methodology were excluded. Variants that did not pass quality filters, but were experimentally validated by real time quantitative PCR, as previously described by Pinto et al (8), were analyzed. This way, only genic high-confidence, or experimentally-validated, variants from AGP subjects with a diagnosis of ASD were considered. Considering the SSC dataset, no quality 
control was performed, since the available data already only contained high-quality rare variants (10). In this, variants were defined as rare when up to $50 \%$ of their sequence overlapped regions present at $>1 \%$ frequency in DGV (10).

AGP, SSC and control datasets were analyzed for the frequency with which the studied genes were targeted by CNVs, and putatively relevant genes were then divided into two categories: genes exclusively targeted by CNVs in ASD patients and genes more-frequently targeted by CNVs in ASD patients, after Bonferroni correction for multiple testing. A resume of the used methodology is shown in figure 1. Genes exclusively targeted by CNVs from ASD-subjects may be relevant, even in very low-frequencies, since ultra-rare mutations unique to patients with the disorder are known to play a role in ASD etiology (7-9). Meanwhile, genes more-frequently found in CNVs from ASD-patients, when compared to control subjects, may reveal a better proxy for the effect of exposure to environmental factors (in a gene-environment interaction model for ASD, subjects that carry CNVs targeting the genes studied in this article only develop ASD when exposed to an external trigger; subjects that have CNVs targeting these genes, but are not exposed, show a normal development).

\section{SNVs quality control and variants prioritization}

Regarding exome-sequencing data, quality control was done by filtering out samples with depth $<8$ and genotype quality $\leq 20$ and by excluding variants with missingness $>10 \%$. Very common variants (MAF>5\%), based on frequencies from The Genome Aggregation Database (gnomAD) (72), were not considered. Variant annotation was done using Variant Effect Predictor (VEP) tool from Ensembl (73) which, among other information, allowed us to know the impact predictions attributed to nonsynonymous mutations by SIFT (74) and PolyPhen-2 (75) in silico tools.

For variants prioritization, only loss-of-function (l-o-f) and missense variants, respectively defined as having high and moderate impact by VEP, were considered. Concerning moderate impact variants, only the ones defined as deleterious by SIFT and probably or possibly damaging by PolyPhen-2 were kept. L-o-f variants include frameshift mutations, loss of start or stop codons, gain of a stop codon and mutations in splice donor and acceptor sites. This process in resumed in figure 1. To further refine this prioritization, we ranked the remaining l-o-f and missense variants according to their frequency in ASC cases and controls, establishing six ranks (A-F). Variants ranked highly (rank A) were the ones exclusively present in 6 or more cases, while the ones ranked lower (rank F) were those more-frequently present in controls. After this, in order to identify genes with high burden of potentially pathogenic SNVs, we counted the numbers of 1-o-f and damaging and deleterious missense SNVs, ranked by class, targeting each gene. 


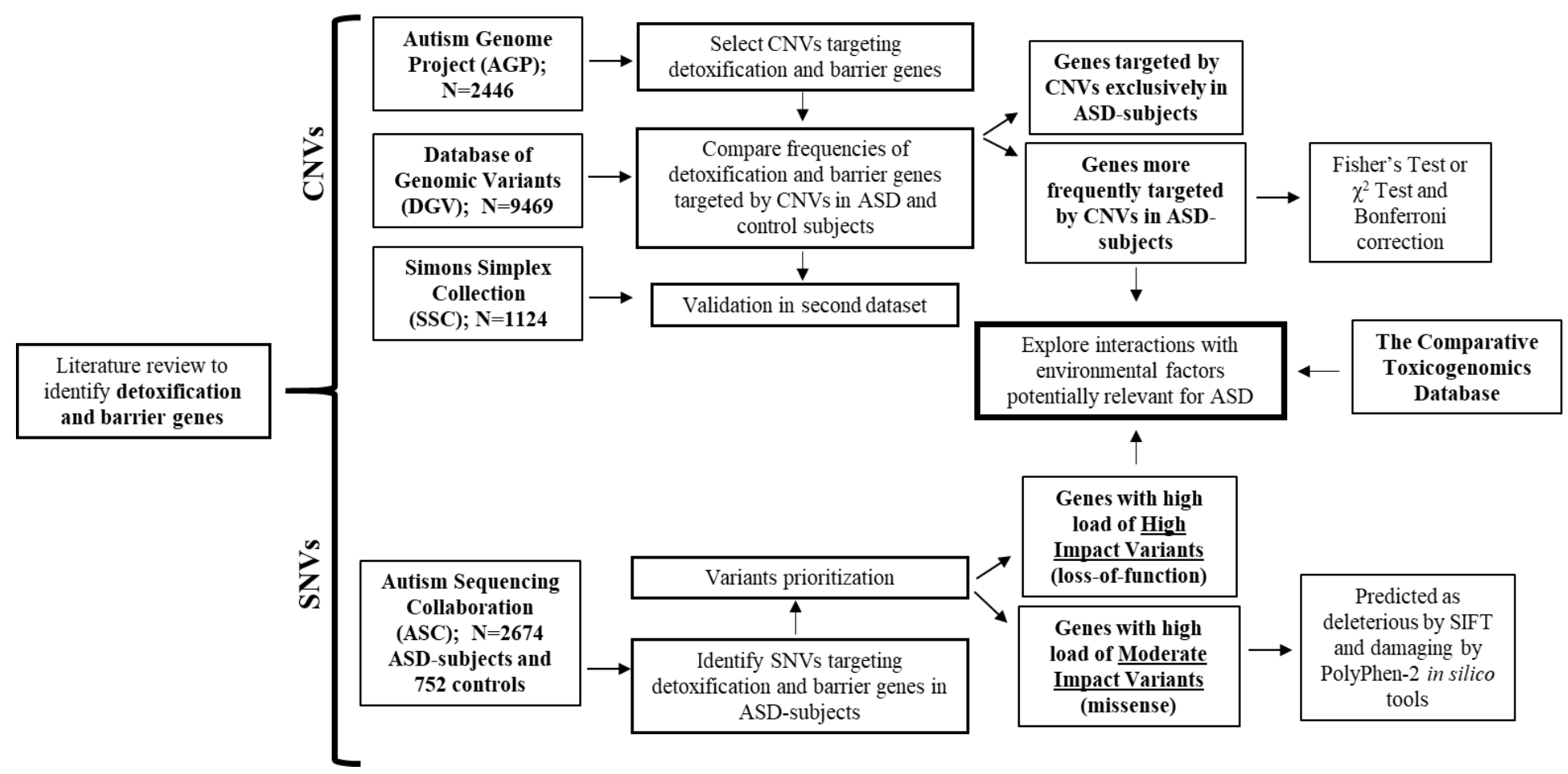

Figure 1: Methodological flowchart resuming the workflow of this study. Large population datasets were used for discovery of detoxification and barrier permeability genes with a high burden of potentially pathogenic CNVs and SNVs in individuals with ASD. The Comparative Toxicogenomics Database was used to explore interactions between the identified genes and environmental factors relevant for the disorder.

\section{Identification of interactions between detoxification and barrier genes and environmental factors potentially relevant for ASD}

To identify gene-environment interactions potentially relevant for the disorder we resorted to The Comparative Toxicogenomics Database (CTD) (figure 1), a manually curated platform that provides information about interactions between chemicals and gene products (76). The CTD organizes chemicals in classes, with broader classes consecutively branching into less inclusive classes. Furthermore, it lists all published references that support each interaction. As of January, 2019, 1854704 curated chemical-gene interactions between 46990 unique genes and 13015 unique chemicals in 590 organisms were recorded by the CTD.

We uploaded the HUGO Gene Nomenclature Committee (HGCN) gene symbols of the studied genes to the CTD query interface. All symbols were found by the CTD. The output files were then manually interrogated for the presence of the MeSH IDs correspondent to each chemical. The MeSH ID is a unique identifier assigned to each chemical by the Medical Subjects Headings (https://www.nlm.nih.gov/mesh/). Only interactions observed in Homo sapiens were considered. We surveyed a total of 54 individual chemicals putatively relevant for ASD (table S1), organized into environmental toxins, medications and nutritional factors. The abbreviations used for each chemical also listed in table S1. A similar approach has been used by Carter and Blizard, where the authors queried 206 candidate genes for autism for interactions with chemicals relevant for ASD (77). 


\section{Statistical Analysis}

Regarding CNVs identification, statistical analysis (Fisher Test or $\chi^{2}$ test) was performed using open source programming language and software environment $\mathrm{R}$. When necessary, the Bonferroni test for multiple comparisons was applied.

\section{Results}

\section{Identification of genes involved in detoxification and regulation of barriers permeability processes}

Through systematic literature review we identified 519 genes involved in detoxification and regulation of barriers permeability processes (table 2). Some of these genes overlap in their roles. For example, GSTP1 is a main glutathione S-transferase that is expressed at the BBB. Meanwhile, ACHE is a gene involved in response to pesticides that is also highly expressed at the placenta. For a full list of the 519 genes identified see figures S1a and S1b.

Table 2: Number of detoxification and permeability regulation of the BBB, placenta or respiratory cilia genes identified through literature review and access to online databases. In italic and parentheses is represented the number of genes solely involved in detoxification or permeability regulation of each of the barriers.

\begin{tabular}{|l|l|l|l|}
\hline Class of genes & $\begin{array}{l}\text { Number of genes (Genes unique to } \\
\text { the process or barrier) }\end{array}$ & Class of genes & $\begin{array}{l}\text { Number of } \\
\text { genes }\end{array}$ \\
\hline \hline Detoxification genes & $297(284)$ & $\begin{array}{l}\text { Detoxification and BBB } \\
\text { genes }\end{array}$ & 7 \\
\hline $\begin{array}{l}\text { Blood-brain barrier } \\
\text { genes }\end{array}$ & $91(81)$ & $\begin{array}{l}\text { Detoxification and placenta } \\
\text { genes }\end{array}$ & 5 \\
\hline $\begin{array}{l}\text { Placenta genes } \\
\text { Respiratory cilia } \\
\text { genes }\end{array}$ & $27(27)$ & BBB and placenta genes & 2 \\
\hline
\end{tabular}

\section{Identification of detoxification and regulation of barrier permeability genes targeted by CNVs from AGP and SSC ASD-subjects}

Using data from AGP, we searched for CNVs from 2446 patients with ASD targeting genes involved in detoxification and regulation of barriers permeability. Moreover, we calculated the frequency with each gene is targeted by CNVs in ASD and control subjects. From the 519 genes identified, 173 (33.3\%) were targeted by CNVs from 555/2446 (22.7\%) ASD-subjects (table 3). Of these 173 genes, 31 (17.9\%) were exclusively targeted by CNVs from 62/2446 (2.5\%) ASD-subjects, while 23 (13.3\%) were more frequently-targeted by CNVs from 261/2446 (10.7\%) ASD-subjects after Bonferroni correction for multiple testing $\left(\mathrm{P}<3.5211 \times 10^{-4}\right)$ (table 3$)$.

Among the genes exclusively targeted by CNVs from ASD-subjects, STS was the most frequent ( $\mathrm{n}=12, \mathrm{~F}=0.50 \%)$, followed by CYP2D6 ( $\mathrm{n}=9, \mathrm{~F}=0.37 \%)$ and $A R S F(\mathrm{n}=5, \mathrm{~F}=0.20 \%)$ (table 4). The genes more-frequently targeted by CNVs in ASD-subjects include nine genes coding UDPglucuronosyltransferases (UGTs), three genes coding for glutathione S-transferases (GSTs), two 
genes coding for members of the ATP-binding cassette (ABC) transporters family and two genes coding for cytochrome P450 family members (table 5). For the additional frequencies for the genes targeted by CNVs in both AGP and control datasets that do not reach statistical significance after correction for multiple testing go to table S2, from supplementary data.

For results validation, we applied the same methodology to the data from the SSC. From the 31 genes found exclusively in CNVs from AGP-subjects, 8(25.8\%) were also exclusively found in CNVs from SSC-subjects. Once more, STS $(\mathrm{n}=7, \mathrm{~F}=0.62 \%)$ and CYP2D6 $(\mathrm{n}=5, \mathrm{~F}=0.45 \%)$ were the most frequently targeted genes. The other 6 genes common two both datasets were CLDN3, ARSF, GUSB, CYP2R1, SLC3A2 and SULT2B1 (table 4). When considering the 23 genes more frequently found in CNVs from AGP-subjects, 7 (30.4\%) were also more frequently-targeted by CNVs in SSC subjects, after correction for multiple testing $\left(\mathrm{P}<4.587 \times 10^{-4}\right)$ (table 5). These were CSH1, MAGEA8, $C Y P 4 X 1, C H S T 5, C S H 2, G H 2$ and $A B C C 1$. Interestingly, two genes coding for glutathione Stransferases (GSTA1 and GSTA2) and three genes coding for sulfotransferases (SULT1A2, SULT1A3 and SULT1A4) were also more-frequently found in CNVs from SSC ASD-subjects, with statistical significance after correction for multiple testing, even though the same was not observed in the AGP dataset (table 5). Again, refer to table S2 for frequency data on additional genes that did not reach statistical significance.

Altogether, we identify a new set of ASD candidate genes, with emphasis on 15 genes which were found associated with the disorder in both AGP and SSC datasets. For a resume of the obtained results see figure $\mathrm{S} 2$. 
Table 3: Numbers and percentages of detoxification and barrier genes targeted by CNVs in individuals from the AGP and SSC datasets and validation results.

\begin{tabular}{|c|c|c|c|c|c|}
\hline & \multicolumn{2}{|c|}{ AGP dataset $(\mathrm{N}=2446)$} & \multicolumn{2}{|c|}{ SSC dataset $(\mathrm{N}=1124)$} & \multirow{2}{*}{\begin{tabular}{|c|} 
Validation \\
Number of common genes between \\
AGP and SSC (and \% relative to \\
number of AGP targeted genes)
\end{tabular}} \\
\hline & $\begin{array}{c}\text { Number of } \\
\text { genes (and } \\
\%)\end{array}$ & $\begin{array}{c}\text { Number of individuals } \\
\text { with CNVs targeting the } \\
\text { genes (and \%) }\end{array}$ & $\begin{array}{c}\text { Number of } \\
\text { genes (and } \\
\%)\end{array}$ & $\begin{array}{c}\text { Number of individuals } \\
\text { with CNVs targeting the } \\
\text { genes (and \%) }\end{array}$ & \\
\hline $\begin{array}{l}\text { Any detoxification and/or } \\
\text { barrier gene }\end{array}$ & \begin{tabular}{|l}
$173 / 519$ \\
$(33.3)$
\end{tabular} & $555 / 2446(22.7)$ & $\begin{array}{l}132 / 519 \\
(25.4)\end{array}$ & 238/1124 (21.2) & 84/173 (48.6) \\
\hline $\begin{array}{l}\text { Genes targeted by CNVs } \\
\text { exclusively in ASD } \\
\text { subjects }\end{array}$ & $31 / 173(17.9)$ & $62 / 2446(2.5)$ & 23/132 (17.4) & $43 / 1124(3.8)$ & 8/31 (25.8) \\
\hline $\begin{array}{l}\text { Genes more-frequently } \\
\text { targeted by CNVs in ASD } \\
\text { subjects }\end{array}$ & 23/173 (13.3) & $261 / 2446(10.7)$ & $12 / 132(9.1)$ & $80 / 1124(7.1)$ & 7/23 (30.4) \\
\hline
\end{tabular}

Table 4: Frequencies observed for genes exclusively targeted by CNVs from individuals with ASD from AGP and/or SSC datasets

\begin{tabular}{|c|c|c|c|c|c|c|}
\hline \multicolumn{3}{|c|}{$\begin{array}{l}\text { Genes exclusively targeted by CNVs from both AGP } \\
\text { and SSC subjects }\end{array}$} & \multicolumn{2}{|c|}{$\begin{array}{c}\text { Genes exclusively targeted by CNVs only } \\
\text { from AGP subjects } \\
\end{array}$} & \multicolumn{2}{|c|}{$\begin{array}{c}\text { Genes exclusively targeted by CNVs only } \\
\text { from SSC subjects }\end{array}$} \\
\hline Gene & $\begin{array}{l}\text { AGP } \\
\mathbf{N}(\%) \\
\end{array}$ & $\begin{array}{c}\text { SSC } \\
\mathbf{N}(\%) \\
\end{array}$ & Gene & $\begin{array}{c}\text { AGP } \\
\mathbf{N}(\%) \\
\end{array}$ & Gene & $\begin{array}{c}\text { SSC } \\
\mathbf{N}(\%) \\
\end{array}$ \\
\hline STS & $12(0.491)$ & $7(0.623)$ & ARSE & $3(0.123)$ & CCDC101 & $44(0.356)$ \\
\hline CYP2D6 & $9(0.368)$ & $5(0.445)$ & $A R S H$ & $3(0.123)$ & CHST14 & $3(0.267)$ \\
\hline$A R S F$ & $5(0.204)$ & $1(0.089)$ & SLC16A1 & $3(0.123)$ & $A D S L$ & $2(0.178)$ \\
\hline GUSB & $3(0.123)$ & $1(0.089)$ & TRIM64B & $3(0.123)$ & CYP4F22 & $2(0.178)$ \\
\hline CLDN3 & $1(0.041)$ & $4(0.356)$ & $A B C G 2$ & $2(0.082)$ & HSD17B1 & $2(0.178)$ \\
\hline CYP2R1 & $1(0.041)$ & $1(0.089)$ & $A K R 7 A 3$ & $2(0.082)$ & CHST4 & $1(0.089)$ \\
\hline SLC3A2 & $1(0.041)$ & $1(0.089)$ & $A L D H 3 A 2$ & $2(0.082)$ & CYP4A11 & $1(0.089)$ \\
\hline \multirow[t]{7}{*}{ SULT2B1 } & $1(0.041)$ & $1(0.089)$ & CHST12 & $2(0.082)$ & CYP4F2 & $1(0.089)$ \\
\hline & & & XAGE3 & $2(0.082)$ & CYP4F8 & $1(0.089)$ \\
\hline & & & ARSG & $1(0.041)$ & DNMT3B & $1(0.089)$ \\
\hline & & & CES3 & $1(0.041)$ & JAM2 & $1(0.089)$ \\
\hline & & & CYP11B2 & $1(0.041)$ & PTGES & $1(0.089)$ \\
\hline & & & CYP7A1 & $1(0.041)$ & PTGS1 & $1(0.089)$ \\
\hline & & & FMO3 & $1(0.041)$ & SLC22A5 & $1(0.089)$ \\
\hline
\end{tabular}




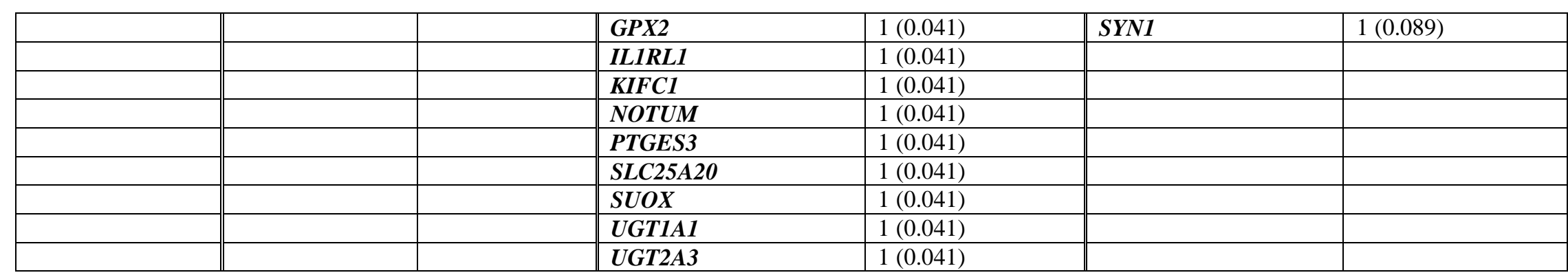

Table 5: Frequencies observed for genes more-frequently targeted by CNVs from individuals with ASD from AGP and/or SSC datasets, after Bonferroni correction for multiple testing. Presented are genes that are more-frequently targeted in both AGP and SSC datasets, and also genes that are more-frequently targeted only in AGP or SSC datasets.

\begin{tabular}{|c|c|c|c|c|c|c|c|c|c|}
\hline & \multicolumn{4}{|c|}{ AGP dataset } & \multicolumn{4}{|c|}{ SSC dataset } & \multirow{2}{*}{\begin{tabular}{|c|}
$\begin{array}{c}\text { Control } \\
\text { dataset }\end{array}$ \\
DGV N (\%) \\
\end{tabular}} \\
\hline & $\begin{array}{c}\text { AGP N } \\
(\%)\end{array}$ & $\begin{array}{c}\text { Test } \\
\text { Statistic } \\
\end{array}$ & p-value & OR $(95 \%$ CI $)$ & $\begin{array}{c}\text { SSC N } \\
(\%) \\
\end{array}$ & $\begin{array}{c}\text { Test } \\
\text { Statistic } \\
\end{array}$ & p-value & OR $(95 \%$ CI $)$ & \\
\hline$\overline{A B C B 1}$ & $20(0.818)$ & 51.83 & $6.04 \times 10^{-13}$ & $15.9(5.96-42.41)$ & $2(0.178)$ & 0.91 & $1.61 \times 10^{-01}$ & $3.44(0.67-17.74)$ & $5(0.052)$ \\
\hline GSTMI & $20(0.818)$ & 51.83 & $6.04 \times 10^{-13}$ & $15.9(5.96-42.41)$ & $2(0.178)$ & 0.91 & $1.61 \times 10^{-01}$ & $3.44(0.67-17.74)$ & $5(0.052)$ \\
\hline CYP21A2 & $67(2.739)$ & 44.14 & $3.05 \times 10^{-11}$ & $2.83(2.07-3.88)$ & $23(2.046)$ & 9.52 & $2.03 \times 10^{-03}$ & $2.1(1.33-3.33)$ & $95(0.985)$ \\
\hline CSH1 & $19(0.777)$ & 41.89 & $9.64 \times 10^{-11}$ & $10.78(4.53-25.68)$ & $9(0.801)$ & 31.25 & $2.27 \times 10^{-08}$ & $11.12(4.13-29.91)$ & $7(0.073)$ \\
\hline MAGEA8 & $16(0.654)$ & 53.12 & $1.04 \times 10^{-10}$ & $63.53(8.42-479.27)$ & $15(1.335)$ & 110.27 & $2.51 \times 10^{-14}$ & $130.5(17.22-988.88)$ & $1(0.010)$ \\
\hline CYP4X1 & $17(0.695)$ & 52.35 & $1.70 \times 10^{-10}$ & $33.76(7.79-146.22)$ & $7(0.623)$ & 36.80 & $3.94 \times 10^{-06}$ & $30.23(6.27-145.69)$ & $2(0.021)$ \\
\hline GSTT2 & $16(0.654)$ & 37.44 & $9.42 \times 10^{-10}$ & $12.7(4.65-34.7)$ & $1(0.089)$ & 0.48 & $4.84 \times 10^{-01}$ & $1.72(0.2-14.71)$ & $5(0.052)$ \\
\hline CHST5 & $33(1.349)$ & 35.92 & $2.06 \times 10^{-09}$ & $4.11(2.52-6.7)$ & $23(2.046)$ & 54.94 & $1.24 \times 10^{-13}$ & $6.28(3.66-10.77)$ & $32(0.332)$ \\
\hline UGT1A8 & $14(0.572)$ & 40.87 & $1.47 \times 10^{-08}$ & $27.77(6.31-122.26)$ & $3(0.267)$ & 8.38 & $9.64 \times 10^{-03}$ & $12.91(2.15-77.34)$ & $2(0.021)$ \\
\hline UGT2B10 & $14(0.572)$ & 40.87 & $1.47 \times 10^{-08}$ & $27.77(6.31-122.26)$ & $0(0)$ & $\mathrm{n} / \mathrm{a}$ & $\mathrm{n} / \mathrm{a}$ & $\mathrm{n} / \mathrm{a}$ & $2(0.021)$ \\
\hline UGT1A10 & $13(0.531)$ & 37.08 & $6.40 \times 10^{-08}$ & $25.77(5.81-114.29)$ & $3(0.267)$ & 8.38 & $9.64 \times 10^{-03}$ & $12.91(2.15-77.34)$ & $2(0.021)$ \\
\hline $\mathrm{CSH} 2$ & $14(0.572)$ & 27.75 & $1.38 \times 10^{-07}$ & $9.25(3.55-24.1)$ & $8(0.712)$ & 27.91 & $1.27 \times 10^{-07}$ & $11.52(3.99-33.26)$ & $6(0.062)$ \\
\hline UGT1A6 & $11(0.450)$ & 33.70 & $2.22 \times 10^{-07}$ & $43.58(5.62-337.76)$ & $3(0.267)$ & 11.61 & $4.18 \times 10^{-03}$ & $25.82(2.68-248.44)$ & $1(0.010)$ \\
\hline UGT1A7 & $11(0.450)$ & 33.70 & $2.22 \times 10^{-07}$ & $43.58(5.62-337.76)$ & $3(0.267)$ & 11.61 & $4.18 \times 10^{-03}$ & $25.82(2.68-248.44)$ & $1(0.010)$ \\
\hline UGT1A9 & $11(0.450)$ & 33.70 & $2.22 \times 10^{-07}$ & $43.58(5.62-337.76)$ & $3(0.267)$ & 11.61 & $4.18 \times 10^{-03}$ & $25.82(2.68-248.44)$ & $1(0.010)$ \\
\hline GH2 & $14(0.572)$ & 25.32 & $4.87 \times 10^{-07}$ & $7.93(3.2-19.67)$ & $8(0.712)$ & 25.16 & $5.27 \times 10^{-07}$ & $9.87(3.57-27.28)$ & $7(0.073)$ \\
\hline
\end{tabular}




\begin{tabular}{|l||l|l|l|l||l||l|l|l|}
\hline UGT1A3 & $10(0.409)$ & 29.85 & $1.06 \times 10^{-06}$ & $39.61(5.07-309.55)$ & $3(0.267)$ & 11.61 & $4.18 \times 10^{-03}$ & $25.82(2.68-248.44)$ \\
\hline UGT1A4 & $10(0.409)$ & 29.85 & $1.06 \times 10^{-06}$ & $39.61(5.07-309.55)$ & $3(0.267)$ & 11.61 & $4.18 \times 10^{-03}$ & $25.82(2.68-248.44)$ \\
\hline UGT1A5 & $10(0.409)$ & 29.85 & $1.06 \times 10^{-06}$ & $39.61(5.07-309.55)$ & $3(0.267)$ & 11.61 & $4.18 \times 10^{-03}$ & $25.82(2.68-248.44)$ \\
\hline GSTT2B & $12(0.491)$ & 26.49 & $3.67 \times 10^{-06}$ & $11.89(3.83-36.89)$ & $3(0.267)$ & 1.72 & $4.18 \times 10^{-03}$ & $2.15(0.24-19.23)$ \\
\hline $\boldsymbol{A B C C 1}$ & $11(0.450)$ & 23.07 & $1.37 \times 10^{-05}$ & $10.89(3.47-34.24)$ & $8(0.712)$ & 34.85 & $4.62 \times 10^{-06}$ & $17.28(5.2-57.49)$ \\
\hline $\boldsymbol{C L D N 5}$ & $7(0.286)$ & 18.48 & $9.05 \times 10^{-05}$ & $27.69(3.41-225.17)$ & $1(0.089)$ & 0.45 & $1.98 \times 10^{-01}$ & $8.59(0.54-137.45)$ \\
\hline $\boldsymbol{C E S 1}$ & $17(0.695)$ & 14.68 & $1.27 \times 10^{-04}$ & $3.55(1.84-6.83)$ & $1(0.089)$ & 0.18 & $7.15 \times 10^{-01}$ & $0.45(0.06-3.37)$ \\
\hline SULT1A3 & $6(0.245)$ & 7.50 & $6.72 \times 10^{-03}$ & $5.93(1.67-21.03)$ & $10(0.890)$ & 49.47 & $9.95 \times 10^{-08}$ & $21.64(6.78-69.13)$ \\
\hline SULT1A4 & $6(0.245)$ & 7.50 & $6.72 \times 10^{-03}$ & $5.93(1.67-21.03)$ & $10(0.890)$ & 49.47 & $9.95 \times 10^{-08}$ & $21.64(6.78-69.13)$ \\
\hline GSTA1 & $7(0.286)$ & 12.44 & $9.23 \times 10^{-04}$ & $9.23(2.38-35.71)$ & $6(0.534)$ & 24.75 & $8.10 \times 10^{-05}$ & $17.26(4.31-69.09)$ \\
\hline GSTA2 & $7(0.286)$ & 12.44 & $9.23 \times 10^{-04}$ & $9.23(2.38-35.71)$ & $6(0.534)$ & 24.75 & $8.10 \times 10^{-05}$ & $17.26(4.31-69.09)$ \\
\hline SULT1A2 & $0(0)$ & $\mathrm{n} / \mathrm{a}$ & $\mathrm{n} / \mathrm{a}$ & $\mathrm{n} / \mathrm{a}$ & $5(0.041)$ \\
\hline
\end{tabular}




\section{Identification of potentially pathogenic SNVs targeting genes involved in detoxification and regulation of barrier permeability using ASC dataset}

Using exome-sequencing data collected through the ASC, we searched for SNVs from 2674 subjects with ASD and 752 controls targeting the 519 studied genes. After quality control we obtained a total of 52180 variants present in cases, targeting said genes (figure 2). These variants were annotated using VEP, which classifies them into four categories according to the impact on the transcript: low, modifier, moderate and high impact. As previously said, moderate and high impact variants include, respectively, missense and l-o-f mutations. Low impact variants include synonymous, start and stop retained and splice region variants, while modifier impact variants comprehend intronic variants and variants located at the 3' and 5' prime UTRs, among others. For variants prioritization only high impact variants and moderate impact variants predicted as detrimental by both SIFT and PolyPhen-2 in silico tools were considered.

From the 52180 variants identified in cases, 381 had a high impact, with 71/381 (18.6\%) being also present in controls. A total of 201/519 (38.7\%) genes were targeted by high impact variants in cases. 17754 moderate impact variants were identified, of which 3339 were predicted has having a detrimental effect by both in silico tools. Of these, 683/3339 (20.5\%) were present in controls. An amount of $417 / 519$ (80.3\%) genes were targeted by the 3339 variants. A total of $420 / 519$ (80.9\%) genes were targeted by the total 3720 high and deleterious and damaging moderate impact variants.

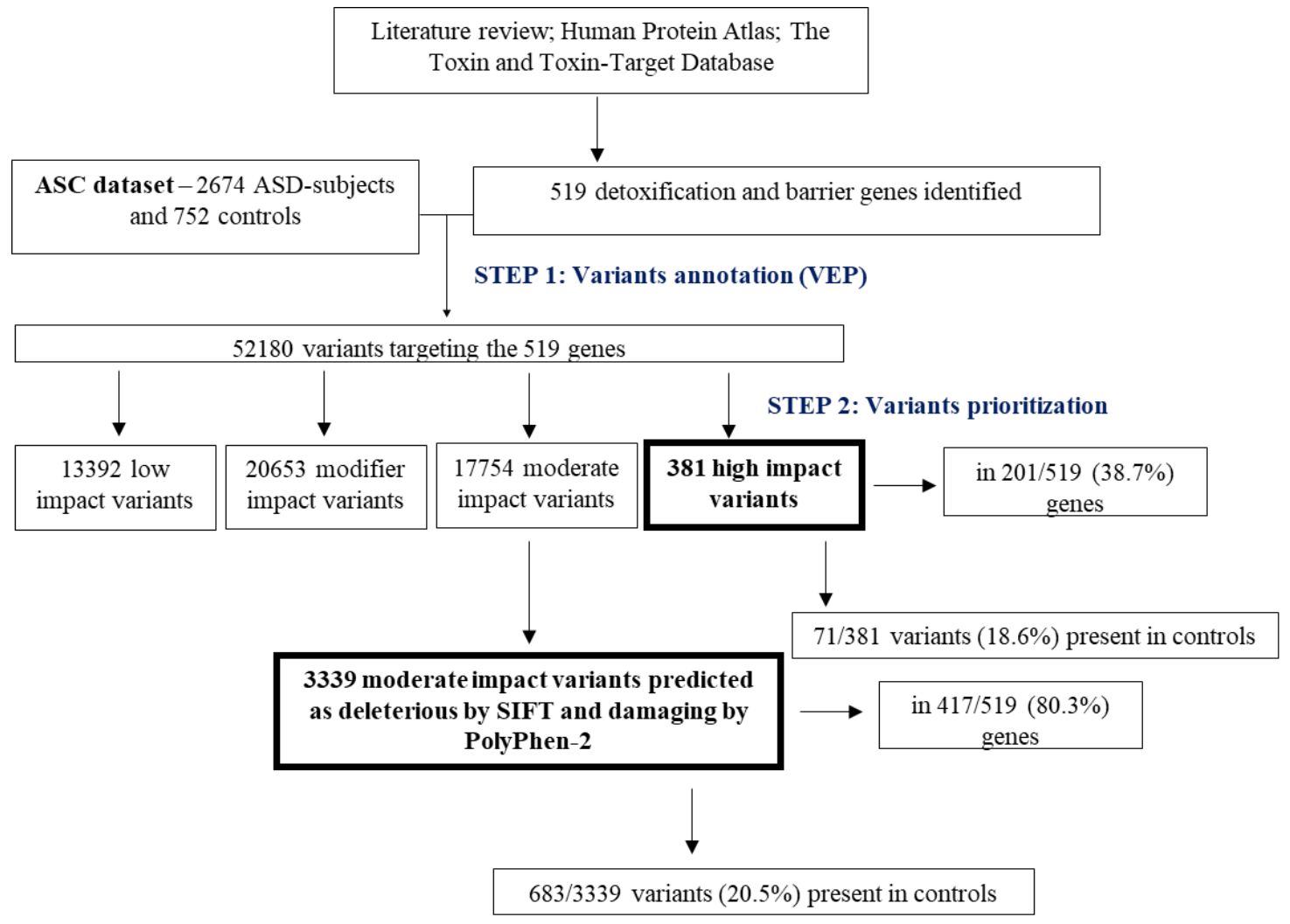

Figure 2: Main results regarding the numbers of high and moderate (predicted as deleterious by SIFT and damaging by PolyPhen-2) impact SNVs targeting detoxification and barrier genes, in cases and controls from ASD dataset. 
A major limitation of our study is the small size of ASC control population $(n=752)$, when compared to case population $(\mathrm{n}=2674)$. Thus, when a variant is exclusively found in 1 or 2 patients, and not in controls, this might be for two reasons: 1) the variant is, indeed, associated with ASD risk; 2) the control population is too small to find that same variant. To try to overcome this issue, we refined the prioritization step by establishing a rank of the 3720 l-o-f and missense variants according to their frequency in cases and controls. As shown in table 6, six ranks (A-F) were defined. Ranks A and $B$ include variants exclusively found in $\geq 6$ or in $3 \leq n \leq 5$ cases, respectively. Given that case population is $2.8 \mathrm{x}$ bigger than the control population, variants that appear in 3 or more patients, and not in controls, are hypothetically associated with the pathology. A total of 192 variants are included in the first two ranks ( 3 of the A rank variants solely appeared in homozygosity, and only in cases) (table 6). Contrary, the 2774 variants that appear only in $1 \leq n \leq 2$ cases and not in controls were classified in rank E, as these may not be associated with the phenotype (table 6). Ranks C and D include $223 \mathrm{SNVs}$ more frequent in cases than controls (table 6). Surprisingly, 531 variants were found to be more common in control population (table 6). As discussed ahead, this can be due to the fact that many of these variants may only have a pathogenic effect in the presence of an external factor.

Table 6: Numbers high and moderate impact variants included in each rank. Again, only missense variants defined as deleterious by SIFT and damaging by PolyPhen-2 were considered. AF - allelic frequency.

\begin{tabular}{|c|l|c|c|c|}
\hline Rank & \multicolumn{1}{|c|}{ Description of rank } & $\mathbf{N}^{\mathbf{0}}$ of variants & $\begin{array}{c}\mathbf{N}^{\mathbf{o}} \text { of high impact } \\
\text { variants }\end{array}$ & $\begin{array}{c}\mathbf{N}^{\mathbf{0}} \text { of moderate } \\
\text { impact variants }\end{array}$ \\
\hline $\mathbf{A}$ & $\begin{array}{l}\text { Variants exclusively present in cases }(\mathrm{n} \geq 6) \text { or } \\
\text { only in homozygosity in cases }\end{array}$ & 44 & 3 & 41 \\
\hline $\mathbf{B}$ & Variants exclusively present in cases $(3 \leq \mathrm{n} \leq 5)$ & 148 & 15 & 133 \\
\hline $\mathbf{C}$ & $\begin{array}{l}\text { Variants more-frequently present in cases } \\
\text { (AF cases/AF controls }>\mathbf{1 . 5})\end{array}$ & 85 & 5 & 80 \\
\hline $\mathbf{D}$ & $\begin{array}{l}\text { Variants more-frequently present in cases }(\mathbf{A F} \\
\text { cases/AF controls between } \mathbf{1} \text { and } \mathbf{1 . 5})\end{array}$ & 138 & 8 & 130 \\
\hline $\mathbf{E}$ & Variants exclusively present in cases $(1 \leq \mathrm{n} \leq 2)$ & 2774 & 292 & 2482 \\
\hline $\mathbf{F}$ & $\begin{array}{l}\text { Variants more frequently present in controls } \\
\text { (AF cases/AF controls }<1)\end{array}$ & 531 & 58 & 473 \\
\hline & Total variants & $\mathbf{3 7 2 0}$ & $\mathbf{3 8 1}$ & $\mathbf{3 3 3 9}$ \\
\hline
\end{tabular}

\section{Identification of genes with high load of potentially pathogenic SNVs}

Upon ranking the 3720 l-o-f and detrimental missense mutations, for each of the 420 genes targeted by such variants, we summed the number of variants per rank.

As listed in table 7, a total of 40 genes were found to be targeted by variants in rank A. Such variants were found in 6 or more cases and never in controls, and thus are the best candidates for an association with ASD, even considering the case vs control size population problem. Notably, only 4 of these 40 genes (CFTR, CYP2D6, AKR1B10 and SLC1A1) had two variants in rank A. For all other genes, only one variant was observed (table 7). For GSTO1 and LGALS16 no other SNVs were found besides a variant in rank A (table 7). 17 genes (DNAH5, CFTR, XDH, ABCA8, ARMC4, LOXL4, 
ALDH1L1, SLC22A5, AFDN, ALOX15, PTGIS, CYP4B1, ALDH3B1, CYP2D6, ADH1A, AKR1B10 and SLC1A1) were also found to carry SNVs from rank 2.

The other 380 genes were not targeted by rank A variants. Still, some, like DNAH7, DNAH11, TJP3, AOC2, CGN, SLC12A7 and TJP1, were found to have a high load of relevant variants, particularly from ranks $\mathrm{B}$ and $\mathrm{C}$, as can be seen in table $\mathrm{S} 3$.

Table 7: Numbers of variants by impact and by rank for each gene targeted by, at least, one variant ranked in rank A. Genes are ordered by the amount of high + moderate impact variants they have. In grey are highlighted the 17 genes targeted by both rank A and rank B variants.

\begin{tabular}{|c|c|c|c|c|c|c|c|c|c|}
\hline \multirow[b]{2}{*}{ Gene } & \multicolumn{3}{|c|}{ Number of variants by impact } & \multicolumn{6}{|c|}{$\mathrm{N}^{\mathbf{0}}$ of variants by rank } \\
\hline & $\begin{array}{l}\text { High Impact } \\
\text { Variants }\end{array}$ & $\begin{array}{c}\text { Moderate } \\
\text { Impact Variants }\end{array}$ & $\begin{array}{l}\text { High + Moderate } \\
\text { Impact Variants }\end{array}$ & $\mathbf{A}$ & B & $\mathbf{C}$ & D & $\mathbf{E}$ & $\mathbf{F}$ \\
\hline DNAH5 & 1 & 84 & 85 & 1 & 2 & 1 & 1 & 73 & 7 \\
\hline CFTR & 6 & 52 & 58 & 2 & 6 & 4 & 1 & 39 & 6 \\
\hline$X D H$ & 3 & 30 & 33 & 1 & 1 & 1 & 2 & 22 & 6 \\
\hline KIF17 & 2 & 27 & 29 & 1 & 0 & 2 & 1 & 18 & 7 \\
\hline ABCA 8 & 5 & 22 & 27 & 1 & 2 & 2 & 2 & 16 & 4 \\
\hline ARMC4 & 3 & 24 & 27 & 1 & 1 & 0 & 0 & 20 & 5 \\
\hline LOXL4 & 2 & 25 & 27 & 1 & 3 & 0 & 2 & 18 & 3 \\
\hline LRP1 & 0 & 27 & 27 & 1 & 0 & 1 & 0 & 21 & 4 \\
\hline$A L D H 1 L 1$ & 3 & 20 & 23 & 1 & 1 & 0 & 2 & 18 & 1 \\
\hline SLC22A5 & 3 & 20 & 23 & 1 & 1 & 0 & 0 & 18 & 3 \\
\hline$A P C$ & 0 & 21 & 21 & 1 & 0 & 0 & 1 & 18 & 1 \\
\hline$A F D N$ & 0 & 19 & 19 & 1 & 1 & 0 & 0 & 15 & 2 \\
\hline$A L O X 15$ & 2 & 15 & 17 & 1 & 3 & 0 & 1 & 10 & 2 \\
\hline CYP27A1 & 2 & 15 & 17 & 1 & 0 & 0 & 1 & 12 & 3 \\
\hline PTGIS & 1 & 16 & 17 & 1 & 1 & 0 & 2 & 12 & 1 \\
\hline ABCG2 & 3 & 12 & 15 & 1 & 0 & 0 & 1 & 13 & 0 \\
\hline CYP4B1 & 1 & 14 & 15 & 1 & 2 & 0 & 0 & 11 & 1 \\
\hline СYР2C19 & 3 & 11 & 14 & 1 & 0 & 1 & 0 & 9 & 3 \\
\hline$C B S$ & 1 & 11 & 12 & 1 & 0 & 0 & 1 & 10 & 0 \\
\hline IFT74 & 1 & 11 & 12 & 1 & 0 & 0 & 0 & 9 & 2 \\
\hline$A L D H 3 B 1$ & 0 & 11 & 11 & 1 & 1 & 0 & 0 & 8 & 1 \\
\hline CYP2D6 & 0 & 11 & 11 & 2 & 1 & 0 & 0 & 6 & 2 \\
\hline ADH1A & 1 & 9 & 10 & 1 & 1 & 0 & 0 & 8 & 0 \\
\hline TXNRD2 & 2 & 8 & 10 & 1 & 0 & 0 & 0 & 7 & 2 \\
\hline UGT2B11 & 1 & 9 & 10 & 1 & 0 & 0 & 1 & 5 & 3 \\
\hline AKR1B10 & 1 & 7 & 8 & 2 & 1 & 0 & 0 & 5 & 0 \\
\hline ALDH18A1 & 1 & 7 & 8 & 1 & 0 & 0 & 0 & 7 & 0 \\
\hline SLC1A1 & 1 & 7 & 8 & 2 & 1 & 0 & 0 & 5 & 0 \\
\hline SULT1C2 & 1 & 7 & 8 & 1 & 0 & 0 & 1 & 3 & 3 \\
\hline GH2 & 1 & 6 & 7 & 1 & 0 & 0 & 0 & 4 & 2 \\
\hline ALDH1A1 & 0 & 6 & 6 & 1 & 0 & 0 & 0 & 5 & 0 \\
\hline CES3 & 2 & 4 & 6 & 1 & 0 & 1 & 0 & 2 & 2 \\
\hline GSTM4 & 1 & 3 & 4 & 1 & 0 & 1 & 0 & 2 & 0 \\
\hline$A K R 1 C 2$ & 0 & 3 & 3 & 1 & 0 & 0 & 0 & 2 & 0 \\
\hline CHST5 & 0 & 3 & 3 & 1 & 0 & 0 & 0 & 1 & 1 \\
\hline COMT & 0 & 3 & 3 & 1 & 0 & 0 & 0 & 2 & 0 \\
\hline CES1 & 1 & 1 & 2 & 1 & 0 & 0 & 0 & 0 & 1 \\
\hline DRD1 & 0 & 2 & 2 & 1 & 0 & 0 & 0 & 1 & 0 \\
\hline GSTO1 & 0 & 1 & 1 & 1 & 0 & 0 & 0 & 0 & 0 \\
\hline LGALS16 & 0 & 1 & 1 & 1 & 0 & 0 & 0 & 0 & 0 \\
\hline
\end{tabular}




\section{Interactions between detoxification and barrier genes targeted by potentially pathogenic CNVs} and SNVs and environmental factors potentially relevant for ASD

To identify potentially relevant gene-environment interactions for ASD we performed an exploratory analysis using the Comparative Toxicogenomics Database (CTD). We interrogated the CTD for interactions between 54 individual chemicals and 55 detoxification and barrier genes. The 54 analyzed chemicals cluster into the three major classes of environmental factors potentially relevant for ASD, referred in the introduction of this article: 1) environmental toxins; 2) medications; 3) nutritional factors (table s1). The 55 queried genes include the 15 genes more-frequently or exclusively targeted by CNVs in ASD subjects, in both AGP and SSC datasets (tables 4 and 5), and the 40 genes with 1-o-f and missense SNVs from rank A (table 7). As AGP was the main dataset for CNVs discovery, we also added $A B C B 1$, GSTM1 and CYP21A2, which were the top genes morefrequently targeted by CNVs in patients from this dataset, but not validated upon SSC analysis (table $5)$.

We identified a total of 212 gene-environment interaction pairs, between 51/55 (92.7\%) genes and 38/54 (70.4\%) chemicals (table S4). Four genes (ARSF, CES3, LGALS16 and MAGEA8) had no reported interactions with the relevant chemicals, with 24 genes interacting only with 1 or 2 environmental factor (figure 3). Notably, for ABCB1, ABCG2, GSTM1, CYP2D6, CYP2C19 and $S L C 3 A 2$ we identified interactions with 10 or more chemicals (figure 3). $A B C C 1$, another member of the $\mathrm{ABC}$ transporters family, interacted with 9 chemicals. Regarding environmental factors, for 16 of them (including 7 PCB congeners, 2 PBDE congeners and 2 phthalates) we did not identify any interplay with the queried genes, which may reflect an understudy of such factors, as discussed below (figure 4). Contrary, 5 of the chemicals (valproic acid, benzo(a)pyrene (b(a)p), bisphenol A, particulate matter and perfluorooctane sulfonic acid (PFOS)) interacted with 10 or more genes (figure 4).

Overall, through this exploratory analysis we identify gene-environment interactions pairs with putative relevance for ASD. Moreover, we present detoxification and barrier genes that interact with more chemicals (and vice-versa), which may pinpoint towards genetic and non-genetic factors that justify further studies in the context of this pathology. 


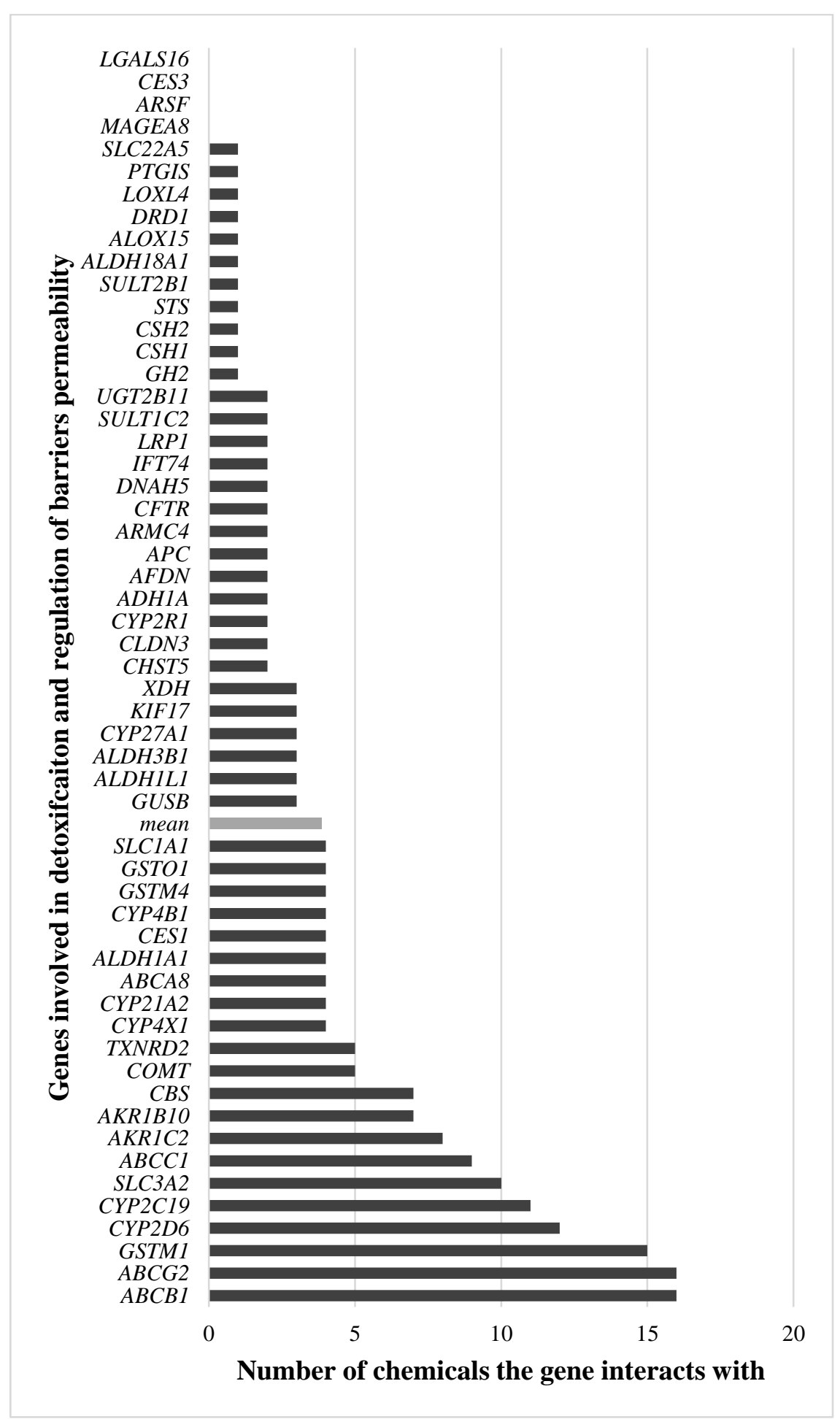

Figure 3: The graphic features the number of individual chemicals potentially relevant for ASD that each of the 55 queried genes interacts with, accordingly to The Comparative Toxicogenomics Database. 


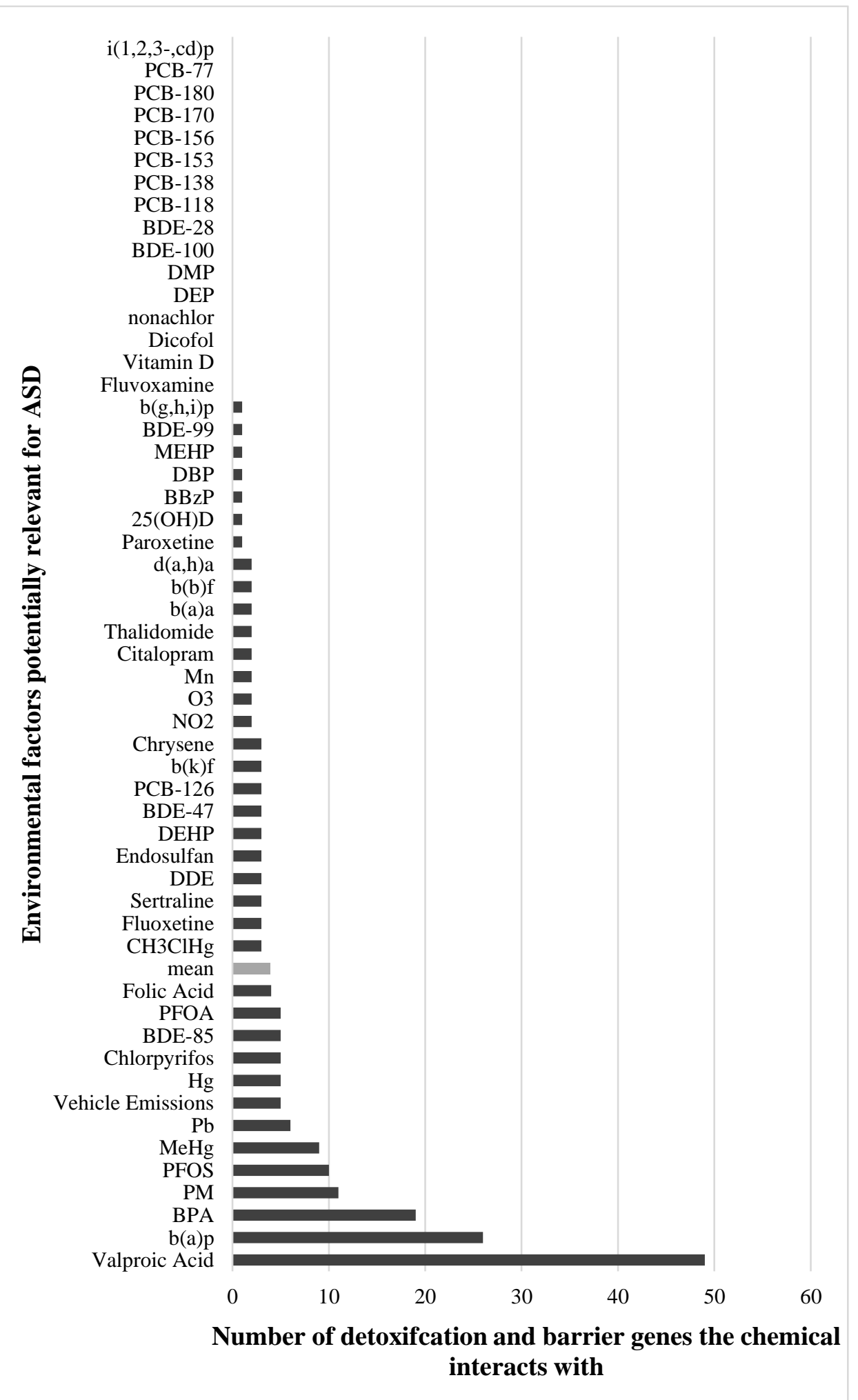

Figure 4: The graphic features number of genes targeted by potentially pathogenic CNVs and/or SNVs that each of the 54 individual chemicals potentially relevant for ASD interacts with, accordingly to The Comparative Toxicogenomics Database. 


\section{Discussion}

Detoxification and barrier genes with a high burden of potentially pathogenic CNVs and SNVs

Through the analysis of two datasets (AGP and SSC) of subjects diagnosed with ASD, we identified a set of 15 genes involved in detoxification and/or regulation of blood-barrier barrier, placenta or respiratory cilia permeability that are significantly overrepresented in CNVs from these subjects, when comparing with controls. Moreover, using the ASC dataset, also composed of subjects with the pathology, we found that a number of detoxification and barrier genes are targeted by potentially pathogenic loss-of-function and/or missense SNVs.

Genes coding for key enzymes involved in detoxification of xenobiotics were identified by us. Cytochrome P450 enzymes (CYP450s) are a family of monooxygenases implicated in phase I metabolism of most environmental toxins and pharmaceutical drugs. These enzymes oxidize molecules, making them more water-soluble. CYP2D6 was identified as exclusively-targeted by CNVs in ASD subjects (AGP: $\mathrm{n}=9, \mathrm{~F}=0.37 \%$; SSC: $\mathrm{n}=5, \mathrm{~F}=0.45 \%$ ), and was also targeted by 3 potentially pathogenic SNVs exclusive to ASC cases. CYP2D6 codes for an enzyme that detoxifies multiple toxins, including up to $25 \%$ of clinical drugs, with many functional polymorphisms in this gene being known to affect the metabolizer status of their carriers (78). ASD patients who are CYP2D6 poor metabolizers have been shown to exhibit an altered response to therapy using risperidone, an antipsychotic drug (79,80). Another identified CYP450-coding gene was CYP4X1, which was significantly more-frequently targeted by CNVs in ASD subjects (AGP: $n=17, F=0.695$; SSC: $n=7, F=0.62$ ). Though this gene is poorly studied, it is suspected to be involved in fatty acids and arachidonic acid metabolism. Interestingly, CYP4X1 has been suggested to be highly expressed at the late term fetal human brain (81), a pattern that has also been observed in rat brain (82). CYP21A2 was found to be more-frequently targeted by CNVs in AGP ASD-subjects ( $n=67, F=2.74$ ). This gene codes for a hydroxylase responsible for steroids biosynthesis. CNVs targeting CYP2Rl were exclusively found in two patients. $C Y P 2 R 1$ codes for vitamin D 25-hydroxylase, an enzyme responsible for the conversion of vitamin $\mathrm{D}$ acquired from sun exposure or diet to its main circulatory form. This is relevant because a growing number of studies report associations between vitamin $\mathrm{D}$ deficiency and ASD.

Genes coding for uridine diphosphate glucuronosyltransferases (UGTs) were found. UGTs are major enzymes of phase II metabolism, and are responsible for glucuronidation reactions, in which substrates are conjugated with a glucuronic acid moiety, increasing their water-solubility. Eight members of the UGT1A gene locus (UGT1A3-UGT1A10) were more-frequently targeted by CNVs in AGP ASD-subjects, and would often appear in the same variant. These genes were also found in SSC dataset, but statistical significance did not remain after Bonferroni correction for multiple testing. A CNV targeting UGT1A1 was also exclusively found in an AGP subject. UGT1A locus, located on chromosome 2, includes nine unique, but highly-similar, transcripts that code for nine enzymes (83). By splicing out in-between sequences, each of the unique exons at the 5' end of the locus is combined with the 3' end exons conserved in all isoforms. Members of the UGT2B locus were also identified: UGT2B10 was more-frequently found in CNVs from AGP ASD-subjects, and one potentially pathogenic SNV exclusive to cases was present in UGT2B11 (84). Both proteins are steroidmetabolizing enzymes. Importantly, human and mouse studies show that few UGTs (e.g. UGT1A4, $1 A 6$ and 1A7) are expressed at endothelial cells and astrocytes of the $\mathrm{BBB}$, where they glucuronidate antipsychotic drugs, benzo(a)pyrene and PCBs that cross this barrier (85). Although no associations 
between UGT variants and autism have been reported until now, we suggest that attention should be given to them, due to the broad amount of toxins they help degrade.

GSTM1 was more-frequently targeted by CNVs in ASD subjects from the AGP dataset ( $\mathrm{n}=20, \mathrm{~F}=0.82)$ and GSTM4 was found to have two relevant SNVs. These genes code for glutathione S-transferases (GSTs), which are enzymes known to catalyze the conjugation of reduced glutathione to multiple xenobiotics in order to make them more hydrophilic. Notably, homozygous deletion of GSTM1 has been associated with ASD onset, with the gene being pointed as a candidate for the disorder (86,87). Other GSTs, particularly GSTT2, and GSTA1 and GSTA2, were also, respectively, found in higher frequency in AGP and SSC ASD-subjects, when compared to controls.

Another relevant detoxification gene identified was CHST5, which was more-frequently found in ASD-subjects (AGP: $n=33, F=1.35 ; S S C n=23, F=2.05$ ) and also carried a missense SNV only present in 6 or more ASC cases. This gene codes for a carbohydrate sulfotransferase, with an exome-sequencing study reporting a rare synonymous mutation associated with the pathology (88). STS, that codes for steroid sulfatase, was the top gene exclusively targeted by CNVs in both primary and validation dataset (AGP: $n=12, F=0.491$; SSC: $n=7, F=0.623$ ). Steroid sulfatase is an enzyme that metabolizes steroid hormones and, in the brain, maintains the balance between neurosteroids and their unconjugated forms (89). Point mutations and deletions in STS are responsible for X-linked ichthyosis. Notably, males with this dermatological disease are sometimes diagnosed with ASD or Attention Deficit Hyperactivity Disorder (ADHD) or manifest more autistic traits than non-affected subjects $(90,91)$. However, Kent et al (90) showed that from 25 males with STS deficiency, the 5 that met the criteria for ASD diagnosis all had large deletions that comprised both STS and NLGN4X genes, with the later coding for a neuroligin already associated with autism. In AGP and SSC datasets, none of the CNVs that included STS also targeted NLGN4X. Thus, while NLGN4X might account for ASD in $\mathrm{X}$-linked ichthyosis, disruptions of STS may contribute to the phenotype.

Genes responsible for regulation of barriers permeability, particularly transporters, were also identified as having a high burden of relevant CNVs and SNVs. Multiple members of the ATPbinding cassette (ABCs) transporters family were found. $A B C C 1$ was more-frequently included in CNVs from AGP and SSC subjects (AGP: $\mathrm{n}=11, \mathrm{~F}=0.45$; SSC: $\mathrm{n}=8, \mathrm{~F}=0.71$ ), when compared to controls, while $A B C B 1$ was only more-frequently found in AGP subjects $(\mathrm{n}=20, \mathrm{~F}=0.82)$. $A B C A 8$ was found to have a high load of potentially pathogenic SNVs, with $A B C G 2$ being identified in both CNVs and SNVs analyses. ABC transporters regulate the flux of xenobiotics across cell membranes. $A B C C 1, A B C B 1$ and $A B C G 2$ are all expressed in both BBB (92) and placenta $(93,94)$, which suggests they may exert a protective role for the fetus, and their substrates include glutathione conjugates and hydrophobic compounds (92). CFTR, also an ABC transporter, was the second gene with the highest load of relevant SNVs. Mutations in CFTR are the main cause of cystic fibrosis, an autosomal recessive disorder characterized by mucus build-up and reduced mucociliary clearance of the respiratory tract, an important line of defense against airborne pollutants (95). CFTR is also expressed in neurons of the developing human brain (96). Other transporters found to carry relevant mutations were members of Solute Carriers (SLCs) family. SLC3A2 (AGP: n=1, F=0.041; SSC: $\mathrm{n}=1, \mathrm{~F}=0.089$ ) and SLC16A1 (AGP: n=3, F=0.123) were exclusively targeted by CNVs from ASD subjects. SLC22A5 carried two potentially pathogenic SNVs exclusive to 3 or more cases. At the BBB and placenta, SLCs are responsible for ionic transport and uptake of nutrients and exogenous chemicals. Substrates for SLC3A2 include methylmercury (97). SLC22A5 and SLC16A1 code for proteins involved in the transport of mitochondrial biomarkers, such as carnitine, pyruvate and lactate. 
Interestingly, a crescent number of studies report low blood levels of carnitine and elevated blood levels of pyruvate and lactate in some ASD patients $(98,99)$.

Genes coding for claudins, which are transmembrane proteins essential for the formation and integrity of BBB tight junctions (100), were also found. CLDN3 was exclusively found in CNVs from subjects with ASD (AGP: $\mathrm{n}=1, \mathrm{~F}=0.04 ; \mathrm{SSC}: \mathrm{n}=4 ; \mathrm{F}=0.36$ ). Meanwhile, $C L D N 5$ was more-frequently targeted by CNVs from AGP ( $\mathrm{n}=7, \mathrm{~F}=0.286$ ), but not SSC, subjects. CLDN3 and CLDN5 code for the predominant claudins expressed at the BBB (100). Elevated levels of claudin-5 have been described in postmortem cerebral cortex and cerebellum tissues of subjects with ASD (101). Additionally, TJP3 was found to have a high burden of potentially pathogenic SNVs (but none from rank A). This gene codes for a scaffolding protein present at tight junctions.

CNVs targeting CSH1 (AGP: $n=19, \mathrm{~F}=0.78$; SSC: n=9, F=0.80), CSH2 (AGP: n=14, F= 0.57; SSC: $\mathrm{n}=8, \mathrm{~F}=0.71$ ) and $G H 2$ (AGP: $\mathrm{n}=14, \mathrm{~F}=0.57$; SSC: $\mathrm{n}=8, \mathrm{~F}=0.71$ ) were more-frequently found in ASD subjects from both AGP and SSC datasets. For GH2, a SNV present in more than 6 cases, and not in controls, was also found. Together with $G H 1$ and CSHL1, these three genes are part of the human growth hormone (GH)/chorionic somatomammotropin (CSH) gene cluster located on 17q2224 band (102). Thus, in our analyses, CNVs would often target these genes together. GH2 codes for placental growth hormone and $\mathrm{CSH} 1$ and $\mathrm{CSH} 2$ code for human placental lactogen. During pregnancy, $\mathrm{GHI}$ expression is abrogated, and syncytiotrophoblast cells synthesize and release these placental hormones, that together act to increase the availability of nutrients to the fetus (103). Notably, GH1, which is expressed postnatally, was not found by us. To our knowledge, variants in 17q22-24 locus have not been described in ASD, but given the role of these genes in regulation of fetal growth, such variants could potentially lead to neurodevelopmental issues.

Finally, DNAH5, DNAH7 and DNAH11 were all found to have a high burden of potentially pathogenic SNVs. These genes code for members of axonemal dynein heavy chain family, which are microtubule-based ATPases that regulate motility of respiratory cilia (104). The correct movement of the cilia is crucial to avoid the contact of exogenous substances with the airways. Of note, these genes all have very large size $(>300 \mathrm{~kb})$.

Overall, we found that subjects with ASD carry potentially pathogenic variants in genes that code for proteins with a wide variety of functions. If the function of these proteins is compromised during early development this might translate into neurodevelopmental problems. Such proteins range from enzymes that increase water-solubility of xenobiotics (CYP450s, UGTs and GSTs), to transporters (ABCs and SLCs), proteins that secure the correct function of barriers (claudins and dyneins) and placental hormones. This emphasizes the complexity of the biological mechanisms that can lead to the pathology.

As previously referred, we hypothesize that subjects carrying variants in these genes will develop ASD only when exposed to an external trigger (or the environmental factors only function as triggers when the genetic susceptibility is present). This is relevant seeing that we defined as important genes more-frequently targeted by CNVs is ASD subjects, after statistical correction for multiple testing, even though they were targeted by variants also in controls. We argue that, in the affected individuals, such CNVs contributed to ASD onset due to an exposure to an external trigger, while the unaffected subjects, carrying CNVs in the same genes, were not exposed to the trigger. Meanwhile, this may partly explain the large amount of l-o-f and missense variants more-frequently found in control subjects from the ASC dataset. Unaffected subjects that carry such variants may not have been exposed to external cues that trigger the pathology. In both CNVs and SNVs cases, we can 
also suggest that the variants described here may have a low to moderate impact and, together with other genetic and non-genetic factors, act in concert to reach the threshold necessary for ASD onset. Some subjects carrying these variants suffered other insults that allowed the threshold to be reached, while other subjects with the same variants did not reach such threshold and experienced a typical development. Protective effects, like the proposed female protective effect (105), can augment the onset threshold in some individuals. In some cases, the dysfunction of a given protein may be compensated by the action of another functional homologue protein.

Identification of gene-environment interactions potentially relevant for ASD

Using the CTD we identified 212 gene-environment interaction pairs, between 51/55 detoxification and barrier genes with a high load of relevant variants and 38/54 chemicals potentially relevant for ASD.

$A B C B 1$ and $A B C G 2$ were the genes identified to interact with more chemicals relevant for ASD, each with 16/54 (29.6\%) interactions. ABCC1 interacted with 9/54 (16.7\%) chemicals. As previously referred, these genes code for transporters responsible for the flux of xenobiotics across cell membranes and their dysregulation might lead to cellular imbalances. CYP2D6 and CYP2C19 were also identified as top genes interacting, respectively, with 12/54 (22.2\%) and 11/54 (20.4\%) chemicals. As CYP2D6 was identified carrying both relevant CNVs and SNVs exclusive to ASD patients and has already been linked to influence risperidone therapy in ASD (79,80), we suggest this cytochrome as a prime candidate for future gene-environment studies in the disorder. GSTM1 interacted with $15 / 54(27.8 \%)$ genes, which was expected since it codes for a main glutathione transferase known to act on multiple substrates. Given the reported associations between null GSTM1 genotype and the pathology, this gene should also be a first candidate for gene-environment interactions (86,87). SLC3A2 was also one of the top identified genes, with 10/54 (18.5\%) interactions. AKR1C2 and AKR1B10 were found to interact with 8/54 (14.8\%) and 7/54 (13.0\%) chemicals. These genes code for members of the NADPH-dependent aldo-keto reductase family. ABC, CYP450, GST and SLC proteins are all products of important pharmacogenes (106), and thus it is possible that studies on their targets are inflated in relation to lesser clinically relevant proteins. This is supported by the fact that no interactions with chemicals were found for ARSF, CES3, LGALS16 and MAGEA8, which have poorly defined functions. For example, according to The Human Protein Atlas, in healthy tissues MAGEA8 protein is only expressed at the testis and placenta and possibly plays a role in embryonic development (107).

Valproic acid was identified as the top chemical, interacting with 49/55 (89.1\%) of the genes. An otherwise safe medication, when ingested during pregnancy valproic acid is known to cause serious birth defects, hence its teratogenic capacity (108). This has likely prompted research on its targets. Even when adjusting for potential confounders (e.g., maternal seizure attacks), fetal exposure to valproic acid remains strongly associated with ASD risk $(34,46)$, a fact that is further reinforced by rodent studies (109). B(a)p, the most well studied PAH (110), interacted with 26/55 (47.2\%) genes. $\mathrm{B}(\mathrm{a}) \mathrm{p}$ results from the combustion of organic matter and is found in tobacco smoke, diesel exhaust and grilled food, with prenatal exposure to this toxin leading to neurobehavioral problems in animal models and humans (111). Other PAHs were found to interact with 1-3 chemicals, with i(1,2,3,-cd)p having no reported associations, which may reflect an understudy of these congeners (110). Bisphenol A, a major EDC used as a starting material for plastics manufacture, being present in consumer goods such as water bottles and food and beverage cans, was found to interact with 19/55 (34.5\%) of the 
queried genes. BPA concentrations are measured in urine and, as such, this toxin has been mostly reported as a biomarker for 3 to 13 years old children with the pathology $(38,112)$. However, by measuring maternal urinary concentrations of this toxin, a study found that children, particularly females, with higher gestational exposure manifested more neurobehavioral problems (37). Particulate matter was identified to interact with 11/55 (20.0\%) genes. PM, microscopic particles suspended in atmospheric air, are generally divided into two categories according to their size: 1) coarse particulate matter $\left(\mathrm{PM}_{10}\right)$ with a diameter between $10 \mu \mathrm{m}$ and $\left.2.5 \mu \mathrm{m} ; 2\right)$ fine particulate matter $\left(\mathrm{PM}_{2.5}\right)$ with a diameter of $2.5 \mu \mathrm{m}$ or less. As they are smaller, $\mathrm{PM}_{2.5}$ are particularly noxious because they easily penetrate the respiratory tract, causing multiple adverse conditions that go beyond respiratory diseases (113). Consistent with this, ASD risk associates stronger with $\mathrm{PM}_{2.5}$ exposure than with $\mathrm{PM}_{10}$ exposure (34). Among the top chemicals was also PFOS, interacting with 10/55 $(18.2 \%)$ genes. PFOS is a PFC used as coating and as a water and stain repellent, with prenatal exposure to this substance linked to multiple neurodevelopmental outcomes (114). Toxic heavy metals, such as lead and mercury (and its derivative methylmercury), and folic acid were also found as top chemicals by the CTD analysis.

While it is expected that some environmental factors have broader targets than others, the current knowledge on neurotoxic effects of chemicals is underestimated (115). Of the hundred thousand chemicals existent, few hundreds have documented neurotoxic effects for humans, with this number decreasing when considering neurodevelopmental effects. This happens because, due to the limitations inherent to address so many compounds, most have not been investigated for potential neurotoxicity (115). Effects of chemicals for which there is more concern regarding human exposure and growing awareness (e.g. BPA, b(a)p, pollutants and valproic acid) may be more investigated. Thus, in the future, we anticipate to identify more than the 212 interaction pairs between the queried genes and chemicals identified by the CTD.

Studies that investigate the interplay between genetic and environmental factors in ASD are sparse. Potential interactions associated with the pathology have been reported for prenatal exposure to $\mathrm{PM}_{10}$ and $\mathrm{NO}_{2}$ and rs 1858830 polymorphism on $M E T$ gene (116), maternal folic acid intake during gestation and rs1801133 polymorphism on MTHFR (52) and $\mathrm{O}_{3}$ exposure and overall burden of copy number duplications (117). We hypothesize that environmental factors can function as a trigger for ASD onset, only in subjects with a genetic susceptibility. Yet, possible biological mechanisms behind this are only now being proposed. Among these are epigenetic alterations, endocrine dysregulations, hypoxic and oxidative stress events, inflammation and mitochondrial dysfunctions $(34,98)$. Epigenetic changes, such as DNA methylation and altered patterns of microRNA expression, have been associated with ASD onset (118). Interestingly, environmental factors relevant for the pathology (e.g. BPA, PCBs and PM) are known to induce epigenetic alterations (119-122). EDCs are able to mimic hormones, leading to endocrine imbalances, and this may be associated with the high male-tofemale ratio observed in ASD diagnosis. STS, one of the identified genes, codes for an enzyme involved in sex steroids metabolism. Most probably, the multitude of genetic and non-genetic factors involved in the disorder can combine in multiple ways, affecting different biological pathways and originating similar, but distinct, clinical ASD phenotypes.

\section{Limitations and strengths of this study}

An important limitation to note in this study is the large size of the datasets used to identify $\mathrm{CNV}$, but the low occurrence of events (individuals carrying CNVs), explaining the wide confidence 
intervals obtained. Nonetheless, our confidence intervals are always concordant with the obtained $p$ values. Larger populations, allowing for the occurrence of more events, may overcome this limitation (still, since many ASD relevant mutations are ultra-rare variants, this could prove to be unattainable). Another limitation of this study is the fact that the ASC dataset, which was used to identify SNVs, has $2.8 \mathrm{x}$ more cases than controls. To counteract this fact we ranked the identified potentially pathogenic missense and 1-o-f variants, and attributed few weight to SNVs exclusively found in 1 or 2 cases ( $n=2774$ variants). While some of these variants may be ultra-rare and associated with ASD risk, others may not have been found in control-subjects because of the reduced size of the control population. Again, this could be resolved with a larger dataset. A last limitation of our strategy is the fact that we identified multiple interactions between environmental factors reported to be associated with ASD and detoxification and barrier genes, but the type of interactions were not analyzed. Among many other effects, an external factor can influence a protein expression or localization, its folding, stability and structure and its interaction with other molecules. Future studies should look into these matter, as different types of effects in the same protein can lead to different outcomes.

Strengths of our strategy include the analysis of both CNVs and SNVs targeting the studied genes in ASD subjects. Since both types of genetic variants are known risk factors for the disorder, an integrative approach allows for the detection of genes with high load of both types of variants. This was verified in this study for CYP2D6 and GH2. In our query using the CTD only interactions observed in humans were considered. While this greatly reduced the amount of discovered interactions, as animal models are an excellent tool to study the effects of exogenous substances, the gene-environment interaction pairs found offer more consistence for a possible association with ASD. Finally, by ranking missense and l-o-f SNVs based on their cases and controls frequencies, and giving more importance to variants only present in 6 or more controls, despite reducing the number of considered variants, allowed the maintaining of the ones more strongly associated with the phenotype in the analyzed dataset.

\section{Conclusions}

In this study we present a two-step strategy that allowed us to discover gene-environment interactions with putative relevance for ASD. First, by using large datasets of genetic information collected from subjects with the pathology, we were able to identify a novel set of ASD-candidate genes targeted by potentially pathogenic CNVs and SNVs. Secondly, using the CTD, we identified interactions between such genes and environmental risk factors for the disorder. It is likely that the identified gene-environment interactions are not, per se, a single causative force, but together with other genetic and non-genetic factors allow the onset of ASD. Each gene-environment interaction pair can be seen as a unit with low to moderate effect that, alone, does not cause the disorder.

Despite the discussed limitations, we expect a positive outcome from this study, as it may contribute in directing future investigations that aim to tackle specific gene-environment interplays in ASD. Exposure to environmental factors can, at some extent, be mitigated, which is an important issue for personalized medicine approaches. ASD risk in genetically susceptible individuals could be decreased if early exposure to environmental triggers is eliminated. Thus, the identification of geneenvironment interactions in ASD may contribute to the implementation of health management policies in the disorder. 


\section{Declarations}

\section{Acknowledgements}

We acknowledge the Simons Foundation for Autism Research (SFARI) and the Database of Genomic Variants (DGV) for the availability of data regarding SSC and DGV datasets. We are grateful to the families recruited through Autism Genome Project, Simons Simplex Collection and Autism Sequencing Consortium projects.

\section{Financial Support}

João Xavier Santos is a fellow of the BioSys PhD Program and an awardee of a scholarship funded by Fundação para a Ciência e Tecnologia, Portugal (Ref: PD/BD/114386/2016). AGP data was collected from patients genotyped in the context of Autism Genome Project (AGP), funded by NIMH, HRB, MRC, Autism Speaks, Hilibrand Foundation, Genome Canada, OGI and CIHR. ASC data was collected from patients genotyped in the context of Autism Sequencing Consortium supported by NIH grants U01MH100233, U01MH100209, U01MH100229 and U01MH100239.

\section{Conflicts of Interest}

The authors report no conflicts of interest.

\section{References}

1. American Psychiatric Association. Diagnostic and statistical manual of mental disorders (5th ed.). 2013.

2. Lord C, Elsabbagh M, Baird G, Veenstra-Vanderweele J. Seminar Autism spectrum disorder. Lancet. 2018; 392(10146):508-20.

3. Elsabbagh M, Divan G, Koh YJ, Kim YS, Kauchali S, Marcín C, et al. Global Prevalence of Autism and Other Pervasive Developmental Disorders. Autism Res. 2012;5(3):160-79.

4. Lyall K, Croen L, Daniels J, Fallin MD, Ladd-Acosta C, Lee B, et al. The Changing Epidemiology of Autism Spectrum Disorders. Annu Rev Public Health. 2017;38:81-102

5. Loomes R, Hull L, Mandy WPL. What Is the Male-to-Female Ratio in Autism Spectrum Disorder? A Systematic Review and Meta-Analysis. J Am Acad Child Adolesc Psychiatry. 2017;56(6):466-74.

6. Werling DM, Geschwind DH. Sex differences in autism spectrum disorders. Curr Opin Neurol. 2013;26(2):146-53.

7. Levy D, Ronemus M, Yamrom B, Lee Y ha, Leotta A, Kendall J, et al. Rare De Novo and Transmitted Copy-Number Variation in Autistic Spectrum Disorders. Neuron. 2011;70(5):886-97.

8. Pinto D, Delaby E, Merico D, Barbosa M, Merikangas A, Klei L, et al. Convergence of Genes and Cellular Pathways Dysregulated in Autism Spectrum Disorders. Am J Hum Genet. 2014;94(5):677-94.

9. Pinto D, Pagnamenta AT, Klei L, Anney R, Merico D, Regan R, et al. Functional Impact of Global Rare Copy Number Variation in Autism Spectrum Disorder. Nature. 2010;466(7304):368-72. 
10. Sanders S, Ercan-sencicek AG, Hus V, Luo R, Murtha MT, Moreno-De-Luca D, et al. Multiple recurrent de novo copy number variations (CNVs), including duplications of the $7 q 11.23$ Williams-Beuren syndrome region, are strongly associated with autism. Neuron. 2011;70(5):863-85.

11. Sebat J, Lakshmi B, Malhotra D, Troge J, Lese- C, Walsh T, et al. Strong Association of De Novo Copy Number Mutations with Autism. Science. 2007;316(5823):445-9.

12. Sanders SJ, Murtha MT, Gupta AR, Murdoch JD, Raubeson MJ, Willsey AJ, et al. De novo mutations revealed by whole exome sequencing are strongly associated with autism. Nature. 2013;485(7397):237-41.

13. Iossifov I, O'Roak BJ, Sanders SJ, Ronemus M, Krumm N, Levy D, et al. The contribution of de novo coding mutations to autism spectrym disorder. Nature. 2014;515(7526):216-21

14. Neale BM, Kou Y, Liu L, Ma'ayan A, Samocha KE, Lin C, et al. Patterns and rates of exonic de novo mutations in autism spectrum disorders. Nature. 2013;485(7397):242-5.

15. Gaugler T, Klei L, Sanders SJ, Bodea CA, Goldberg AP, Lee AB, et al. Most genetic risk for autism resides with common variation. Nat Genet. 2014;46(8):881-5.

16. Devlin B, Scherer SW. Genetic architecture in autism spectrum disorder. Curr Opin Genet Dev. 2012;22(3):229-37.

17. Sandin S, Lichtenstein P, Kuja-Halkola R, Larsson H, Hultman CM, Reichenberg A. The familial risk of autism. JAMA. 2014;311(17):1770-7.

18. Sandin S, Lichtenstein P, Kuja-Halkola R, Hultman C, Larsson H, Reichenberg A. The Heritability of Autism Spectrum Disorder Analysis method B. JAMA. 2017;318(12):1182-4.

19. Pettersson E, Lichtenstein P, Larsson H, Song J, Attention Deficit/Hyperactivity Disorder Working Group of the Ipsych-Broad-PGC Consortium, et al. Genetic influences on eight psychiatric disorders based on family data of 4408646 full and half-siblings, and genetic data of 333748 cases and controls. 2018; 1-8

20. Eapen V. Genetic basis of autism: Is there a way forward? Curr Opin Psychiatry. 2011;24(3):226-36.

21. Pinson A, Bourguignon JP, Parent AS. Exposure to endocrine disrupting chemicals and neurodevelopmental alterations. Andrology. 2016;4(4):706-22.

22. Braun JM, Kalkbrenner AE, Just AC, Yolton K, Calafat AM, Sjödin A, et al. Gestational exposure to endocrine-disrupting chemicals and reciprocal social, repetitive, and stereotypic behaviors in 4- and 5-year-old children: the HOME study. Environ Health Perspect. 2014;122(5):513-20.

23. Eskenazi B, Marks AR, Bradman A, Harley K, Barr DB, Johnson C, et al. Organophosphate pesticide exposure and neurodevelopment in young Mexican-American children. Environ Health Perspect. 2007;115(5):792-8.

24. Arora M, Reichenberg A, Willfors C, Austin C, Gennings C, Berggren S, et al. Fetal and postnatal metal dysregulation in autism. Nat Commun. 2017;8:15493.

25. Hertz-Picciotto I, Schmidt RJ, Walker CK, Bennett DH, Oliver M, Shedd-Wise KM, et al. A Prospective Study of Environmental Exposures and Early Biomarkers in Autism Spectrum Disorder: Design, Protocols, and Preliminary Data from the MARBLES Study. Environ 
Health Perspect. 2018;126(11):117004.

26. Kim SM, Han DH, Lyoo HS, Min KJ, Kim KH, Renshaw P. Exposure to environmental toxins in mothers of children with autism spectrum disorder. Psychiatry Investig. 2010;7(2):122-7.

27. Ming X, Brimacombe M, Malek JH, Jani N, Wagner GC. Autism spectrum disorders and identified toxic land fills: co-occurrence across States. Environ Health Insights. 2008;2:55-9.

28. Shelton JF, Geragthy EM, Tancredi DJ, Delwiche LD, Schmidt RJ, Ritz B, et al. Neurodevelopmental Disorders and Prenatal Residential Proximity to Agricultural Pesticides: The CHARGE Study. Environ Health Perspect. 2014;122(10):1103-9.

29. Becerra T, Wilhelm M, Olsen J, Cockburn M, Ritz B. Ambient air pollution and autism in Los Angeles County, California. Environ Health Perspect. 2012;121(3):380-6.

30. Volk HE, Lurmann F, Penfold B, Hertz-Picciotto I, McConnell R. Traffic-related air pollution, particulate matter, and autism. JAMA psychiatry. 2013;70(1):71-7.

31. Croen LA, Grether JK, Yoshida CK, Odouli R, Hendrick V. Antidepressant use during pregnancy and childhood autism spectrum disorders. Arch Gen Psychiatry. 2011;68(11):1104-12.

32. Taylor LE, Swerdfeger AL, Eslick GD. Vaccines are not associated with autism: An evidencebased meta-analysis of case-control and cohort studies. Vaccine. 2014;32(29):3623-9.

33. Rossignol D a, Genuis SJ, Frye RE. Environmental toxicants and autism spectrum disorders: a systematic review. Transl Psychiatry. 2014;4(2):e360.

34. Modabbernia A, Velthorst E, Reichenberg A. Environmental risk factors for autism: an evidence-based review of systematic reviews and meta-analyses. Mol Autism. 2017;8(1):116.

35. Jung CR, Lin YT, Hwang BF. Air Pollution and Newly Diagnostic Autism Spectrum Disorders: A Population-Based Cohort Study in Taiwan. PLoS One. 2013;8(9):e75510.

36. Volk HE, Hertz-Picciotto I, Delwiche L, Lurmann F, Mcconnell R. Residential proximity to freeways and autism in CHARGE study. Enviro Health Perspect. 2011;119(6):873-7.

37. Braun JM, Kalkbrenner AE, Calafat AM, Yolton K, Ye Xiaoyun et al. Impact of Early-Life Bisphenol A Exposure on Behavior and Executive Function in Children. 2011;128(5):87382.

38. Stein TP, Schluter MD, Steer RA, Guo L, Ming X. Bisphenol A Exposure in Children With Autism Spectrum Disorders. Autism Res. 2015;8(3):272-83.

39. Roberts AL, Lyall K, Hart JE, Laden F, Just AC, Bobb JF, et al. Perinatal air pollutant exposures and autism spectrum disorder in the children of Nurses' Health Study II participants. Environ Health Perspect. 2013;121(8):978-84.

40. Philippat C, Barkoski J, Tancredi DJ, Elms B, Barr DB, Ozonoff S, et al. Prenatal exposure to organophosphate pesticides and risk of autism spectrum disorders and other non-typical development at 3 years in a high-risk cohort. Int J Hyg Environ Health. 2018;221(3):548-55.

41. Testa C, Nuti F, Hayek J, De Felice C, Chelli M, Rovero P, et al. Di-(2-ethylhexyl) phthalate and autism spectrum disorders. ASN Neuro. 2012;4(4):223-9.

42. Miodovnik A, Engel SM, Zhu C, Ye X, Soorya LV, Silva MJ, Calafat AM, Wolf MS. 
Endocrine disruptors and childhood social impairment. Neurotoxicology. 2012;32(2):261-7.

43. Cheslack-Postava K, Rantakokko P V., Hinkka-Yli-Salom??ki S, Surcel HM, McKeague IW, Kiviranta HA, et al. Maternal serum persistent organic pollutants in the Finnish Prenatal Study of Autism: A pilot study. Neurotoxicol Teratol. 2013;38(212):1-5.

44. Lyall K, Yau VM, Hansen R, Kharrazi M, Yoshida CK, Calafat AM et al. Prenatal maternal serum concentrations of per- and polyfluoroalkyl substances in association with autism spectrum disorder and intellectual disability. Environ Health Perspect. 2018;126(1):017001.

45. Bromley RL, Mawer GE, Briggs M, Cheyne C, Clayton-smith J, García-fiñana M, et al. The prevalence of neurodevelopmental disorders in children prenatally exposed to antiepileptic drugs. Journal Neurol Neurosurg Psychiatry. 2014;84(6):637-43.

46. Christensen J, Gronborg TK, Sorensen MJ, Schendel D, Parner ET, Pedersen LH, et al. Prenatal valproate exposure and risk of Autism Spectrum Disorders. Jama. 2014;309(16):1696-703

47. Rodier PM, Ingram JL, Tisdale B, Nelson S, Romano J. Embryological origin for autism: Developmental anomalies of the cranial nerve motor nuclei. $J$ Comp Neurol. 1996;370(2):247-61.

48. Stromland K, Nordin V, Miller M, Akerstrom B, Gillberg C. Autism in Thalidomide Embryopathy: A population study. 1994;36(4):351-56.

49. Rai D, Lee BK, Dalman C, Newschaffer C, Lewis G, Magnusson C. Antidepressants during Pregnancy and Autism in Offspring: Population Based Cohort Study. BMJ. 2017;358:j2811

50. Gidaya NB, Lee BK, Burstyn I, Yudell M, Mortensen EL, Newschaffer CJ. In utero exposure to selective serotonin reuptake inhibitors and risk for autism spectrum disorder. J Autism Dev Disord. 2014;44(10):2558-67.

51. Al-Farsi YM, Waly MI, Deth RC, Al-Sharbati MM, Al-Shafaee M, Al-Farsi O, et al. Low folate and vitamin B12 nourishment is common in Omani children with newly diagnosed autism. Nutrition. 2013;29(3):537-41.

52. Schmidt RJ, Tancredi DJ, Ozonoff S, Hansen RL, Hartiala J, Allayee H, et al. Maternal periconceptional folic acid intake and risk of autism spectrum disorders and developmental delay in the CHARGE (CHildhood Autism Risks from Genetics and Environment) casecontrol study. Am J Clin Nutr. 2012;96(1):80-9.

53. Schug TT, Blawas AM, Gray K, Heindel JJ, Lawler CP. Elucidating the links between endocrine disruptors and neurodevelopment. Endocrinology. 2015;156(6):1941-51.

54. de Cock M, Maas YGH, Van De Bor M. Does perinatal exposure to endocrine disruptors induce autism spectrum and attention deficit hyperactivity disorders? Review. Acta Paediatr. 2012;101(8):811-8.

55. Diamanti-Kandarakis E, Bourguignon JP, Giudice LC, Hauser R, Prins GS, Soto AM, et al. Endocrine-disrupting chemicals: An Endocrine Society scientific statement. Endocr Rev. 2009;30(4):293-342.

56. Ballabh P, Braun A, Nedergaard M. The blood-brain barrier: An overview: Structure, regulation, and clinical implications. Neurobiol Dis. 2004;16(1):1-13.

57. Griffiths SK, Campbell JP. Placental structure, function and drug transfer. Contin Educ 
Anaesthesia, Crit Care Pain. 2015;15(2):84-9.

58. Antunes MB, Cohen NA. Mucociliary clearance -- a critical upper airway host defense mechanism and methods of assessment. Curr Opin Allergy Clin Immunol. 2007;7(1):5-10.

59. Zheng W, Aschner M, Ghersi-Egea J-F. Brain barrier systems: a new frontier in metal neurotoxicological research. Toxicol Appl Pharmacol. 2003;192(1):1-11.

60. Schonfelder G, Wittfoht W, Hopp H, Talsness CE, Paul M, Chahoud I. Parent bisphenol a accumulation in the human maternal-fetal-placental unit. Environ Health Perspect. 2002;110(11):703-7.

61. Mose T, Mortensen GK, Hedegaard M, Knudsen LE. Phthalate monoesters in perfusate from a dual placenta perfusion system, the placenta tissue and umbilical cord blood. Reprod Toxicol. 2007;23(1):83-91.

62. Gundacker $\mathrm{C}$, Hengstschläger $\mathrm{M}$. The role of the placenta in fetal exposure to heavy metals. Wien Med Wochenschrift. 2012;162(9-10):201-6.

63. Acosta-Maldonado B, Sánchez-Ramórez B, Reza-López S, Levario-Carrillo M. Effects of exposure to pesticides during pregnancy on placental maturity and weight of newborns: A cross-sectional pilot study in women from the Chihuahua State, Mexico. Hum Exp Toxicol. 2009;28(8):451-9.

64. Zhang X, Li X, Jing Y, Fang X, Zhang X, Lei B, et al. Transplacental transfer of polycyclic aromatic hydrocarbons in paired samples of maternal serum, umbilical cord serum, and placenta in Shanghai, China. Environ Pollut. 2017;222:267-75.

65. Cooper GM, Coe BP, Girirajan S, Rosenfeld JA, Vu TH, Baker C, et al. A copy number variation morbidity map of developmental delay. Nat Genet. 2011;43(9):838-46.

66. Shaikh T, Gai X, Perin JC, Glessner JT, Xie H, Murphy K, O'Hara R et al. High-resolution mapping and analysis of copy number variations in the human genome: A data resource for clinical and research applications. Genome Res. 2009;19(9)1682-90.

67. MacDonald JR, Ziman R, Yuen RKC, Feuk L, Scherer SW. The Database of Genomic Variants: A curated collection of structural variation in the human genome. Nucleic Acids Res. 2014;42(D1):986-92.

68. Buxbaum JD, Daly MJ, Devlin B, Lehner T, Roeder K, State MW, Autism Sequencing Consortium. The Autism Sequencing Consortium: Large-Scale, High-Throughput Sequencing in Autism Spectrum Disorders. Neuron. 2012;76(6):1052-6.

69. Thul PJ, Åkesson L, Wiking M, Mahdessian D, Geladaki A, Ait Blal H, et al. A subcellular map of the human proteome. Science. 2017;356(6340):eaal3321.

70. Wishart D, Arndt D, Pon A, Sajed T, Guo AC, Djoumbou Y, et al. T3DB: The toxic exposome database. Nucleic Acids Res. 2015;43(D1):D928-34.

71. Lim E, Pon A, Djoumbou Y, Knox C, Shrivastava S, Guo AC, et al. T3DB: A comprehensively annotated database of common toxins and their targets. Nucleic Acids Res. 2009;38(D1):781-6.

72. Lek M, Karczewski KJ, Minikel E V., Samocha KE, Banks E, Fennell T, et al. Analysis of protein-coding genetic variation in 60,706 humans. Nature. 2016;536(7616):285-91.

73. McLaren W, Gil L, Hunt SE, Riat HS, Ritchie GRS, Thormann A, et al. The Ensembl Variant 
Effect Predictor. Genome Biol; 2016;17(1):1-14.

74. Sim NL, Kumar P, Hu J, Henikoff S, Schneider G, Ng PC. SIFT web server: Predicting effects of amino acid substitutions on proteins. Nucleic Acids Res. 2012;40(W1):452-7.

75. Adzhubei IA, Schmidt S, Peshkin L, Ramensky VE, et al. A method and server for predicting damaging missense mutations. Nat Methods. 2010;7(4):248-9.

76. Davis AP, Grondin CJ, Johnson RJ, Sciaky D, McMorran R, Wiegers J, et al. The Comparative Toxicogenomics Database: Update 2019. Nucleic Acids Res. 2019;47(D1):D948-54.

77. Carter CJ, Blizard RA. Autism genes are selectively targeted by environmental pollutants including pesticides, heavy metals, bisphenol A, phthalates and many others in food, cosmetics or household products. Neurochem Int; 2016;101:83-109.

78. Ingelman-Sundberg M, Sim SC, Gomez A, Rodriguez-Antona C. Influence of cytochrome P450 polymorphisms on drug therapies: Pharmacogenetic, pharmacoepigenetic and clinical aspects. Pharmacol Ther. 2007;116(3):496-526.

79. Youngster I, Zachor DA, Gabis LV, Bar-Chaim A, Benveniste-Levkovitz P, Britzi M, et al. CYP2D6 genotyping in paediatric patients with autism treated with risperidone: A preliminary cohort study. Dev Med Child Neurol. 2014;56(10):990-4.

80. Puangpetch A, Vanwong N, Nuntamool N, Hongkaew Y, Chamnanphon M, Sukasem C. CYP2D6 polymorphisms and their influence on risperidone treatment. Pharmgenomics Pers Med. 2016;9:131-47.

81. Choudhary D, Jansson I, Stoilov I, Sarfarazi M, Schenkman JB. Expression patterns of mouse and human CYP orthologs (families 1-4) during development and in different adult tissues. Arch Biochem Biophys. 2005;436(1):50-61.

82. Bylund J, Zhang C, Harder DR. Identification of a novel cytochrome P450, CYP4X1, with unique localization specific to the brain. Biochem Biophys Res Commun. 2002;296(3):67784.

83. Gong QH, Cho JW, Huang T, Potter C, Gholami N, Basu NK, et al. Thirteen UDPglucuronosyltransferase genes are encoded at the human UGT1 gene complex locus. Pharmacogenetics. 2001;11(4):357-68.

84. Turgeon D, Carrier JS, Lévesque E, Hum DW, Bélanger A. Relative enzymatic activity, protein stability, and tissue distribution of human steroid-metabolizing UGT2B subfamily members. Endocrinology. 2001;142(2):778-87.

85. Ouzzine M, Gulberti S, Ramalanjaona N, Magdalou J, Fournel-Gigleux S. The UDPglucuronosyltransferases of the blood-brain barrier: their role in drug metabolism and detoxication. Front Cell Neurosci. 2014;8:1-12.

86. James SJ, Melnyk S, Jernigan S, Cleves MA, Halsted CH, Wong DH, et al. Metabolic endophenotype and related genotypes are associated with oxidative stress in children with autism. Am J Med Genet B Neuropsychiatr Genet. 2006;141B(8): 947-56.

87. Buyske S, Williams TA, Mars AE, Stenroos ES, Ming SX, Wang R, et al. Analysis of caseparent trios at a locus with a deletion allele: association of GSTM1 with autism. BMC Genet. 2006;7:8.

88. O’Roak BJ, Deriziotis P, Lee C, Vives L, Schwartz JJ, Girirajan S, et al. Exome sequencing 
in sporadic autism spectrum disorders identifies severe de novo mutations. 2012;43(6):5859.

89. Kříž L, Bičíková M, Hampl R. Roles of steroid sulfatase in brain and other tissues. Physiol Res. 2008;57(5):657-68.

90. Kent L, Emerton J, Bhadravathi V, Weisblatt E, Pasco G, Willatt LR, et al. X-linked ichthyosis (steroid sulfatase deficiency) is associated with increased risk of attention deficit hyperactivity disorder, autism and social communication deficits. J Med Genet. 2008;45(8):519-24.

91. Chatterjee S, Humby T, Davies W. Behavioural and psychiatric phenotypes in men and boys with X-linked ichthyosis: Evidence from a worldwide online survey. PLoS One. 2016;11(10):1-16.

92. Begley DJ. ABC Transporters and the Blood-Brain Barrier. Curr Pharm Des. 2004;10(12):1295-312.

93. Joshi AA, Vaidya SS, St-pierre M V, Mikheev AM, Kelly E, Nyandege AN, et al. Placental ABC transporters: biological impact and pharmaceutical significance. Pharm Res. 2016;33(12):2847-78.

94. Mao Q. BCRP/ABCG2 in the placenta: Expression, function and regulation. Pharm Res. 2008;25(6):1244-55.

95. Wolff RK. Effects of airborne pollutants on mucociliary clearance. Environ Health Perspect. 1986;66:223-37.

96. Marcorelles P, Friocourt G, Uguen A, Ledé F, Férec C, Laquerrière A. Cystic Fibrosis Transmembrane Conductance Regulator Protein (CFTR) Expression in the Developing Human Brain: Comparative Immunohistochemical Study between Patients with Normal and Mutated CFTR. J Histochem Cytochem. 2014;62(11):791-801.

97. Yin Z, Jiang H, Syversen T, Rocha JBT, Farina M, Aschner M. The methylmercury-L-cysteine conjugate is a substrate for the L-type large neutral amino acid transporter. J Neurochem. 2008;107(4):1083-90.

98. Rossignol DA, Frye RE. Mitochondrial dysfunction in autism spectrum disorders: A systematic review and meta-analysis. Mol Psychiatry. 2012;17(3):290-314.

99. Griffiths KK, Levy RJ. Evidence of mitochondrial dysfunction in autism: Biochemical links, genetic-based associations, and non-energy-related mechanisms. Oxid Med Cell Longev; 2017;2017:4314025.

100. Luissint AC, Artus C, Glacial F, Ganeshamoorthy K, Couraud PO. Tight junctions at the blood brain barrier: Physiological architecture and disease-associated dysregulation. Fluids Barriers CNS. 2012;9(1):1-12.

101. Fiorentino M, Sapone A, Senger S, Camhi SS, Kadzielski SM, Buie TM, et al. Blood-brain barrier and intestinal epithelial barrier alterations in autism spectrum disorders. Mol Autism. 2016;7(1):1-17.

102. Shewchuk BM, Liebhaber SA, Cooke NE. Specification of unique Pit-1 activity in the hGH locus control region. Proc Natl Acad Sci. 2002;99(18):11784-9.

103. Handwerger S, Freemark M. The Roles of Placental Growth Hormone and Placental Lactogen in the Regulation of Human Fetal Growth and Development. J Pediatr Endocrinol Metab. 
2000;13:343.

104. Ishikawa T. Structural biology of cytoplasmic and axonemal dyneins. J Struct Biol; 2012;179(2):229-34.

105. Hull L, Mandy W. Protective effect or missed diagnosis? Females with autism spectrum disorder. Future Neurol. 2017;12(3):159-69.

106. Ingelman-Sundberg M, Mkrtchian S, Zhou Y, Lauschke VM. Integrating rare genetic variants into pharmacogenetic drug response predictions. Hum Genomics. 2018;12(1):26.

107. Lifantseva N, Koltsova A, Krylova T, Yakovleva T, Poljanskaya G, Gordeeva O. Expression patterns of cancer-testis antigens in human embryonic stem cells and their cell derivatives indicate lineage tracks. Stem Cells Int. 2011;2011:795239.

108. Macfarlane A, Greenhalgh T. Sodium valproate in pregnancy: What are the risks and should we use a shared decision-making approach? BMC Pregnancy Childbirth. BMC Pregnancy and Childbirth; 2018;18(1):1-11.

109. Nicolini C, Fahnestock M. The valproic acid-induced rodent model of autism. Exp Neurol 2018;299(Pt A):217-27.

110. Moorthy B, Chu C, Carlin DJ. Polycyclic aromatic hydrocarbons: From metabolism to lung cancer. Toxicol Sci. 2015;145(1):5-15.

111. Das SK, Patel B, Patri M. Neurotoxic effect of benzo[a]pyrene and its possible association with 6-hydroxydopamine induced neurobehavioral changes during early adolescence period in rats. J Toxicol. 2016;2016:8606410.

112. Kardas F, Bayram AK, Demirci E, Akin L, Ozmen S, Kendirci M, et al. Increased Serum Phthalates (MEHP, DEHP) and Bisphenol A Concentrations in Children with Autism Spectrum Disorder. J Child Neurol. 2016;31(5):629-35.

113. Kim KH, Kabir E, Kabir S. A review on the human health impact of airborne particulate matter. Environ Int. 2015;137(3):136-43.

114. Rappazzo KM, Coffman E, Hines EP. Exposure to perfluorinated alkyl substances and health outcomes in children: A systematic review of the epidemiologic literature. Int J Environ Res Public Health. 2017;14(7):1-22.

115. Landrigan PJ. What causes autism? Exploring the environmental contribution. Curr Opin Pediatr. 2010;22(2):219-25.

116. Volk HE, Kerin T, Lurmann F, Hertz-Picciotto I, McConnell R, Campbell DB. Autism spectrum disorder: interaction of air pollution with the MET receptor tyrosine kinase gene. Epidemiology. 2014;25(1):44-7.

117. Kim D, Volk H, Girirajan S, Pendergrass S, Hall MA, Verma SS, et al. The joint effect of air pollution exposure and copy number variation on risk for autism. Autism Res. 2017;10(9):1470-80.

118. Eshraghi AA, Liu G, Kay SS, Eshraghi RS, Mittal J, Moshiree B, et al. Epigenetics and Autism Spectrum Disorder: Is There a Correlation?. Front Cell Neurosci. 2018;12:78.

119. Li J, Li WX, Bai C, Song Y. Particulate matter-induced epigenetic changes and lung cancer. Clin Respir J. 2017;11(5):539-46. 
120. Yaoi T, Itoh K, Nakamura K, Ogi H, Fujiwara Y, Fushiki S. Genome-wide analysis of epigenomic alterations in fetal mouse forebrain after exposure to low doses of bisphenol A. Biochem Biophys Res Commun. 2008;376(3):563-7.

121. Mileva G, Baker SL, Konkle ATM, Bielajew C. Bisphenol-A: Epigenetic Reprogramming and Effects on Reproduction and Behavior. Int J Environ Res Public Health. 2014;11(7):753761.

122. Casati L, Colciago A, Negri-Cesi P, Celotti F. Polychlorinated biphenyls affect histone modification pattern in early development of rats: a role for androgen receptor-dependent modulation?. Epigenomics. 2012;4(1):101-12 


\section{Supplementary data}

Table S1: Individual chemicals potentially relevant for ASD studied for interactions with genes involved in detoxification and regulation of barriers permeability, using the Comparative Toxicogenomics Database.

\begin{tabular}{|c|c|c|c|c|c|}
\hline Category & Individual chemical & MeSH ID & Category & Individual chemical & $\begin{array}{c}\text { MeSH } \\
\text { ID } \\
\end{array}$ \\
\hline \multirow{4}{*}{ Air Pollutants } & Nitrogen dioxide $\left(\mathrm{NO}_{2}\right)$ & D009585 & \multirow{6}{*}{ Phthalates } & Butylbenzyl phthalate (BBzP) & $\mathrm{C} 027561$ \\
\hline & Ozone $\left(\mathrm{O}_{3}\right)$ & D010126 & & Dibutyl phthalate (DBP) & D003993 \\
\hline & Particulate matter (PM) & D052638 & & Diethyl phthalate (DEP) & $\mathrm{C} 007379$ \\
\hline & Vehicle emissions & D001335 & & Diethylhexyl phthalate (DEHP) & D004051 \\
\hline Bisphenol A & Bisphenol A (BPA) & $\mathrm{C} 006780$ & & Dimethyl phthalate (DMP) & $\mathrm{C} 024629$ \\
\hline \multirow{5}{*}{ Heavy Metals } & Lead $(\mathrm{Pb})$ & D007854 & & Mono-(2-ethylhexyl)phthalate (MEHP) & $\mathrm{C} 016599$ \\
\hline & Manganese (Mn) & D008345 & \multirow{5}{*}{$\begin{array}{l}\text { Polybrominated } \\
\text { diphenyl ethers }\end{array}$} & 2,2',3,4,4'-pentabromodiphenyl ether (BDE-85) & $\mathrm{C} 086401$ \\
\hline & Mercury $(\mathrm{Hg})$ & D008628 & & 2,2',4,4',5-brominated diphenyl ether (BDE-99) & C477694 \\
\hline & Methylmercuric chloride $\left(\mathrm{CH}_{3} \mathrm{ClHg}\right)$ & $\mathrm{C} 004925$ & & 2,2',4,4',6-brominated diphenyl ether (BDE-100) & C517827 \\
\hline & Methylmercury compounds (MeHg) & D008767 & & 2,2',4,4'-tetrabromodiphenyl ether (BDE-47) & C511295 \\
\hline \multirow{7}{*}{$\begin{array}{c}\text { Medications } \\
\text { (Selective serotonin } \\
\text { reuptake inhibitors } \\
\text { (SSRIs) and } \\
\text { teratogens) }\end{array}$} & Citalopram & D015283 & & 2,2',4-tribromodiphenyl ether (BDE-28) & C533760 \\
\hline & Fluoxetine & D005473 & \multirow{8}{*}{$\begin{array}{l}\text { Polychlorinated } \\
\text { biphenyls }\end{array}$} & 2,2',3,3',4,4',5-heptachlorobiphenyl (PCB-170) & C541131 \\
\hline & Fluvoxamine & D016666 & & 2,2',3,4,4',5,5'-heptachlorobiphenyl (PCB-180) & C410127 \\
\hline & Paroxetine & D017374 & & 2,2',3',4,4',5-hexachlorobiphenyl (PCB-138) & C029790 \\
\hline & Sertraline & D020280 & & 2,3,3',4,4',5-hexachlorobiphenyl (PCB-156) & C087667 \\
\hline & Thalidomide & D013792 & & 2,3',4,4',5-pentachlorobiphenyl (PCB-118) & $\mathrm{C} 070055$ \\
\hline & Valproate (VPA) & D014635 & & 2,4,5,2',4',5'-hexachlorobiphenyl (PCB-153) & C014024 \\
\hline \multirow{3}{*}{ Nutritional factors } & 25-hydroxyvitamin D [25(OH)D] & $\mathrm{C} 104450$ & & 3,4,3',4'-tetrachlorobiphenyl (PCB-77) & $\mathrm{C} 028451$ \\
\hline & Folic acid & D005492 & & 3,4,5,3',4'-pentachlorobiphenyl (PCB-126) & $\mathrm{C} 023035$ \\
\hline & Vitamin D & D014807 & \multirow{8}{*}{$\begin{array}{c}\text { Polycyclic } \\
\text { Aromatic } \\
\text { Hydrocaborns }\end{array}$} & Benzo(a)anthracene $[\mathrm{b}(\mathrm{a}) \mathrm{a}]$ & C030935 \\
\hline \multirow{5}{*}{ Pesticides } & Chlorpyrifos & D004390 & & Benzo(a)pyrene [b(a)p] & D001564 \\
\hline & Dichlorodiphenyldichloroethylene (DDE) & D003633 & & Benzo(b)fluoranthene [b(b)f] & C006703 \\
\hline & Dicofol & D004010 & & Benzo(g,h,i)perylene $[\mathrm{b}(\mathrm{g}, \mathrm{h}, \mathrm{i}) \mathrm{p}]$ & C006718 \\
\hline & Endosulfan & D004726 & & Benzo(k)fluoranthene $[\mathrm{b}(\mathrm{k}) \mathrm{f}]$ & C022921 \\
\hline & Nonachlor & $\mathrm{C} 001870$ & & Chrysene & $\mathrm{C} 031180$ \\
\hline \multirow{2}{*}{$\begin{array}{c}\text { Perfluorinated } \\
\text { compounds }\end{array}$} & Perfluorooctane sulfonic acid (PFOS) & $\mathrm{C} 076994$ & & Dibenzo(a,h)anthracene $[\mathrm{d}(\mathrm{a}, \mathrm{h}) \mathrm{a}]$ & $\mathrm{C} 026486$ \\
\hline & Perfluorooctanoic acid (PFOA) & $\mathrm{C} 023036$ & & Indeno( $(1,2,3,-$ cd $)$ pyrene $[\mathrm{i}(1,2,3,-\mathrm{cd}) \mathrm{p}]$ & C041508 \\
\hline
\end{tabular}


Table S2: Frequency of genes targeted by CNVs from individuals with ASD (from both AGP and/or SSC datasets) and control datasets, but that failed to achieve statistical significance after Bonferroni correction for multiple testing. Presented are only genes that do not appear in table 5 .

\begin{tabular}{|c|c|c|c|c|c|c|c|c|c|}
\hline \multirow[b]{2}{*}{ Gene list } & \multicolumn{4}{|c|}{ AGP dataset } & \multicolumn{4}{|c|}{ SSC dataset } & \multirow{2}{*}{\begin{tabular}{|c|} 
Control dataset \\
DGV N \\
$(\%)$
\end{tabular}} \\
\hline & $\begin{array}{c}\text { AGP N } \\
(\%)\end{array}$ & Test statistic & p-value & OR $(95 \%$ CI $)$ & $\begin{array}{c}\text { SSC N } \\
(\%)\end{array}$ & Test statistic & $p$-value & OR $(95 \%$ CI $)$ & \\
\hline$A B C A 2$ & $7(0.286)$ & 8.58 & 0.003402 & $5.54(1.76-17.46)$ & $2(0.178)$ & 0.91 & 0.160502 & $3.44(0.67-17.74)$ & $5(0.052)$ \\
\hline ADAMTS18 & $1(0.041)$ & 0.028 & 0.36358 & $3.95(0.25-63.11)$ & $2(0.178)$ & 5.03 & 0.030365 & $17.2(1.56-189.82)$ & $1(0.01)$ \\
\hline ADORA2A & $1(0.041)$ & \begin{tabular}{|l|}
$3.75 \times 10-25$ \\
\end{tabular} & 1 & $0.99(0.11-8.83)$ & $1(0.089)$ & \begin{tabular}{|l|}
$1.72 \times 10-24$ \\
\end{tabular} & 0.423657 & $2.15(0.24-19.23)$ & $4(0.041)$ \\
\hline$A H R$ & $2(0.082)$ & $7.16 \times 10-27$ & 1 & $1.13(0.23-5.43)$ & $1(0.089)$ & $3.80 \times 10-31$ & 0.585968 & $1.23(0.15-9.98)$ & $7(0.073)$ \\
\hline$A K R 1 C 2$ & $2(0.082)$ & 0.08 & 0.350127 & $1.97(0.36-10.78)$ & $1(0.089)$ & $1.72 \times 10-24$ & 0.423657 & $2.15(0.24-19.23)$ & $4(0.041)$ \\
\hline$A L D H 2$ & $9(0.368)$ & \begin{tabular}{|l|}
7.09 \\
\end{tabular} & 0.00776 & $3.56(1.44-8.77)$ & $6(0.53)$ & 9.83 & 0.001718 & $5.17(1.88-14.26)$ & $10(0.104)$ \\
\hline$A L D H 3 B 2$ & $3(0.123)$ & 0.32 & 0.398461 & $1.97(0.49-7.9)$ & $1(0.089)$ & $1.22 \times 10-24$ & 0.537703 & $1.43(0.17-11.9)$ & $6(0.062)$ \\
\hline ALDH5A1 & $1(0.041)$ & 0.028 & 0.36358 & $3.95(0.25-63.11)$ & $1(0.089)$ & 0.45 & 0.197793 & $8.59(0.54-137.45)$ & $1(0.01)$ \\
\hline ALDH7A1 & $1(0.041)$ & 0.028 & 0.36358 & $3.95(0.25-63.11)$ & $2(0.178)$ & 5.03 & 0.030365 & $17.2(1.56-189.82)$ & $1(0.01)$ \\
\hline$A L P P$ & $11(0.45)$ & 2.40 & 0.121247 & $1.89(0.92-3.88)$ & $1(0.089)$ & 0.45 & 0.506186 & $0.37(0.05-2.76)$ & $23(0.238)$ \\
\hline ANKRD11 & $1(0.041)$ & $2.56 \times 10-30$ & 1 & $0.79(0.09-6.76)$ & $1(0.089)$ & $5.42 \times 10-31$ & 0.483817 & $1.72(0.2-14.71)$ & $5(0.052)$ \\
\hline$A R S D$ & $2(0.082)$ & 1.65 & 0.106128 & $7.9(0.72-87.11)$ & $3(0.267)$ & 11.61 & 0.004178 & $25.82(2.68-248.44)$ & $1(0.01)$ \\
\hline ATP1B4 & $1(0.041)$ & 0.028 & 0.36358 & $3.95(0.25-63.11)$ & $1(0.089)$ & 0.45 & 0.197793 & $8.59(0.54-137.45)$ & $1(0.01)$ \\
\hline B3GAT1 & $3(0.123)$ & 0.60 & 0.207965 & $2.37(0.57-9.92)$ & $1(0.089)$ & $5.42 \times 10-31$ & 0.483817 & $1.72(0.2-14.71)$ & $5(0.052)$ \\
\hline B3GAT2 & $2(0.082)$ & \begin{tabular}{|l|}
0.74 \\
\end{tabular} & 0.184213 & $3.95(0.56-28.04)$ & $1(0.089)$ & 0.12 & 0.281506 & $4.3(0.39-47.41)$ & $2(0.021)$ \\
\hline CFTR & $2(0.082)$ & 1.65 & 0.106128 & $7.9(0.72-87.11)$ & $1(0.089)$ & 0.45 & 0.197793 & $8.59(0.54-137.45)$ & $1(0.01)$ \\
\hline CGNL1 & $2(0.082)$ & 3.06 & 0.047601 & $0.26(0.06-1.1)$ & $6(0.534)$ & 0.91 & 0.340893 & $1.72(0.71-4.14)$ & $30(0.311)$ \\
\hline CHST11 & $1(0.041)$ & 0.028 & 0.36358 & $3.95(0.25-63.11)$ & $2(0.178)$ & 5.03 & 0.030365 & $17.2(1.56-189.82)$ & $1(0.01)$ \\
\hline CHST6 & $2(0.082)$ & 0.085 & 0.350127 & $1.97(0.36-10.78)$ & $1(0.089)$ & $1.72 \times 10-24$ & 0.423657 & $2.15(0.24-19.23)$ & $4(0.041)$ \\
\hline CHST8 & $1(0.041)$ & \begin{tabular}{|l|}
$2.56 \times 10-30$ \\
\end{tabular} & 1 & $0.79(0.09-6.76)$ & $1(0.089)$ & \begin{tabular}{|l|}
$5.42 \times 10-31$ \\
\end{tabular} & 0.483817 & $1.72(0.2-14.71)$ & $5(0.052)$ \\
\hline COMT & $9(0.368)$ & 12.36 & 0.000438 & $5.94(2.11-16.69)$ & $1(0.089)$ & $1.22 \times 10-24$ & 0.537703 & $1.43(0.17-11.9)$ & $6(0.062)$ \\
\hline CYP2B6 & $3(0.123)$ & 0.043 & 0.47322 & $1.48(0.39-5.58)$ & $1(0.089)$ & $9.37 \times 10-25$ & 1 & $1.07(0.13-8.59)$ & $8(0.083)$ \\
\hline CYP4F 12 & $9(0.368)$ & 0.63 & 0.428012 & $1.48(0.69-3.19)$ & $1(0.089)$ & 9.52 & 0.50918 & $0.36(0.05-2.64)$ & $24(0.249)$ \\
\hline CYP4F3 & $1(0.041)$ & 0.028 & 0.36358 & $3.95(0.25-63.11)$ & $1(0.089)$ & 0.45 & 0.197793 & $8.59(0.54-137.45)$ & $1(0.01)$ \\
\hline CYP4V2 & $2(0.082)$ & 0.0063 & 0.635006 & $1.58(0.31-8.14)$ & $1(0.089)$ & $5.42 \times 10-31$ & 0.483817 & $1.72(0.2-14.71)$ & $5(0.052)$ \\
\hline DHRS4 & $6(0.245)$ & 11.68 & 0.001305 & $11.86(2.39-58.8)$ & $1(0.089)$ & 0.12 & 0.281506 & $4.3(0.39-47.41)$ & $2(0.021)$ \\
\hline DNAI2 & $4(0.164)$ & 2.21 & 1 & $1.05(0.35-3.17)$ & $1(0.089)$ & 0.019 & 1 & $0.57(0.08-4.33)$ & $15(0.155)$ \\
\hline DYX1C1 & $1(0.041)$ & 2.39 & 0.492306 & $1.97(0.18-21.77)$ & $1(0.089)$ & 0.12 & 0.281506 & $4.3(0.39-47.41)$ & $2(0.021)$ \\
\hline FMO5 & $5(0.204)$ & 11.16 & 0.001683 & $19.76(2.31-169.24)$ & $3(0.267)$ & 11.61 & 0.004178 & $25.82(2.68-248.44)$ & $1(0.01)$ \\
\hline GABRA5 & $7(0.286)$ & 0.21 & 0.649191 & $0.77(0.34-1.72)$ & $1(0.089)$ & 1.62 & 0.174416 & $0.24(0.03-1.74)$ & $36(0.373)$ \\
\hline
\end{tabular}




\begin{tabular}{|c|c|c|c|c|c|c|c|c|c|}
\hline GABRB3 & $7(0.286)$ & 10.31 & 0.002094 & $6.92(2.02-23.66)$ & $1(0.089)$ & $1.72 \times 10-24$ & 0.423657 & $2.15(0.24-19.23)$ & $4(0.041)$ \\
\hline GABRG3 & $7(0.286)$ & 4.00 & 1 & $0.95(0.42-2.18)$ & $2(0.178)$ & 0.19 & 0.766294 & $0.59(0.14-2.48)$ & $29(0.301)$ \\
\hline GAL3ST2 & $5(0.204)$ & 11.16 & 0.001683 & $19.76(2.31-169.24)$ & $4(0.356)$ & 18.99 & 0.000541 & $34.46(3.85-308.57)$ & $1(0.01)$ \\
\hline GSTM5 & $1(0.041)$ & 2.01 & 0.100068 & $0.21(0.03-1.55)$ & $2(0.178)$ & $1.43 \times 10-27$ & 1 & $0.9(0.21-3.88)$ & $19(0.197)$ \\
\hline HBG1 & $4(0.164)$ & 1.95 & 0.088543 & $3.16(0.85-11.77)$ & $3(0.267)$ & 3.71 & 0.042465 & $5.16(1.23-21.63)$ & $5(0.052)$ \\
\hline HBG2 & $4(0.164)$ & 1.95 & 0.088543 & $3.16(0.85-11.77)$ & $3(0.267)$ & 3.71 & 0.042465 & $5.16(1.23-21.63)$ & $5(0.052)$ \\
\hline$I D S$ & $2(0.082)$ & 0.74 & 0.184213 & $3.95(0.56-28.04)$ & $1(0.089)$ & 0.12 & 0.281506 & $4.3(0.39-47.41)$ & $2(0.021)$ \\
\hline INSL4 & $1(0.041)$ & $6.58 \times 10-25$ & 1 & $1.32(0.14-12.65)$ & $1(0.089)$ & 0.018 & 0.356491 & $2.86(0.3-27.55)$ & $3(0.031)$ \\
\hline MIF & $2(0.082)$ & 0.085 & 0.350127 & $1.97(0.36-10.78)$ & $1(0.089)$ & $1.72 \times 10-24$ & 0.423657 & $2.15(0.24-19.23)$ & $4(0.041)$ \\
\hline MTNR1A & $2(0.082)$ & 1.65 & 0.106128 & \begin{tabular}{|l}
$7.9(0.72-87.11)$ \\
\end{tabular} & $2(0.178)$ & 5.03 & 0.030365 & $17.2(1.56-189.82)$ & $1(0.01)$ \\
\hline NOS3 & $1(0.041)$ & 0.17 & 0.697933 & $0.44(0.06-3.46)$ & $1(0.089)$ & $6.41 \times 10-28$ & 1 & $0.95(0.12-7.54)$ & $9(0.093)$ \\
\hline OCLN & $26(1.063)$ & 9.85 & 0.0017 & $2.19(1.36-3.55)$ & $5(0.445)$ & $3.37 \times 10-27$ & 1 & $0.91(0.36-2.3)$ & $47(0.487)$ \\
\hline PARD3 & $3(0.123)$ & $6.25 \times 10-26$ & 1 & $0.85(0.24-2.94)$ & $1(0.089)$ & 0.003 & 1 & $0.61(0.08-4.66)$ & $14(0.145)$ \\
\hline PRKCE & $5(0.204)$ & 0.25 & 0.613609 & $1.52(0.54-4.26)$ & $3(0.267)$ & 0.46 & 0.229386 & $1.98(0.56-6.97)$ & $13(0.135)$ \\
\hline SCNN1D & $9(0.368)$ & 10.75 & 0.001043 & $5.09(1.89-13.67)$ & $4(0.356)$ & 5.39 & 0.021342 & $4.92(1.44-16.83)$ & $7(0.073)$ \\
\hline SLC1A1 & $2(0.082)$ & 0.0063 & 0.635006 & $1.58(0.31-8.14)$ & $4(0.356)$ & 7.80 & 0.009658 & $6.89(1.85-25.69)$ & $5(0.052)$ \\
\hline SLCO1C1 & $1(0.041)$ & 0.028 & 0.36358 & $3.95(0.25-63.11)$ & $3(0.267)$ & 11.61 & 0.004178 & $25.82(2.68-248.44)$ & $1(0.01)$ \\
\hline$T A C 3$ & $1(0.041)$ & 0.028 & 0.36358 & $3.95(0.25-63.11)$ & $1(0.089)$ & 0.45 & 0.197793 & $8.59(0.54-137.45)$ & $1(0.01)$ \\
\hline TFRC & $2(0.082)$ & 1.65 & 0.106128 & $7.9(0.72-87.11)$ & $1(0.089)$ & 0.45 & 0.197793 & $8.59(0.54-137.45)$ & $1(0.01)$ \\
\hline$T X N R D 2$ & $8(0.327)$ & 13.31 & 0.000625 & $7.91(2.38-26.3)$ & $1(0.089)$ & $1.72 \times 10-24$ & 0.423657 & $2.15(0.24-19.23)$ & $4(0.041)$ \\
\hline AKR1B10 & $1(0.041)$ & $2.39 \times 10-27$ & 0.492306 & $1.97(0.18-21.77)$ & $0(0)$ & $\mathrm{n} / \mathrm{a}$ & $\mathrm{n} / \mathrm{a}$ & $\mathrm{n} / \mathrm{a}$ & $2(0.021)$ \\
\hline AKR1B15 & $1(0.041)$ & $2.39 \times 10-27$ & 0.492306 & $1.97(0.18-21.77)$ & $0(0)$ & $\mathrm{n} / \mathrm{a}$ & $\mathrm{n} / \mathrm{a}$ & $\mathrm{n} / \mathrm{a}$ & $2(0.021)$ \\
\hline AKR1C1 & $1(0.041)$ & $2.39 \times 10-27$ & 0.492306 & $1.97(0.18-21.77)$ & $0(0)$ & $\mathrm{n} / \mathrm{a}$ & $\mathrm{n} / \mathrm{a}$ & $\mathrm{n} / \mathrm{a}$ & $2(0.021)$ \\
\hline$A L D H 1 A 3$ & $1(0.041)$ & 8.48 & 0.000717 & $0.09(0.01-0.62)$ & $0(0)$ & $\mathrm{n} / \mathrm{a}$ & $\mathrm{n} / \mathrm{a}$ & $\mathrm{n} / \mathrm{a}$ & $46(0.477)$ \\
\hline ALDH3A1 & $2(0.082)$ & 0.74 & 0.184213 & $3.95(0.56-28.04)$ & $0(0)$ & $\mathrm{n} / \mathrm{a}$ & $\mathrm{n} / \mathrm{a}$ & $\mathrm{n} / \mathrm{a}$ & $2(0.021)$ \\
\hline$A L O X 5$ & $1(0.041)$ & 0.028 & 0.36358 & $3.95(0.25-63.11)$ & $0(0)$ & $\mathrm{n} / \mathrm{a}$ & $\mathrm{n} / \mathrm{a}$ & $\mathrm{n} / \mathrm{a}$ & $1(0.01)$ \\
\hline ANKRD33 & $1(0.041)$ & 0.028 & 0.36358 & $3.95(0.25-63.11)$ & $0(0)$ & $\mathrm{n} / \mathrm{a}$ & $\mathrm{n} / \mathrm{a}$ & $\mathrm{n} / \mathrm{a}$ & $1(0.01)$ \\
\hline$A R S A$ & $2(0.082)$ & 0.30 & 0.267282 & $2.63(0.44-15.76)$ & $0(0)$ & $\mathrm{n} / \mathrm{a}$ & $\mathrm{n} / \mathrm{a}$ & $\mathrm{n} / \mathrm{a}$ & $3(0.031)$ \\
\hline ARSJ & $1(0.041)$ & $2.39 \times 10-27$ & 0.492306 & $1.97(0.18-21.77)$ & $0(0)$ & $\mathrm{n} / \mathrm{a}$ & $\mathrm{n} / \mathrm{a}$ & $\mathrm{n} / \mathrm{a}$ & $2(0.021)$ \\
\hline BCHE & $1(0.041)$ & $2.56 \times 10-30$ & 1 & $0.79(0.09-6.76)$ & $0(0)$ & $\mathrm{n} / \mathrm{a}$ & $\mathrm{n} / \mathrm{a}$ & $\mathrm{n} / \mathrm{a}$ & $5(0.052)$ \\
\hline CBR3 & $7(0.286)$ & 1.87 & 0.171303 & $2.13(0.85-5.34)$ & $0(0)$ & $\mathrm{n} / \mathrm{a}$ & $\mathrm{n} / \mathrm{a}$ & $\mathrm{n} / \mathrm{a}$ & $13(0.135)$ \\
\hline$C B S$ & $2(0.082)$ & 0.085 & 0.350127 & $1.97(0.36-10.78)$ & $0(0)$ & $\mathrm{n} / \mathrm{a}$ & $\mathrm{n} / \mathrm{a}$ & $\mathrm{n} / \mathrm{a}$ & $4(0.041)$ \\
\hline CES2 & $1(0.041)$ & 0.028 & 0.36358 & $3.95(0.25-63.11)$ & $0(0)$ & $\mathrm{n} / \mathrm{a}$ & $\mathrm{n} / \mathrm{a}$ & $\mathrm{n} / \mathrm{a}$ & $1(0.01)$ \\
\hline CHAT & $3(0.123)$ & 4.43 & 0.028043 & $11.85(1.23-113.95)$ & $0(0)$ & $\mathrm{n} / \mathrm{a}$ & $\mathrm{n} / \mathrm{a}$ & $\mathrm{n} / \mathrm{a}$ & $1(0.01)$ \\
\hline CHST10 & $2(0.082)$ & 0.74 & 0.184213 & $3.95(0.56-28.04)$ & $0(0)$ & $\mathrm{n} / \mathrm{a}$ & $\mathrm{n} / \mathrm{a}$ & $\mathrm{n} / \mathrm{a}$ & $2(0.021)$ \\
\hline
\end{tabular}




\begin{tabular}{|c|c|c|c|c|c|c|c|c|c|}
\hline CRYZ & $2(0.082)$ & 1.65 & 0.106128 & $7.9(0.72-87.11)$ & $0(0)$ & n/a & $\mathrm{n} / \mathrm{a}$ & $\mathrm{n} / \mathrm{a}$ & $1(0.01)$ \\
\hline CYP11B1 & $1(0.041)$ & 0.028 & 0.36358 & $3.95(0.25-63.11)$ & $0(0)$ & n/a & $\mathrm{n} / \mathrm{a}$ & $\mathrm{n} / \mathrm{a}$ & $1(0.01)$ \\
\hline CYP24A1 & $1(0.041)$ & $2.39 \times 10-27$ & 0.492306 & $1.97(0.18-21.77)$ & $0(0)$ & $\mathrm{n} / \mathrm{a}$ & $\mathrm{n} / \mathrm{a}$ & $\mathrm{n} / \mathrm{a}$ & $2(0.021)$ \\
\hline CYP27B1 & $1(0.041)$ & $2.39 \times 10-27$ & 0.492306 & $1.97(0.18-21.77)$ & $0(0)$ & $\mathrm{n} / \mathrm{a}$ & $\mathrm{n} / \mathrm{a}$ & $\mathrm{n} / \mathrm{a}$ & $2(0.021)$ \\
\hline CYP2C18 & $2(0.082)$ & 0.049 & 0.74907 & $0.66(0.15-2.94)$ & $0(0)$ & $\mathrm{n} / \mathrm{a}$ & $\mathrm{n} / \mathrm{a}$ & $\mathrm{n} / \mathrm{a}$ & $12(0.124)$ \\
\hline CYP2C19 & $2(0.082)$ & 0.12 & 0.749765 & $0.61(0.14-2.69)$ & $0(0)$ & $\mathrm{n} / \mathrm{a}$ & $\mathrm{n} / \mathrm{a}$ & $\mathrm{n} / \mathrm{a}$ & $13(0.135)$ \\
\hline CYP2W1 & $1(0.041)$ & $3.75 \times 10-25$ & 1 & $0.99(0.11-8.83)$ & $0(0)$ & n/a & $\mathrm{n} / \mathrm{a}$ & $\mathrm{n} / \mathrm{a}$ & $4(0.041)$ \\
\hline СYP46A1 & $1(0.041)$ & $2.39 \times 10-27$ & 0.492306 & $1.97(0.18-21.77)$ & $0(0)$ & $\mathrm{n} / \mathrm{a}$ & $\mathrm{n} / \mathrm{a}$ & $\mathrm{n} / \mathrm{a}$ & $2(0.021)$ \\
\hline CYP7B1 & $1(0.041)$ & 0.028 & 0.36358 & $3.95(0.25-63.11)$ & $0(0)$ & $\mathrm{n} / \mathrm{a}$ & $\mathrm{n} / \mathrm{a}$ & $\mathrm{n} / \mathrm{a}$ & $1(0.01)$ \\
\hline$D C X R$ & $2(0.082)$ & 0.085 & 0.350127 & \begin{tabular}{|l|}
$1.97(0.36-10.78)$ \\
\end{tabular} & $0(0)$ & n/a & $\mathrm{n} / \mathrm{a}$ & n/a & $4(0.041)$ \\
\hline DRD4 & $1(0.041)$ & $4.44 \times 10-26$ & 1 & $0.66(0.08-5.46)$ & $0(0)$ & $\mathrm{n} / \mathrm{a}$ & $\mathrm{n} / \mathrm{a}$ & $\mathrm{n} / \mathrm{a}$ & $6(0.062)$ \\
\hline EPHX4 & $1(0.041)$ & $4.44 \times 10-26$ & 1 & $0.66(0.08-5.46)$ & $0(0)$ & $\mathrm{n} / \mathrm{a}$ & $\mathrm{n} / \mathrm{a}$ & $\mathrm{n} / \mathrm{a}$ & $6(0.062)$ \\
\hline FBN2 & $2(0.082)$ & 0.74 & 0.184213 & $3.95(0.56-28.04)$ & $0(0)$ & n/a & $\mathrm{n} / \mathrm{a}$ & $\mathrm{n} / \mathrm{a}$ & $2(0.021)$ \\
\hline$F C G R 2 B$ & $5(0.204)$ & 2.22 & 0.136027 & $2.82(0.89-8.9)$ & $0(0)$ & $\mathrm{n} / \mathrm{a}$ & $\mathrm{n} / \mathrm{a}$ & $\mathrm{n} / \mathrm{a}$ & $7(0.073)$ \\
\hline GPR32 & $1(0.041)$ & 0.028 & 0.36358 & $3.95(0.25-63.11)$ & $0(0)$ & $\mathrm{n} / \mathrm{a}$ & $\mathrm{n} / \mathrm{a}$ & $\mathrm{n} / \mathrm{a}$ & $1(0.01)$ \\
\hline GPX5 & $1(0.041)$ & $2.39 \times 10-27$ & 0.492306 & $1.97(0.18-21.77)$ & $0(0)$ & n/a & $\mathrm{n} / \mathrm{a}$ & $\mathrm{n} / \mathrm{a}$ & $2(0.021)$ \\
\hline GPX6 & $1(0.041)$ & $2.39 \times 10-27$ & 0.492306 & $1.97(0.18-21.77)$ & $0(0)$ & n/a & $\mathrm{n} / \mathrm{a}$ & $\mathrm{n} / \mathrm{a}$ & $2(0.021)$ \\
\hline GSTO1 & $1(0.041)$ & 0.028 & 0.36358 & $3.95(0.25-63.11)$ & $0(0)$ & $\mathrm{n} / \mathrm{a}$ & $\mathrm{n} / \mathrm{a}$ & $\mathrm{n} / \mathrm{a}$ & $1(0.01)$ \\
\hline GSTO2 & $1(0.041)$ & 0.028 & 0.36358 & $3.95(0.25-63.11)$ & $0(0)$ & n/a & $\mathrm{n} / \mathrm{a}$ & $\mathrm{n} / \mathrm{a}$ & $1(0.01)$ \\
\hline GSTP1 & $2(0.082)$ & 0.74 & 0.184213 & $3.95(0.56-28.04)$ & $0(0)$ & $\mathrm{n} / \mathrm{a}$ & $\mathrm{n} / \mathrm{a}$ & $\mathrm{n} / \mathrm{a}$ & $2(0.021)$ \\
\hline IGF2 & $1(0.041)$ & $6.58 \times 10-25$ & 1 & $1.32(0.14-12.65)$ & $0(0)$ & n/a & $\mathrm{n} / \mathrm{a}$ & $\mathrm{n} / \mathrm{a}$ & $3(0.031)$ \\
\hline$I Y D$ & $1(0.041)$ & 0.028 & 0.36358 & $3.95(0.25-63.11)$ & $0(0)$ & n/a & $\mathrm{n} / \mathrm{a}$ & $\mathrm{n} / \mathrm{a}$ & $1(0.01)$ \\
\hline JAM3 & $1(0.041)$ & $2.39 \times 10-27$ & 0.492306 & $1.97(0.18-21.77)$ & $0(0)$ & $\mathrm{n} / \mathrm{a}$ & $\mathrm{n} / \mathrm{a}$ & n/a & $2(0.021)$ \\
\hline KIF17 & $1(0.041)$ & 0.028 & 0.36358 & $3.95(0.25-63.11)$ & $0(0)$ & n/a & $\mathrm{n} / \mathrm{a}$ & $\mathrm{n} / \mathrm{a}$ & $1(0.01)$ \\
\hline LRPI & $1(0.041)$ & 1.17 & 0.221204 & $0.26(0.03-1.99)$ & $0(0)$ & n/a & $\mathrm{n} / \mathrm{a}$ & $\mathrm{n} / \mathrm{a}$ & $15(0.155)$ \\
\hline МАРКВIР2 & $2(0.082)$ & 0.74 & 0.184213 & $3.95(0.56-28.04)$ & $0(0)$ & n/a & $\mathrm{n} / \mathrm{a}$ & $\mathrm{n} / \mathrm{a}$ & $2(0.021)$ \\
\hline NOTCH1 & $6(0.245)$ & 6.05 & 0.0139 & $4.74(1.45-15.55)$ & $0(0)$ & $\mathrm{n} / \mathrm{a}$ & $\mathrm{n} / \mathrm{a}$ & $\mathrm{n} / \mathrm{a}$ & $5(0.052)$ \\
\hline$P A O X$ & $4(0.164)$ & 6.49 & 0.004026 & $0.27(0.1-0.75)$ & $0(0)$ & $\mathrm{n} / \mathrm{a}$ & $\mathrm{n} / \mathrm{a}$ & $\mathrm{n} / \mathrm{a}$ & $58(0.601)$ \\
\hline PARD6G & $1(0.041)$ & $2.39 \times 10-27$ & 0.492306 & $1.97(0.18-21.77)$ & $0(0)$ & $\mathrm{n} / \mathrm{a}$ & $\mathrm{n} / \mathrm{a}$ & $\mathrm{n} / \mathrm{a}$ & $2(0.021)$ \\
\hline PHLDA2 & $1(0.041)$ & 0.028 & 0.36358 & $3.95(0.25-63.11)$ & $0(0)$ & n/a & $\mathrm{n} / \mathrm{a}$ & n/a & $1(0.01)$ \\
\hline PSG8 & $25(1.022)$ & 2.75 & 0.097063 & $1.52(0.96-2.42)$ & $0(0)$ & n/a & $\mathrm{n} / \mathrm{a}$ & $\mathrm{n} / \mathrm{a}$ & $65(0.674)$ \\
\hline PSG9 & $30(1.226)$ & 6.96 & 0.008334 & $1.83(1.19-2.83)$ & $0(0)$ & $\mathrm{n} / \mathrm{a}$ & $\mathrm{n} / \mathrm{a}$ & $\mathrm{n} / \mathrm{a}$ & $65(0.674)$ \\
\hline SHANK2 & $3(0.123)$ & 0.32 & 0.398461 & $1.97(0.49-7.9)$ & $0(0)$ & $\mathrm{n} / \mathrm{a}$ & $\mathrm{n} / \mathrm{a}$ & $\mathrm{n} / \mathrm{a}$ & $6(0.062)$ \\
\hline$S L C 12 A 7$ & $3(0.123)$ & 1.71 & 0.18304 & $0.41(0.12-1.34)$ & $0(0)$ & $\mathrm{n} / \mathrm{a}$ & $\mathrm{n} / \mathrm{a}$ & $\mathrm{n} / \mathrm{a}$ & $29(0.301)$ \\
\hline
\end{tabular}




\begin{tabular}{|c|c|c|c|c|c|c|c|c|c|}
\hline SLC19A1 & $6(0.245)$ & 0.11 & 0.742279 & $1.32(0.52-3.32)$ & $0(0)$ & $\mathrm{n} / \mathrm{a}$ & $\mathrm{n} / \mathrm{a}$ & $\mathrm{n} / \mathrm{a}$ & $18(0.187)$ \\
\hline$S L C 7 A 5$ & $1(0.041)$ & $2.39 \times 10-27$ & 0.492306 & $1.97(0.18-21.77)$ & $0(0)$ & $\mathrm{n} / \mathrm{a}$ & $\mathrm{n} / \mathrm{a}$ & $\mathrm{n} / \mathrm{a}$ & $2(0.021)$ \\
\hline SULF1 & $1(0.041)$ & $2.39 \times 10-27$ & 0.492306 & $1.97(0.18-21.77)$ & $0(0)$ & $\mathrm{n} / \mathrm{a}$ & $\mathrm{n} / \mathrm{a}$ & $\mathrm{n} / \mathrm{a}$ & $2(0.021)$ \\
\hline SULF2 & $2(0.082)$ & 1.65 & 0.106128 & $7.9(0.72-87.11)$ & $0(0)$ & $\mathrm{n} / \mathrm{a}$ & $\mathrm{n} / \mathrm{a}$ & $\mathrm{n} / \mathrm{a}$ & $1(0.01)$ \\
\hline SULT1B1 & $1(0.041)$ & 0.028 & 0.36358 & $3.95(0.25-63.11)$ & $0(0)$ & $\mathrm{n} / \mathrm{a}$ & $\mathrm{n} / \mathrm{a}$ & $\mathrm{n} / \mathrm{a}$ & $1(0.01)$ \\
\hline SULT2A1 & $2(0.082)$ & 0.085 & 0.350127 & $1.97(0.36-10.78)$ & $0(0)$ & $\mathrm{n} / \mathrm{a}$ & $\mathrm{n} / \mathrm{a}$ & $\mathrm{n} / \mathrm{a}$ & $4(0.041)$ \\
\hline$T J P 1$ & $3(0.123)$ & 4.43 & 0.028043 & $11.85(1.23-113.95)$ & $0(0)$ & $\mathrm{n} / \mathrm{a}$ & $\mathrm{n} / \mathrm{a}$ & $\mathrm{n} / \mathrm{a}$ & $1(0.01)$ \\
\hline TXNRD3 & $1(0.041)$ & 0.028 & 0.36358 & $3.95(0.25-63.11)$ & $0(0)$ & $\mathrm{n} / \mathrm{a}$ & $\mathrm{n} / \mathrm{a}$ & $\mathrm{n} / \mathrm{a}$ & $1(0.01)$ \\
\hline UGT2A1 & $2(0.082)$ & 6.02 & 0.004728 & $0.18(0.04-0.76)$ & $0(0)$ & $\mathrm{n} / \mathrm{a}$ & $\mathrm{n} / \mathrm{a}$ & $\mathrm{n} / \mathrm{a}$ & $43(0.446)$ \\
\hline UGT2A2 & $2(0.082)$ & 5.79 & 0.007233 & $0.19(0.05-0.77)$ & $0(0)$ & $\mathrm{n} / \mathrm{a}$ & $\mathrm{n} / \mathrm{a}$ & $\mathrm{n} / \mathrm{a}$ & $42(0.435)$ \\
\hline UGT2B11 & $1(0.041)$ & 0.028 & 0.36358 & $3.95(0.25-63.11)$ & $0(0)$ & $\mathrm{n} / \mathrm{a}$ & $\mathrm{n} / \mathrm{a}$ & $\mathrm{n} / \mathrm{a}$ & $1(0.01)$ \\
\hline UGT2B4 & $1(0.041)$ & 0.028 & 0.36358 & $3.95(0.25-63.11)$ & $0(0)$ & $\mathrm{n} / \mathrm{a}$ & $\mathrm{n} / \mathrm{a}$ & $\mathrm{n} / \mathrm{a}$ & $1(0.01)$ \\
\hline$A B C A 8$ & $0(0)$ & $\mathrm{n} / \mathrm{a}$ & $\mathrm{n} / \mathrm{a}$ & $\mathrm{n} / \mathrm{a}$ & $1(0.089)$ & 0.12 & 0.281506 & $4.3(0.39-47.41)$ & $2(0.021)$ \\
\hline$A K R 1 C 4$ & $0(0)$ & $\mathrm{n} / \mathrm{a}$ & $\mathrm{n} / \mathrm{a}$ & $\mathrm{n} / \mathrm{a}$ & $1(0.089)$ & 0.018 & 0.356491 & $2.86(0.3-27.55)$ & $3(0.031)$ \\
\hline ALDH18A1 & $0(0)$ & $\mathrm{n} / \mathrm{a}$ & $\mathrm{n} / \mathrm{a}$ & $\mathrm{n} / \mathrm{a}$ & $1(0.089)$ & 0.45 & 0.197793 & $8.59(0.54-137.45)$ & $1(0.01)$ \\
\hline ALDH1A2 & $0(0)$ & $\mathrm{n} / \mathrm{a}$ & $\mathrm{n} / \mathrm{a}$ & $\mathrm{n} / \mathrm{a}$ & $1(0.089)$ & $1.72 \times 10-24$ & 0.423657 & $2.15(0.24-19.23)$ & $4(0.041)$ \\
\hline$A L D H 3 B 1$ & $0(0)$ & $\mathrm{n} / \mathrm{a}$ & $\mathrm{n} / \mathrm{a}$ & $\mathrm{n} / \mathrm{a}$ & $1(0.089)$ & $3.80 \times 10-24$ & 0.585968 & $1.23(0.15-9.98)$ & $7(0.073)$ \\
\hline ALDH8A1 & $0(0)$ & $\mathrm{n} / \mathrm{a}$ & $\mathrm{n} / \mathrm{a}$ & $\mathrm{n} / \mathrm{a}$ & $4(0.356)$ & 14.74 & 0.001487 & $17.23(3.15-94.16)$ & $2(0.021)$ \\
\hline$A L O X 12$ & $0(0)$ & $\mathrm{n} / \mathrm{a}$ & $\mathrm{n} / \mathrm{a}$ & $\mathrm{n} / \mathrm{a}$ & $1(0.089)$ & 0.45 & 0.197793 & $8.59(0.54-137.45)$ & $1(0.01)$ \\
\hline$A L O X E 3$ & $0(0)$ & $\mathrm{n} / \mathrm{a}$ & $\mathrm{n} / \mathrm{a}$ & $\mathrm{n} / \mathrm{a}$ & $1(0.089)$ & 0.12 & 0.281506 & $4.3(0.39-47.41)$ & $2(0.021)$ \\
\hline CHST9 & $0(0)$ & $\mathrm{n} / \mathrm{a}$ & $\mathrm{n} / \mathrm{a}$ & $\mathrm{n} / \mathrm{a}$ & $2(0.178)$ & 5.03 & 0.030365 & $17.2(1.56-189.82)$ & $1(0.01)$ \\
\hline CYP2U1 & $0(0)$ & $\mathrm{n} / \mathrm{a}$ & $\mathrm{n} / \mathrm{a}$ & $\mathrm{n} / \mathrm{a}$ & $1(0.089)$ & 0.45 & 0.197793 & $8.59(0.54-137.45)$ & $1(0.01)$ \\
\hline DHRS3 & $0(0)$ & $\mathrm{n} / \mathrm{a}$ & $\mathrm{n} / \mathrm{a}$ & $\mathrm{n} / \mathrm{a}$ & $1(0.089)$ & $1.72 \times 10-24$ & 0.423657 & $2.15(0.24-19.23)$ & $4(0.041)$ \\
\hline DNAH5 & $0(0)$ & $\mathrm{n} / \mathrm{a}$ & $\mathrm{n} / \mathrm{a}$ & $\mathrm{n} / \mathrm{a}$ & $1(0.089)$ & $5.42 \times 10-31$ & 0.483817 & $1.72(0.2-14.71)$ & $5(0.052)$ \\
\hline GALNS & $0(0)$ & $\mathrm{n} / \mathrm{a}$ & $\mathrm{n} / \mathrm{a}$ & $\mathrm{n} / \mathrm{a}$ & $1(0.089)$ & $1.72 \times 10-24$ & 0.423657 & $2.15(0.24-19.23)$ & $4(0.041)$ \\
\hline GH1 & $0(0)$ & $\mathrm{n} / \mathrm{a}$ & $\mathrm{n} / \mathrm{a}$ & $\mathrm{n} / \mathrm{a}$ & $1(0.089)$ & 0.12 & 0.281506 & $4.3(0.39-47.41)$ & $2(0.021)$ \\
\hline HSD3B1 & $0(0)$ & $\mathrm{n} / \mathrm{a}$ & $\mathrm{n} / \mathrm{a}$ & $\mathrm{n} / \mathrm{a}$ & $1(0.089)$ & 0.45 & 0.197793 & $8.59(0.54-137.45)$ & $1(0.01)$ \\
\hline IFT74 & $0(0)$ & $\mathrm{n} / \mathrm{a}$ & $\mathrm{n} / \mathrm{a}$ & $\mathrm{n} / \mathrm{a}$ & $4(0.356)$ & 7.80 & 0.009658 & $6.89(1.85-25.69)$ & $5(0.052)$ \\
\hline$J A G 2$ & $0(0)$ & $\mathrm{n} / \mathrm{a}$ & $\mathrm{n} / \mathrm{a}$ & $\mathrm{n} / \mathrm{a}$ & $4(0.356)$ & 0.02 & 1 & $0.82(0.29-2.28)$ & $42(0.435)$ \\
\hline KISS1 & $0(0)$ & $\mathrm{n} / \mathrm{a}$ & $\mathrm{n} / \mathrm{a}$ & $\mathrm{n} / \mathrm{a}$ & $1(0.089)$ & 0.12 & 0.281506 & $4.3(0.39-47.41)$ & $2(0.021)$ \\
\hline NAT1 & $0(0)$ & $\mathrm{n} / \mathrm{a}$ & $\mathrm{n} / \mathrm{a}$ & $\mathrm{n} / \mathrm{a}$ & $1(0.089)$ & 0.018 & 0.356491 & $2.86(0.3-27.55)$ & $3(0.031)$ \\
\hline NOS1AP & $0(0)$ & $\mathrm{n} / \mathrm{a}$ & $\mathrm{n} / \mathrm{a}$ & $\mathrm{n} / \mathrm{a}$ & $1(0.089)$ & $9.37 \times 10-25$ & 1 & $1.07(0.13-8.59)$ & $8(0.083)$ \\
\hline NOTCH3 & $0(0)$ & $\mathrm{n} / \mathrm{a}$ & $\mathrm{n} / \mathrm{a}$ & $\mathrm{n} / \mathrm{a}$ & $1(0.089)$ & 0.45 & 0.197793 & $8.59(0.54-137.45)$ & $1(0.01)$ \\
\hline $\mathrm{NQO2}$ & $\mid 0(0)$ & $\mathrm{n} / \mathrm{a}$ & $\mathrm{n} / \mathrm{a}$ & $\mathrm{n} / \mathrm{a}$ & $1(0.089)$ & 0.45 & 0.197793 & $8.59(0.54-137.45)$ & $1(0.01)$ \\
\hline
\end{tabular}




\begin{tabular}{|c|c|c|c|c|c|c|c|c|c|}
\hline NTRK2 & $0(0)$ & $\mathrm{n} / \mathrm{a}$ & $\mathrm{n} / \mathrm{a}$ & $\mathrm{n} / \mathrm{a}$ & $3(0.267)$ & 11.61 & 0.004178 & $25.82(2.68-248.44)$ & $1(0.01)$ \\
\hline PTGES2 & $0(0)$ & $\mathrm{n} / \mathrm{a}$ & $\mathrm{n} / \mathrm{a}$ & $\mathrm{n} / \mathrm{a}$ & $1(0.089)$ & 0.45 & 0.197793 & $8.59(0.54-137.45)$ & $1(0.01)$ \\
\hline PTGS2 & $0(0)$ & $\mathrm{n} / \mathrm{a}$ & $\mathrm{n} / \mathrm{a}$ & $\mathrm{n} / \mathrm{a}$ & $3(0.267)$ & 3.71 & 0.042465 & $5.16(1.23-21.63)$ & $5(0.052)$ \\
\hline SGSH & $0(0)$ & $\mathrm{n} / \mathrm{a}$ & $\mathrm{n} / \mathrm{a}$ & $\mathrm{n} / \mathrm{a}$ & $1(0.089)$ & 0.12 & 0.281506 & $4.3(0.39-47.41)$ & $2(0.021)$ \\
\hline SLC25A25 & $0(0)$ & $\mathrm{n} / \mathrm{a}$ & $\mathrm{n} / \mathrm{a}$ & $\mathrm{n} / \mathrm{a}$ & $1(0.089)$ & 0.12 & 0.281506 & $4.3(0.39-47.41)$ & $2(0.021)$ \\
\hline SLC7A1 & $0(0)$ & $\mathrm{n} / \mathrm{a}$ & $\mathrm{n} / \mathrm{a}$ & $\mathrm{n} / \mathrm{a}$ & $1(0.089)$ & 0.45 & 0.197793 & $8.59(0.54-137.45)$ & $1(0.01)$ \\
\hline SULT1C2 & $0(0)$ & $\mathrm{n} / \mathrm{a}$ & $\mathrm{n} / \mathrm{a}$ & $\mathrm{n} / \mathrm{a}$ & $1(0.089)$ & 0.12 & 0.281506 & $4.3(0.39-47.41)$ & $2(0.021)$ \\
\hline SULT1C3 & $0(0)$ & $\mathrm{n} / \mathrm{a}$ & $\mathrm{n} / \mathrm{a}$ & $\mathrm{n} / \mathrm{a}$ & $1(0.089)$ & 0.45 & 0.197793 & $8.59(0.54-137.45)$ & $1(0.01)$ \\
\hline SULT1C4 & | $0(0)$ & $\mathrm{n} / \mathrm{a}$ & $\mathrm{n} / \mathrm{a}$ & $\mathrm{n} / \mathrm{a}$ & $1(0.089)$ & 0.45 & 0.197793 & $8.59(0.54-137.45)$ & $1(0.01)$ \\
\hline
\end{tabular}


Table S3: Numbers of variants by impact and by rank for the 380 genes not targeted by variants from rank A. Genes are ordered by the amount of high + moderate impact variants they have.

\begin{tabular}{|c|c|c|c|c|c|c|c|c|}
\hline \multirow[b]{2}{*}{ Gene } & \multicolumn{3}{|c|}{ Number of variants by impact } & \multicolumn{5}{|c|}{$\begin{array}{c}N^{\mathbf{0}} \text { of variants by } \\
\text { rank }\end{array}$} \\
\hline & $\begin{array}{l}\text { High Impact } \\
\text { Variants }\end{array}$ & $\begin{array}{l}\text { Moderate Impact } \\
\text { Variants }\end{array}$ & $\begin{array}{c}\text { High + Moderate Impact } \\
\text { Variants }\end{array}$ & B & C & D & $\mathbf{E}$ & $\mathbf{F}$ \\
\hline DNAH7 & 10 & 98 & 108 & 4 & 3 & 1 & 76 & 24 \\
\hline DNAH11 & 7 & 68 & 75 & 4 & 0 & 0 & 64 & 7 \\
\hline$V W F$ & 3 & 40 & 43 & 0 & 1 & 2 & 35 & 5 \\
\hline TJP3 & 4 & 30 & 34 & 2 & 2 & 2 & 25 & 3 \\
\hline$A B C C 1$ & 0 & 31 & 31 & 1 & 0 & 0 & 26 & 4 \\
\hline ATP1A4 & 5 & 26 & 31 & 0 & 1 & 1 & 20 & 9 \\
\hline$A B C C 3$ & 4 & 26 & 30 & 1 & 1 & 2 & 23 & 3 \\
\hline CCDC40 & 2 & 27 & 29 & 1 & 1 & 0 & 25 & 2 \\
\hline NOTCH3 & 0 & 29 & 29 & 0 & 1 & 2 & 22 & 4 \\
\hline NOTCH1 & 0 & 26 & 26 & 0 & 0 & 0 & 21 & 5 \\
\hline$A O C 2$ & 4 & 20 & 24 & 2 & 0 & 0 & 20 & 2 \\
\hline$C G N$ & 3 & 21 & 24 & 3 & 1 & 2 & 12 & 6 \\
\hline ADAMTS18 & 3 & 20 & 23 & 0 & 1 & 0 & 19 & 3 \\
\hline$A O X 1$ & 9 & 14 & 23 & 1 & 0 & 1 & 21 & 0 \\
\hline РАРPA2 & 1 & 22 & 23 & 0 & 1 & 0 & 19 & 3 \\
\hline SLC12A7 & 2 & 21 & 23 & 2 & 0 & 0 & 20 & 1 \\
\hline$M P D Z$ & 1 & 21 & 22 & 0 & 1 & 3 & 16 & 2 \\
\hline ANKRD11 & 0 & 21 & 21 & 0 & 1 & 1 & 18 & 1 \\
\hline CGNL1 & 2 & 19 & 21 & 0 & 0 & 1 & 15 & 5 \\
\hline LOXL2 & 1 & 20 & 21 & 1 & 0 & 0 & 18 & 2 \\
\hline$A D C Y 10$ & 3 & 17 & 20 & 0 & 0 & 0 & 18 & 2 \\
\hline FBN2 & 0 & 20 & 20 & 0 & 0 & 0 & 18 & 2 \\
\hline$A L D H 3 B 2$ & 1 & 18 & 19 & 3 & 1 & 3 & 8 & 4 \\
\hline FMO2 & 3 & 16 & 19 & 2 & 2 & 1 & 10 & 4 \\
\hline NOTCH4 & 2 & 17 & 19 & 0 & 3 & 1 & 14 & 1 \\
\hline$A L D H 4 A 1$ & 0 & 18 & 18 & 0 & 0 & 1 & 13 & 4 \\
\hline CYP2C8 & 3 & 15 & 18 & 0 & 1 & 1 & 13 & 3 \\
\hline CYP4F12 & 1 & 17 & 18 & 2 & 0 & 0 & 14 & 2 \\
\hline FMO4 & 1 & 17 & 18 & 1 & 1 & 1 & 13 & 2 \\
\hline NOS3 & 0 & 18 & 18 & 1 & 1 & 0 & 12 & 4 \\
\hline PAPPA & 1 & 17 & 18 & 0 & 0 & 0 & 16 & 2 \\
\hline$T B X A S 1$ & 2 & 15 & 17 & 0 & 0 & 0 & 12 & 5 \\
\hline$T J P 1$ & 0 & 17 & 17 & 3 & 0 & 1 & 7 & 6 \\
\hline UGT2B10 & 3 & 14 & 17 & 0 & 1 & 1 & 12 & 3 \\
\hline CYP1A2 & 4 & 12 & 16 & 1 & 1 & 0 & 10 & 4 \\
\hline CYP24A1 & 2 & 14 & 16 & 1 & 1 & 0 & 10 & 4 \\
\hline CYP2A13 & 1 & 15 & 16 & 5 & 1 & 0 & 8 & 2 \\
\hline CYP2B6 & 3 & 13 & 16 & 0 & 1 & 2 & 11 & 2 \\
\hline CYP4F11 & 1 & 15 & 16 & 0 & 1 & 0 & 13 & 2 \\
\hline DHRS2 & 3 & 13 & 16 & 1 & 0 & 2 & 12 & 1 \\
\hline NOS2 & 2 & 14 & 16 & 1 & 0 & 2 & 12 & 1 \\
\hline NOTCH2 & 0 & 16 & 16 & 0 & 1 & 1 & 13 & 1 \\
\hline SCNN1A & 1 & 15 & 16 & 0 & 1 & 1 & 12 & 2 \\
\hline UGT2B15 & 4 & 12 & 16 & 1 & 1 & 0 & 8 & 6 \\
\hline $\boldsymbol{C P}$ & 2 & 13 & 15 & 2 & 0 & 3 & 8 & 2 \\
\hline CYP1A1 & 0 & 15 & 15 & 4 & 2 & 0 & 7 & 2 \\
\hline CYP4F3 & 1 & 14 & 15 & 0 & 2 & 0 & 8 & 5 \\
\hline
\end{tabular}




\begin{tabular}{|c|c|c|c|c|c|c|c|c|}
\hline JUP & 1 & 14 & 15 & 0 & 0 & 0 & 13 & 2 \\
\hline UGT2A1 & 3 & 12 & 15 & 0 & 0 & 1 & 11 & 3 \\
\hline ARSI & 1 & 13 & 14 & 0 & 0 & 0 & 12 & 2 \\
\hline CYP2F1 & 1 & 13 & 14 & 0 & 0 & 1 & 11 & 2 \\
\hline POMT2 & 1 & 13 & 14 & 0 & 0 & 0 & 13 & 1 \\
\hline ALDH9A1 & 3 & 10 & 13 & 0 & 0 & 1 & 9 & 3 \\
\hline$A L O X 15 B$ & 2 & 11 & 13 & 0 & 0 & 1 & 10 & 2 \\
\hline СУР2C9 & 1 & 12 & 13 & 2 & 2 & 0 & 7 & 2 \\
\hline СУР7А1 & 0 & 13 & 13 & 1 & 0 & 0 & 10 & 2 \\
\hline FMO5 & 4 & 9 & 13 & 0 & 1 & 0 & 11 & 1 \\
\hline MTR & 0 & 13 & 13 & 0 & 0 & 0 & 11 & 2 \\
\hline PARD3 & 0 & 13 & 13 & 0 & 0 & 0 & 11 & 2 \\
\hline ABCA2 & 0 & 12 & 12 & 0 & 0 & 0 & 10 & 2 \\
\hline ALOXE3 & 1 & 11 & 12 & 1 & 1 & 0 & 7 & 3 \\
\hline AOCI & 1 & 11 & 12 & 1 & 0 & 0 & 10 & 1 \\
\hline $\mathrm{CDH5}$ & 2 & 10 & 12 & 0 & 0 & 0 & 10 & 2 \\
\hline CES2 & 0 & 12 & 12 & 1 & 0 & 0 & 10 & 1 \\
\hline CHST6 & 0 & 12 & 12 & 1 & 1 & 0 & 6 & 4 \\
\hline CYP4V2 & 1 & 11 & 12 & 0 & 0 & 1 & 10 & 1 \\
\hline POMT1 & 3 & 9 & 12 & 0 & 0 & 1 & 9 & 2 \\
\hline PSG3 & 2 & 10 & 12 & 2 & 0 & 0 & 6 & 4 \\
\hline SLCO1C1 & 1 & 11 & 12 & 0 & 0 & 1 & 10 & 1 \\
\hline UGT2A3 & 3 & 9 & 12 & 0 & 0 & 0 & 7 & 5 \\
\hline ALDH3A1 & 2 & 9 & 11 & 0 & 0 & 0 & 8 & 3 \\
\hline ALDH5A1 & 5 & 6 & 11 & 0 & 0 & 2 & 8 & 1 \\
\hline BCHE & 0 & 11 & 11 & 1 & 1 & 1 & 8 & 0 \\
\hline СYР2C18 & 1 & 10 & 11 & 0 & 0 & 0 & 9 & 2 \\
\hline СУРЗА43 & 1 & 10 & 11 & 0 & 0 & 2 & 8 & 1 \\
\hline DNAII & 3 & 8 & 11 & 2 & 0 & 0 & 8 & 1 \\
\hline PSG7 & 2 & 9 & 11 & 0 & 1 & 1 & 8 & 1 \\
\hline RSPH4A & 1 & 10 & 11 & 1 & 0 & 0 & 8 & 2 \\
\hline SHANK2 & 1 & 10 & 11 & 0 & 0 & 0 & 10 & 1 \\
\hline UGT1A6 & 0 & 11 & 11 & 0 & 0 & 0 & 10 & 1 \\
\hline UGT2B7 & 0 & 11 & 11 & 0 & 0 & 1 & 9 & 1 \\
\hline$A B C B 1$ & 0 & 10 & 10 & 0 & 0 & 0 & 10 & 0 \\
\hline AKR1A1 & 2 & 8 & 10 & 1 & 0 & 1 & 5 & 3 \\
\hline$A K R 1 C 3$ & 3 & 7 & 10 & 1 & 0 & 1 & 6 & 2 \\
\hline AKR7A3 & 2 & 8 & 10 & 0 & 0 & 0 & 7 & 3 \\
\hline ALDH1B1 & 2 & 8 & 10 & 0 & 0 & 0 & 6 & 4 \\
\hline$A L O X 12 B$ & 1 & 9 & 10 & 0 & 0 & 0 & 10 & 0 \\
\hline$A L P P$ & 1 & 9 & 10 & 0 & 1 & 0 & 7 & 2 \\
\hline CYP11A1 & 0 & 10 & 10 & 0 & 0 & 0 & 10 & 0 \\
\hline СУР3А4 & 1 & 9 & 10 & 0 & 0 & 0 & 6 & 4 \\
\hline DRD4 & 0 & 10 & 10 & 0 & 0 & 0 & 10 & 0 \\
\hline$D Y X 1 C 1$ & 1 & 9 & 10 & 0 & 0 & 1 & 7 & 2 \\
\hline EPHX1 & 0 & 10 & 10 & 1 & 1 & 0 & 8 & 0 \\
\hline EPHX2 & 2 & 8 & 10 & 0 & 1 & 1 & 6 & 2 \\
\hline FMO1 & 3 & 7 & 10 & 0 & 0 & 0 & 9 & 1 \\
\hline FMO3 & 1 & 9 & 10 & 0 & 0 & 0 & 8 & 2 \\
\hline ILIRLI & 0 & 10 & 10 & 0 & 0 & 0 & 9 & 1 \\
\hline PSG9 & 4 & 6 & 10 & 0 & 1 & 0 & 6 & 3 \\
\hline SCNN1B & 1 & 9 & 10 & 0 & 0 & 0 & 8 & 2 \\
\hline TJP2 & 0 & 10 & 10 & 1 & 0 & 0 & 9 & 0 \\
\hline ALDH2 & 0 & 9 & 9 & 1 & 0 & 0 & 8 & 0 \\
\hline
\end{tabular}




\begin{tabular}{|c|c|c|c|c|c|c|c|c|}
\hline ALDH8A1 & 0 & 9 & 9 & 0 & 0 & 0 & 7 & 2 \\
\hline ARSJ & 2 & 7 & 9 & 0 & 0 & 0 & 7 & 2 \\
\hline CCDC114 & 0 & 9 & 9 & 0 & 0 & 0 & 6 & 3 \\
\hline CCDC39 & 1 & 8 & 9 & 2 & 0 & 2 & 5 & 0 \\
\hline CHAT & 1 & 8 & 9 & 0 & 0 & 3 & 3 & 3 \\
\hline CHST4 & 0 & 9 & 9 & 0 & 0 & 0 & 8 & 1 \\
\hline CYP11B2 & 0 & 9 & 9 & 0 & 0 & 0 & 9 & 0 \\
\hline CYP26B1 & 0 & 9 & 9 & 1 & 0 & 1 & 6 & 1 \\
\hline СYР2A6 & 2 & 7 & 9 & 0 & 0 & 1 & 8 & 0 \\
\hline СYР39А1 & 1 & 8 & 9 & 0 & 0 & 2 & 4 & 3 \\
\hline GPX6 & 3 & 6 & 9 & 2 & 0 & 0 & 6 & 1 \\
\hline GSTA3 & 0 & 9 & 9 & 0 & 2 & 1 & 3 & 3 \\
\hline GSTO2 & 4 & 5 & 9 & 1 & 0 & 0 & 6 & 2 \\
\hline HSD17B1 & 0 & 9 & 9 & 1 & 0 & 0 & 8 & 0 \\
\hline HTRA4 & 0 & 9 & 9 & 1 & 1 & 0 & 7 & 0 \\
\hline INMT & 2 & 7 & 9 & 0 & 0 & 2 & 6 & 1 \\
\hline LRRC6 & 1 & 8 & 9 & 0 & 0 & 1 & 8 & 0 \\
\hline МАРКВIP2 & 0 & 9 & 9 & 0 & 0 & 2 & 6 & 1 \\
\hline MET & 0 & 9 & 9 & 1 & 0 & 1 & 6 & 1 \\
\hline MTRR & 2 & 7 & 9 & 0 & 0 & 0 & 7 & 2 \\
\hline PON2 & 2 & 7 & 9 & 0 & 0 & 0 & 7 & 2 \\
\hline PON3 & 3 & 6 & 9 & 0 & 1 & 0 & 6 & 2 \\
\hline PSG8 & 5 & 4 & 9 & 0 & 0 & 0 & 7 & 2 \\
\hline SCNN1D & 0 & 9 & 9 & 0 & 0 & 0 & 7 & 2 \\
\hline SLC27A1 & 0 & 9 & 9 & 0 & 0 & 0 & 8 & 1 \\
\hline SLCO2A1 & 0 & 9 & 9 & 0 & 0 & 0 & 8 & 1 \\
\hline SULF2 & 0 & 9 & 9 & 0 & 0 & 0 & 9 & 0 \\
\hline$T P M T$ & 0 & 9 & 9 & 0 & 1 & 3 & 5 & 0 \\
\hline$A D A M 12$ & 1 & 7 & 8 & 0 & 1 & 0 & 7 & 0 \\
\hline$A D H 1 B$ & 1 & 7 & 8 & 0 & 1 & 1 & 5 & 1 \\
\hline AKR1C4 & 3 & 5 & 8 & 0 & 0 & 1 & 7 & 0 \\
\hline ALDH6A1 & 1 & 7 & 8 & 1 & 0 & 0 & 5 & 2 \\
\hline ALOX12 & 0 & 8 & 8 & 0 & 1 & 0 & 6 & 1 \\
\hline ANKRD33 & 0 & 8 & 8 & 0 & 0 & 0 & 5 & 3 \\
\hline CYP2A7 & 2 & 6 & 8 & 0 & 0 & 2 & 4 & 2 \\
\hline CYP2E1 & 0 & 8 & 8 & 0 & 0 & 0 & 7 & 1 \\
\hline CYP2J2 & 1 & 7 & 8 & 0 & 0 & 0 & 6 & 2 \\
\hline CYP3A5 & 1 & 7 & 8 & 1 & 0 & 0 & 5 & 2 \\
\hline CYP4A22 & 0 & 8 & 8 & 1 & 2 & 0 & 2 & 3 \\
\hline CYP4F22 & 2 & 6 & 8 & 0 & 0 & 0 & 7 & 1 \\
\hline GFAP & 0 & 8 & 8 & 0 & 0 & 1 & 6 & 1 \\
\hline HSD3B1 & 0 & 8 & 8 & 0 & 0 & 0 & 5 & 3 \\
\hline INSR & 0 & 8 & 8 & 0 & 0 & 0 & 6 & 2 \\
\hline LGALS13 & 2 & 6 & 8 & 0 & 1 & 0 & 7 & 0 \\
\hline NAT2 & 1 & 7 & 8 & 0 & 0 & 1 & 7 & 0 \\
\hline $\mathrm{NQO2}$ & 3 & 5 & 8 & 0 & 0 & 0 & 8 & 0 \\
\hline SCNNIG & 0 & 8 & 8 & 0 & 0 & 0 & 7 & 1 \\
\hline SLC25A25 & 0 & 8 & 8 & 0 & 0 & 0 & 7 & 1 \\
\hline UGT2B 4 & 0 & 8 & 8 & 1 & 0 & 0 & 6 & 1 \\
\hline ADH5 & 2 & 5 & 7 & 0 & 1 & 0 & 5 & 1 \\
\hline ADSL & 0 & 7 & 7 & 0 & 0 & 0 & 6 & 1 \\
\hline$A H R$ & 0 & 7 & 7 & 0 & 0 & 0 & 7 & 0 \\
\hline$A L O X 5$ & 0 & 7 & 7 & 0 & 0 & 0 & 6 & 1 \\
\hline$A R S B$ & 0 & 7 & 7 & 0 & 0 & 0 & 7 & 0 \\
\hline
\end{tabular}




\begin{tabular}{|c|c|c|c|c|c|c|c|c|}
\hline$A R S G$ & 3 & 4 & 7 & 0 & 0 & 0 & 6 & 1 \\
\hline ARSK & 0 & 7 & 7 & 1 & 1 & 0 & 4 & 1 \\
\hline CBR3 & 3 & 4 & 7 & 0 & 0 & 0 & 6 & 1 \\
\hline CTH & 2 & 5 & 7 & 0 & 0 & 1 & 5 & 1 \\
\hline СУР19А1 & 0 & 7 & 7 & 1 & 0 & 0 & 6 & 0 \\
\hline CYP2R1 & 0 & 7 & 7 & 0 & 0 & 0 & 7 & 0 \\
\hline СУРЗА7 & 1 & 6 & 7 & 0 & 0 & 0 & 6 & 1 \\
\hline СУР7B1 & 0 & 7 & 7 & 1 & 0 & 0 & 6 & 0 \\
\hline СУР8B1 & 0 & 7 & 7 & 0 & 0 & 0 & 5 & 2 \\
\hline DNMT1 & 0 & 7 & 7 & 1 & 0 & 0 & 6 & 0 \\
\hline FOXP2 & 1 & 6 & 7 & 0 & 1 & 0 & 6 & 0 \\
\hline GSTA5 & 2 & 5 & 7 & 0 & 0 & 0 & 4 & 3 \\
\hline JAG2 & 0 & 7 & 7 & 0 & 0 & 0 & 5 & 2 \\
\hline LOXL1 & 0 & 7 & 7 & 0 & 0 & 0 & 6 & 1 \\
\hline NOTUM & 1 & 6 & 7 & 0 & 0 & 1 & 6 & 0 \\
\hline NQO1 & 1 & 6 & 7 & 1 & 2 & 0 & 3 & 1 \\
\hline PNMT & 0 & 7 & 7 & 0 & 0 & 1 & 2 & 4 \\
\hline PSG4 & 1 & 6 & 7 & 1 & 0 & 0 & 5 & 1 \\
\hline PSG5 & 2 & 5 & 7 & 0 & 0 & 0 & 6 & 1 \\
\hline SGSH & 0 & 7 & 7 & 1 & 0 & 1 & 5 & 0 \\
\hline$S L C 1 A 3$ & 0 & 7 & 7 & 0 & 0 & 0 & 7 & 0 \\
\hline SULT1C3 & 1 & 6 & 7 & 3 & 0 & 0 & 2 & 2 \\
\hline SULT2A1 & 1 & 6 & 7 & 1 & 0 & 1 & 5 & 0 \\
\hline$T F$ & 0 & 7 & 7 & 0 & 0 & 1 & 5 & 1 \\
\hline$A C H E$ & 0 & 6 & 6 & 0 & 0 & 1 & 5 & 0 \\
\hline ACKR2 & 0 & 6 & 6 & 0 & 0 & 0 & 4 & 2 \\
\hline ADH4 & 0 & 6 & 6 & 2 & 0 & 0 & 3 & 1 \\
\hline$A K R 1 C 1$ & 2 & 4 & 6 & 0 & 0 & 0 & 5 & 1 \\
\hline AKR7A2 & 1 & 5 & 6 & 1 & 0 & 0 & 5 & 0 \\
\hline$A L A D$ & 0 & 6 & 6 & 0 & 0 & 0 & 6 & 0 \\
\hline ALDH7A1 & 0 & 6 & 6 & 0 & 0 & 0 & 4 & 2 \\
\hline CBRI & 1 & 5 & 6 & 0 & 0 & 1 & 5 & 0 \\
\hline CCDC151 & 1 & 5 & 6 & 0 & 0 & 0 & 6 & 0 \\
\hline CHST9 & 0 & 6 & 6 & 0 & 0 & 1 & 4 & 1 \\
\hline CYP27C1 & 1 & 5 & 6 & 0 & 0 & 0 & 6 & 0 \\
\hline СYP4A11 & 3 & 3 & 6 & 0 & 0 & 0 & 5 & 1 \\
\hline CYP4F2 & 1 & 5 & 6 & 2 & 0 & 1 & 2 & 1 \\
\hline CYP4X1 & 1 & 5 & 6 & 0 & 0 & 0 & 6 & 0 \\
\hline DHRS1 & 0 & 6 & 6 & 0 & 0 & 0 & 5 & 1 \\
\hline DNAAF1 & 1 & 5 & 6 & 1 & 0 & 0 & 4 & 1 \\
\hline DNAI2 & 2 & 4 & 6 & 2 & 0 & 1 & 3 & 0 \\
\hline EPYC & 1 & 5 & 6 & 0 & 0 & 2 & 2 & 2 \\
\hline FOLR2 & 1 & 5 & 6 & 0 & 0 & 0 & 5 & 1 \\
\hline GAL3ST3 & 0 & 6 & 6 & 1 & 0 & 0 & 4 & 1 \\
\hline GSTAI & 0 & 6 & 6 & 0 & 0 & 0 & 6 & 0 \\
\hline GSTA2 & 2 & 4 & 6 & 0 & 0 & 0 & 5 & 1 \\
\hline LTA4H & 0 & 6 & 6 & 1 & 0 & 0 & 4 & 1 \\
\hline MTHFR & 0 & 6 & 6 & 0 & 0 & 0 & 6 & 0 \\
\hline NOS1 & 0 & 6 & 6 & 0 & 0 & 0 & 5 & 1 \\
\hline PAOX & 0 & 6 & 6 & 1 & 0 & 1 & 4 & 0 \\
\hline PRKCE & 0 & 6 & 6 & 0 & 0 & 0 & 5 & 1 \\
\hline PSG2 & 1 & 5 & 6 & 0 & 1 & 0 & 4 & 1 \\
\hline PSG6 & 1 & 5 & 6 & 0 & 0 & 1 & 4 & 1 \\
\hline PTGRI & 2 & 4 & 6 & 0 & 0 & 2 & 4 & 0 \\
\hline
\end{tabular}




\begin{tabular}{|c|c|c|c|c|c|c|c|c|}
\hline PTGS1 & 0 & 6 & 6 & 1 & 0 & 0 & 4 & 1 \\
\hline SIGLEC6 & 0 & 6 & 6 & 0 & 0 & 0 & 2 & 4 \\
\hline$S L C 13 A 4$ & 0 & 6 & 6 & 0 & 0 & 0 & 6 & 0 \\
\hline SLC6A12 & 0 & 6 & 6 & 0 & 0 & 0 & 5 & 1 \\
\hline SULF1 & 0 & 6 & 6 & 0 & 0 & 0 & 5 & 1 \\
\hline SULT1A1 & 2 & 4 & 6 & 0 & 0 & 0 & 6 & 0 \\
\hline SULT1E1 & 2 & 4 & 6 & 0 & 0 & 0 & 6 & $\overline{0}$ \\
\hline TFRC & 0 & 6 & 6 & 0 & 0 & 0 & 5 & 1 \\
\hline TXNRD1 & 1 & 5 & 6 & 0 & 0 & 0 & 5 & 1 \\
\hline UGT1A10 & 1 & 5 & 6 & 0 & 0 & 0 & 3 & 3 \\
\hline ADH6 & 0 & 5 & 5 & 1 & 0 & 0 & 4 & $\overline{0}$ \\
\hline$A R S A$ & 1 & 4 & 5 & 0 & 0 & 1 & 2 & 2 \\
\hline ATP1A3 & 0 & 5 & 5 & 1 & 0 & 0 & 4 & 0 \\
\hline CHST1 & 1 & 4 & 5 & 0 & 0 & 0 & 5 & 0 \\
\hline CHST12 & 0 & 5 & 5 & 0 & 0 & 0 & 5 & 0 \\
\hline CHST14 & 0 & 5 & 5 & 0 & 0 & 0 & 5 & 0 \\
\hline CYP11B1 & 0 & 5 & 5 & 0 & 0 & 0 & 5 & $\overline{0}$ \\
\hline CYP26A1 & 0 & 5 & 5 & 0 & 0 & 0 & 4 & 1 \\
\hline DNMT3B & 0 & 5 & 5 & 0 & 1 & 0 & 4 & 0 \\
\hline FLT1 & 0 & 5 & 5 & 0 & 0 & 0 & 5 & 0 \\
\hline FOLR1 & 2 & 3 & 5 & 0 & 0 & 0 & 4 & 1 \\
\hline GAL3ST2 & 1 & 4 & 5 & 0 & 0 & 0 & 2 & 3 \\
\hline GPX5 & 0 & 5 & 5 & 0 & 0 & 1 & 3 & 1 \\
\hline GPX7 & 0 & 5 & 5 & 0 & 0 & 0 & 5 & 0 \\
\hline GUSB & 0 & 5 & 5 & 0 & 0 & 1 & 4 & $\overline{0}$ \\
\hline IFT81 & 1 & 4 & 5 & 0 & 0 & 1 & 3 & 1 \\
\hline JAG1 & 0 & 5 & 5 & 0 & 0 & 0 & 5 & 0 \\
\hline JAM3 & 1 & 4 & 5 & 0 & 0 & 0 & 5 & $\overline{0}$ \\
\hline NTRK2 & 0 & 5 & 5 & 0 & 0 & 0 & 4 & 1 \\
\hline PON1 & 0 & 5 & 5 & 0 & 0 & 0 & 5 & 0 \\
\hline PSG11 & 1 & 4 & 5 & 0 & 0 & 0 & 3 & 2 \\
\hline PTGR2 & 0 & 5 & 5 & 0 & 0 & 0 & 4 & 1 \\
\hline$S L C 1 A 2$ & 1 & 4 & 5 & 0 & 0 & 0 & 4 & 1 \\
\hline$S L C 1 A 4$ & 1 & 4 & 5 & $\overline{1}$ & 0 & 0 & 3 & 1 \\
\hline SLC25A20 & 1 & 4 & 5 & 0 & 0 & 0 & 3 & 2 \\
\hline SLC3A2 & 0 & 5 & 5 & 0 & 0 & 1 & 1 & 3 \\
\hline SMOX & 1 & 4 & 5 & 0 & 1 & 0 & 4 & $\overline{0}$ \\
\hline SULT1B1 & 3 & 2 & 5 & 0 & 0 & 0 & 4 & 1 \\
\hline$V C L$ & 0 & 5 & 5 & 0 & 0 & 0 & 5 & 0 \\
\hline$A B C C 5$ & 0 & 4 & 4 & 1 & 0 & 0 & 3 & 0 \\
\hline AKR1D1 & 2 & 2 & 4 & 0 & 0 & 0 & 4 & 0 \\
\hline ALDH1A2 & 0 & 4 & 4 & 0 & 0 & 0 & 3 & 1 \\
\hline CHST10 & 0 & 4 & 4 & 1 & 0 & 0 & 2 & 1 \\
\hline CHST11 & 1 & 3 & 4 & 0 & 0 & 0 & 3 & 1 \\
\hline CHST13 & 1 & 3 & 4 & 0 & 1 & 0 & 3 & 0 \\
\hline CRYZ & 3 & 1 & 4 & 0 & 0 & 0 & 2 & 2 \\
\hline CYP20A1 & 1 & 3 & 4 & 0 & 0 & 0 & 2 & 2 \\
\hline CYP27B1 & 1 & 3 & 4 & 0 & 0 & 0 & 4 & $\overline{0}$ \\
\hline CYP2S1 & 1 & 3 & 4 & 1 & 0 & 0 & 2 & 1 \\
\hline CYP2U1 & 2 & 2 & 4 & 0 & 0 & 0 & 4 & $\overline{0}$ \\
\hline CYP2W1 & 0 & 4 & 4 & 0 & 0 & 0 & 2 & 2 \\
\hline DNAAF2 & 1 & 3 & 4 & 0 & 0 & 0 & 4 & 0 \\
\hline GALNS & 0 & 4 & 4 & 0 & 0 & 0 & 4 & 0 \\
\hline GH1 & 0 & 4 & 4 & 0 & 0 & 0 & 4 & $\overline{0}$ \\
\hline
\end{tabular}




\begin{tabular}{|c|c|c|c|c|c|c|c|c|}
\hline GPR32 & 0 & 4 & 4 & 0 & 0 & 0 & 4 & 0 \\
\hline GPX4 & 0 & 4 & 4 & 0 & 0 & 0 & 3 & 1 \\
\hline$H G F$ & 2 & 2 & 4 & 0 & 0 & 0 & 3 & 1 \\
\hline MFSD2A & 0 & 4 & 4 & 0 & 0 & 0 & 3 & 1 \\
\hline MTTP & 0 & 4 & 4 & 1 & 0 & 0 & 3 & 0 \\
\hline NAT1 & 1 & 3 & 4 & 0 & 0 & 1 & 0 & 3 \\
\hline NFKB1 & 0 & 4 & 4 & 0 & 0 & 0 & 4 & 0 \\
\hline PRG2 & 0 & 4 & 4 & 0 & 0 & 0 & 3 & 1 \\
\hline PROK1 & 1 & 3 & 4 & 0 & 0 & 1 & 3 & 0 \\
\hline PSG1 & 3 & 1 & 4 & 1 & 0 & 0 & 3 & 0 \\
\hline SERPINE2 & 1 & 3 & 4 & 0 & 0 & 0 & 3 & 1 \\
\hline SLC2A14 & 0 & 4 & 4 & 0 & 1 & 0 & 3 & 0 \\
\hline SLC35D2 & 0 & 4 & 4 & 0 & 0 & 0 & 4 & 0 \\
\hline SULT2B1 & 0 & 4 & 4 & 0 & 1 & 1 & 1 & 1 \\
\hline TPST1 & 0 & 4 & 4 & 0 & 0 & 0 & 3 & 1 \\
\hline UGT2B 28 & 1 & 3 & 4 & 0 & 0 & 0 & 2 & 2 \\
\hline ACTN1 & 0 & 3 & 3 & 0 & 0 & 0 & 2 & 1 \\
\hline$A D A$ & 0 & 3 & 3 & 0 & 0 & 0 & 2 & 1 \\
\hline$A D R B 2$ & 1 & 2 & 3 & 1 & 0 & 0 & 2 & 0 \\
\hline AKR1BI & 0 & 3 & 3 & 0 & 0 & 0 & 3 & 0 \\
\hline AKR1B15 & 0 & 3 & 3 & 0 & 0 & 1 & 2 & 0 \\
\hline$A L D H 1 A 3$ & 0 & 3 & 3 & 0 & 0 & 0 & 2 & 1 \\
\hline$A L D H 3 A 2$ & 0 & 3 & 3 & 0 & 0 & 0 & 1 & 2 \\
\hline$A Q P 9$ & 0 & 3 & 3 & 0 & 0 & 0 & 2 & 1 \\
\hline ATP1B2 & 1 & 2 & 3 & 2 & 0 & 0 & 1 & 0 \\
\hline ATP1B3 & 0 & 3 & 3 & 0 & 0 & 0 & 3 & 0 \\
\hline B3GAT2 & 0 & 3 & 3 & 0 & 0 & 0 & 2 & 1 \\
\hline CHST8 & 0 & 3 & 3 & 0 & 0 & 0 & 3 & 0 \\
\hline CLDN3 & 0 & 3 & 3 & 0 & 0 & 0 & 1 & 2 \\
\hline CYP1B1 & 0 & 3 & 3 & 0 & 0 & 0 & 3 & 0 \\
\hline CYP4Z1 & 0 & 3 & 3 & 0 & 0 & 0 & 3 & 0 \\
\hline CYP51A1 & 0 & 3 & 3 & 0 & 0 & 0 & 3 & 0 \\
\hline$D C X R$ & 0 & 3 & 3 & 0 & 0 & 0 & 3 & 0 \\
\hline EPHX3 & 0 & 3 & 3 & 0 & 0 & 0 & 3 & 0 \\
\hline$F A M 26 D$ & 0 & 3 & 3 & 0 & 0 & 1 & 2 & 0 \\
\hline GABBR2 & 0 & 3 & 3 & 0 & 0 & 0 & 3 & 0 \\
\hline GABRA5 & 0 & 3 & 3 & 0 & 0 & 0 & 2 & 1 \\
\hline GAL3ST1 & 0 & 3 & 3 & 0 & 0 & 0 & 2 & 1 \\
\hline GNS & 0 & 3 & 3 & 0 & 0 & 0 & 3 & 0 \\
\hline GSTM5 & 2 & 1 & 3 & 0 & 0 & 0 & 3 & 0 \\
\hline GSTP1 & 0 & 3 & 3 & 0 & 0 & 0 & 3 & 0 \\
\hline HSD11B1 & 0 & 3 & 3 & 0 & 0 & 0 & 3 & 0 \\
\hline INSL4 & 2 & 1 & 3 & 0 & 0 & 0 & 3 & 0 \\
\hline IYD & 0 & 3 & 3 & 0 & 0 & 0 & 3 & 0 \\
\hline NNMT & 0 & 3 & 3 & 0 & 0 & 0 & 3 & 0 \\
\hline PARD6B & 0 & 3 & 3 & 1 & 0 & 0 & 2 & 0 \\
\hline PRKCZ & 0 & 3 & 3 & 0 & 0 & 0 & 3 & 0 \\
\hline PTGES2 & 0 & 3 & 3 & 0 & 0 & 0 & 3 & 0 \\
\hline SLC16A1 & 0 & 3 & 3 & 0 & 0 & 0 & 3 & 0 \\
\hline SLC19A1 & 0 & 3 & 3 & 1 & 0 & 1 & 1 & 0 \\
\hline$S L C 2 A 3$ & 0 & 3 & 3 & 0 & 0 & 1 & 2 & 0 \\
\hline SLC6A4 & 0 & 3 & 3 & 0 & 0 & 0 & 3 & 0 \\
\hline SULT1C4 & 0 & 3 & 3 & 0 & 0 & 0 & 2 & 1 \\
\hline TP53I3 & 1 & 2 & 3 & 1 & 0 & 0 & 1 & 1 \\
\hline
\end{tabular}




\begin{tabular}{|c|c|c|c|c|c|c|c|c|}
\hline TPST2 & 0 & 3 & 3 & 0 & 0 & 0 & 3 & 0 \\
\hline UGT1A8 & 1 & 2 & 3 & 0 & 0 & 0 & 2 & 1 \\
\hline AOC3 & 2 & 0 & 2 & 0 & 0 & 0 & 2 & 0 \\
\hline$A Q P 4$ & 0 & 2 & 2 & 0 & 0 & 0 & 2 & 0 \\
\hline ATP1A2 & 0 & 2 & 2 & 0 & 0 & 0 & 1 & 1 \\
\hline B3GAT3 & 0 & 2 & 2 & 0 & 0 & 0 & 2 & 0 \\
\hline CHST3 & 0 & 2 & 2 & 0 & 0 & 0 & 2 & 0 \\
\hline CLDN1 & 0 & 2 & 2 & 0 & 0 & 1 & 1 & 0 \\
\hline СУР46A1 & 0 & 2 & 2 & 0 & 0 & 0 & 2 & 0 \\
\hline$E B I 3$ & 0 & 2 & 2 & 0 & 0 & 0 & 2 & 0 \\
\hline EPHX4 & 0 & 2 & 2 & 0 & 0 & 0 & 1 & 1 \\
\hline FCGR2B & 0 & 2 & 2 & 0 & 0 & 0 & 2 & 0 \\
\hline GABRAI & 0 & 2 & 2 & 0 & 0 & 0 & 2 & 0 \\
\hline GNGT1 & 0 & 2 & 2 & 0 & 0 & 0 & 2 & 0 \\
\hline GSTA4 & 0 & 2 & 2 & 0 & 0 & 0 & 2 & 0 \\
\hline GSTM2 & 1 & 1 & 2 & 0 & 0 & 0 & 1 & 1 \\
\hline GSTZ1 & 1 & 1 & 2 & 0 & 0 & 0 & 0 & 2 \\
\hline HNMT & 0 & 2 & 2 & 0 & 0 & 0 & 2 & 0 \\
\hline LGALS14 & 1 & 1 & 2 & 1 & 0 & 0 & 1 & 0 \\
\hline MGST1 & 1 & 1 & 2 & 0 & 0 & 0 & 2 & 0 \\
\hline MGST2 & 1 & 1 & 2 & 0 & 0 & 1 & 1 & 0 \\
\hline MGST3 & 0 & 2 & 2 & 0 & 0 & 0 & 2 & 0 \\
\hline MTF1 & 0 & 2 & 2 & 0 & 0 & 0 & 2 & 0 \\
\hline OCLN & 0 & 2 & 2 & 0 & 0 & 1 & 0 & 1 \\
\hline PARD6G & 0 & 2 & 2 & 0 & 0 & 0 & 1 & 1 \\
\hline PTGES & 0 & 2 & 2 & 0 & 0 & 0 & 2 & 0 \\
\hline$Q D P R$ & 0 & 2 & 2 & 0 & 0 & 0 & 2 & 0 \\
\hline$R A B 3 B$ & 0 & 2 & 2 & 0 & 0 & 0 & 2 & 0 \\
\hline SLC39A8 & 0 & 2 & 2 & 0 & 0 & 1 & 1 & 0 \\
\hline SLC7A1 & 0 & 2 & 2 & 0 & 0 & 0 & 2 & 0 \\
\hline TFPI2 & 0 & 2 & 2 & 0 & 0 & 0 & 2 & 0 \\
\hline WNT3A & 0 & 2 & 2 & 0 & 0 & 0 & 2 & 0 \\
\hline$A D H 1 C$ & 0 & 1 & 1 & 0 & 0 & 0 & 1 & 0 \\
\hline ATP1A1 & 0 & 1 & 1 & 0 & 0 & 0 & 1 & 0 \\
\hline ATP1B1 & 0 & 1 & 1 & 0 & 0 & 0 & 1 & 0 \\
\hline B3GAT1 & 1 & 0 & 1 & 0 & 0 & 0 & 1 & 0 \\
\hline$C \boldsymbol{G A}$ & 0 & 1 & 1 & 0 & 0 & 0 & 1 & 0 \\
\hline CGB1 & 0 & 1 & 1 & 0 & 0 & 0 & 1 & 0 \\
\hline CLDN12 & 0 & 1 & 1 & 0 & 0 & 0 & 1 & 0 \\
\hline $\mathrm{CRH}$ & 0 & 1 & 1 & 0 & 0 & 0 & 1 & 0 \\
\hline CSH1 & 0 & 1 & 1 & 0 & 0 & 0 & 1 & 0 \\
\hline $\mathrm{CSH} 2$ & 0 & 1 & 1 & 0 & 0 & 1 & 0 & 0 \\
\hline CYP26C1 & 0 & 1 & 1 & 0 & 0 & 0 & 1 & 0 \\
\hline DHRS3 & 0 & 1 & 1 & 0 & 1 & 0 & 0 & 0 \\
\hline DHRS4 & 0 & 1 & 1 & 0 & 0 & 0 & 0 & 1 \\
\hline GABRB3 & 0 & 1 & 1 & 0 & 0 & 0 & 1 & 0 \\
\hline GSTK1 & 0 & 1 & 1 & 0 & 0 & 0 & 1 & 0 \\
\hline GSTM3 & 0 & 1 & 1 & 0 & 0 & 0 & 1 & 0 \\
\hline$J A M 2$ & 0 & 1 & 1 & 0 & 0 & 0 & 0 & 1 \\
\hline KRTAP26-1 & 0 & 1 & 1 & 0 & 0 & 0 & 0 & 1 \\
\hline LOX & 0 & 1 & 1 & 0 & 0 & 0 & 1 & 0 \\
\hline MEST & 0 & 1 & 1 & 0 & 0 & 0 & 1 & 0 \\
\hline MT1A & 0 & 1 & 1 & 0 & 0 & 0 & 1 & 0 \\
\hline MT1B & 0 & 1 & 1 & 0 & 0 & 1 & 0 & 0 \\
\hline
\end{tabular}


bioRxiv preprint doi: https://doi.org/10.1101/520544; this version posted January 15,2019 . The copyright holder for this preprint (which was not certified by peer review) is the author/funder. All rights reserved. No reuse allowed without permission.

\begin{tabular}{|l|c|c|r||r|r|r|r|r|} 
NOS1AP & 0 & 1 & 1 & 0 & 0 & 0 & 1 & 0 \\
\hline PTGS2 & 0 & 1 & 1 & 0 & 0 & 0 & 1 & 0 \\
\hline RSPH9 & 0 & 1 & 1 & 0 & 0 & 0 & 1 & 0 \\
\hline SLC25A12 & 0 & 1 & 1 & 0 & 0 & 0 & 1 & 0 \\
\hline SLC25A24 & 1 & 0 & 1 & 0 & 0 & 0 & 1 & 0 \\
\hline SLC29A1 & 0 & 1 & 1 & 0 & 0 & 0 & 1 & 0 \\
\hline SLC7A5 & 0 & 1 & 1 & 0 & 0 & 0 & 1 & 0 \\
\hline TAC3 & 0 & 1 & 1 & 0 & 0 & 1 & 0 & 0 \\
\hline VEGFA & 0 & 1 & 1 & 0 & 0 & 0 & 1 & 0 \\
\hline
\end{tabular}


Cytochrome P450 enzymes

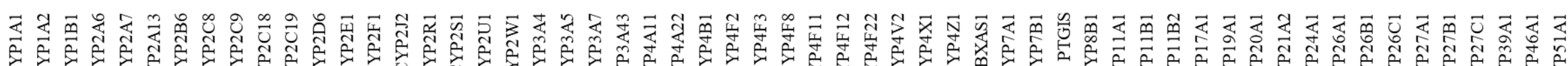

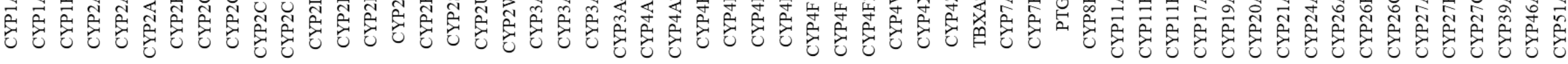

\begin{tabular}{|c|c|c|c|c|}
\hline FMOs & Amine Oxidases & PTGs & Lipoxygenases & UDP-glucuronosyltransferases \\
\hline 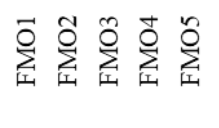 & 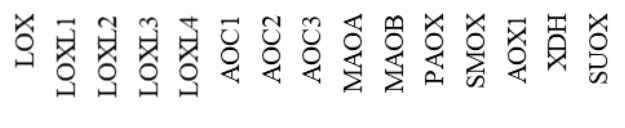 & 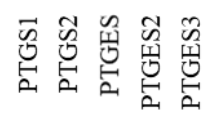 & 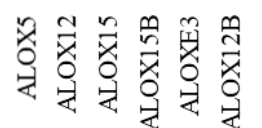 & 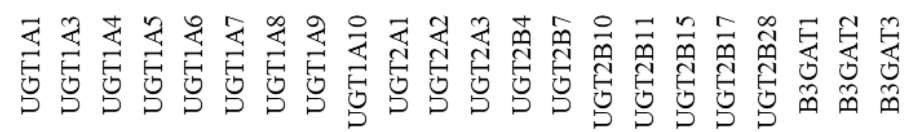 \\
\hline
\end{tabular}

\section{NATs} Glutathione S-transferases

Sulfotransferases

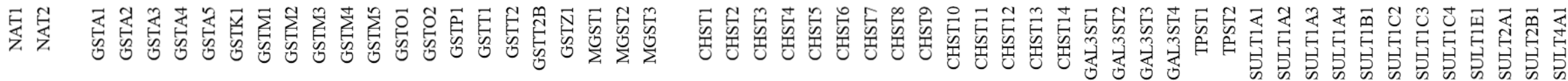

EHs

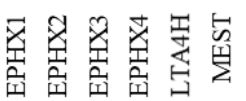

Sulfatases

\section{NAPH-dependent carbonyl and quinone reductases}

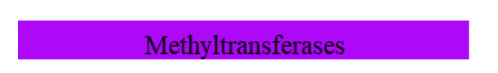

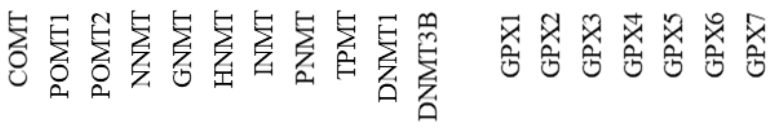

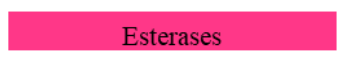

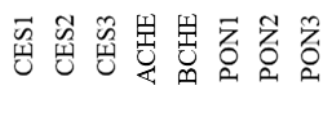

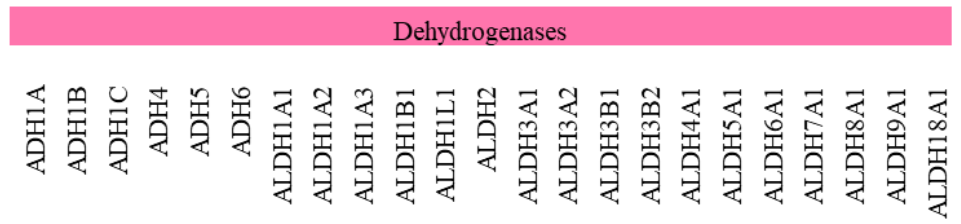

NOSs

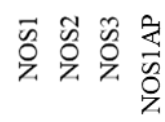

\section{$\begin{array}{lll}\text { GABA receptors } & \text { Folate metabolism enzymes enzymes/receptors }\end{array}$}

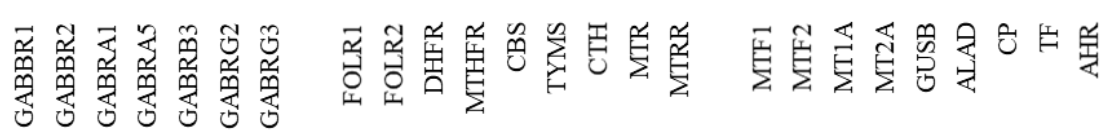

Figure S1a: Genes involved in detoxification processes identified through systematic literature review. Gene symbols are in accordance with HUGO Gene Nomenclature Committee (HGCN). 
Blood-brain barrier genes

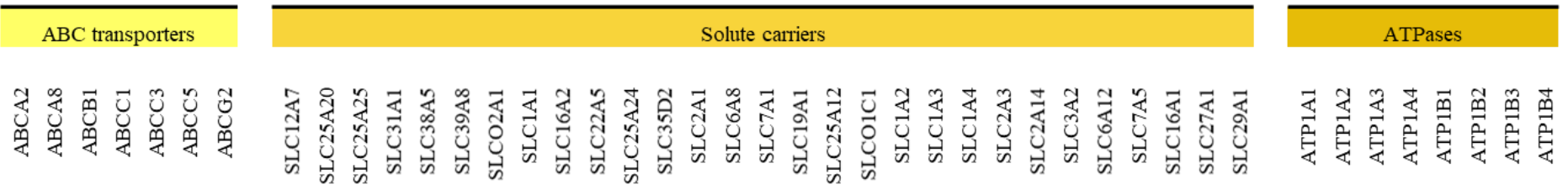

Brain endothelial junctional complex proteins

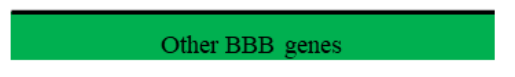

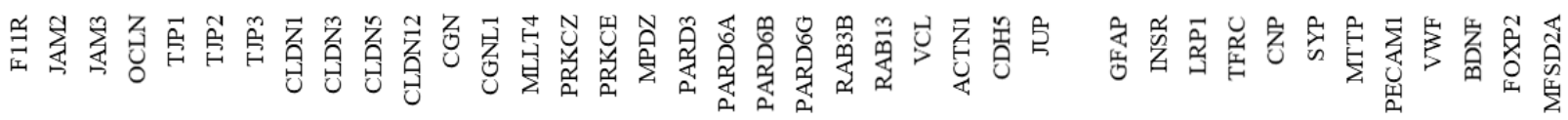

\begin{tabular}{|c|c|c|c|c|c|c|}
\hline PSGs & hCGs & Other Hormones & Galectins & NOTCHs & Other Receptors and Transporters & ERVs \\
\hline 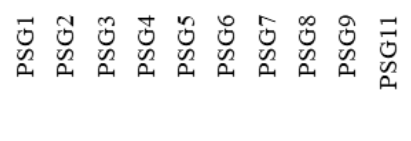 & 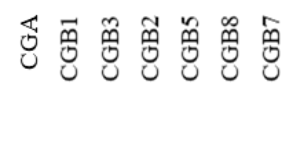 & 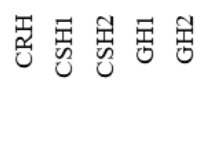 & 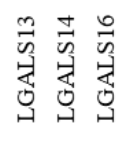 & 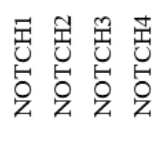 & 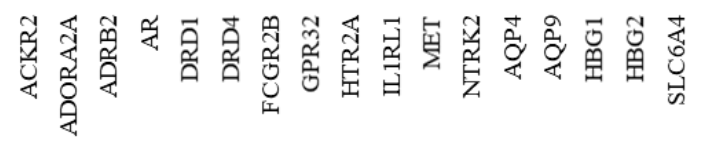 & 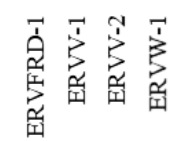 \\
\hline
\end{tabular}

Placenta genes

Genes related to morphogenesis

Other genes highly-expressed at the placenta

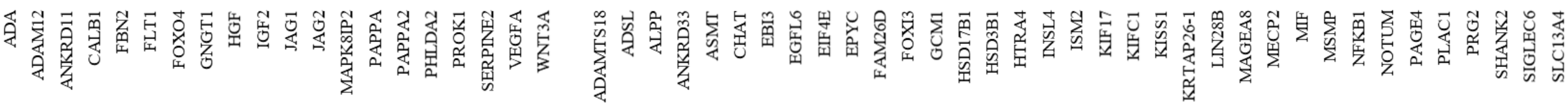

Other genes

Respiratory cilia genes

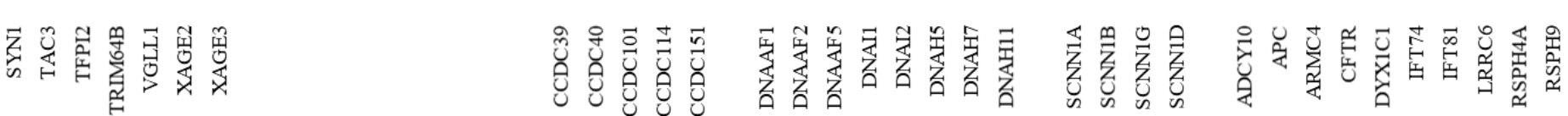

Figure S1b: Genes involved in regulation of barriers permeability processes identified through systematic literature review. Gene symbols are in accordance with HUGO Gene Nomenclature Committee (HGCN). 
Literature review; Human Protein Atlas; The Toxin and Toxin-Target Database

AGP dataset - 2446 ASD-subjects with 27944

high-confidence or experimentally validated genic CNVs
Toxin and Toxint Target Database
519 detoxification and barrier genes identified

STEP 1: Select CNVs targeting detoxification and barrier permeability genes

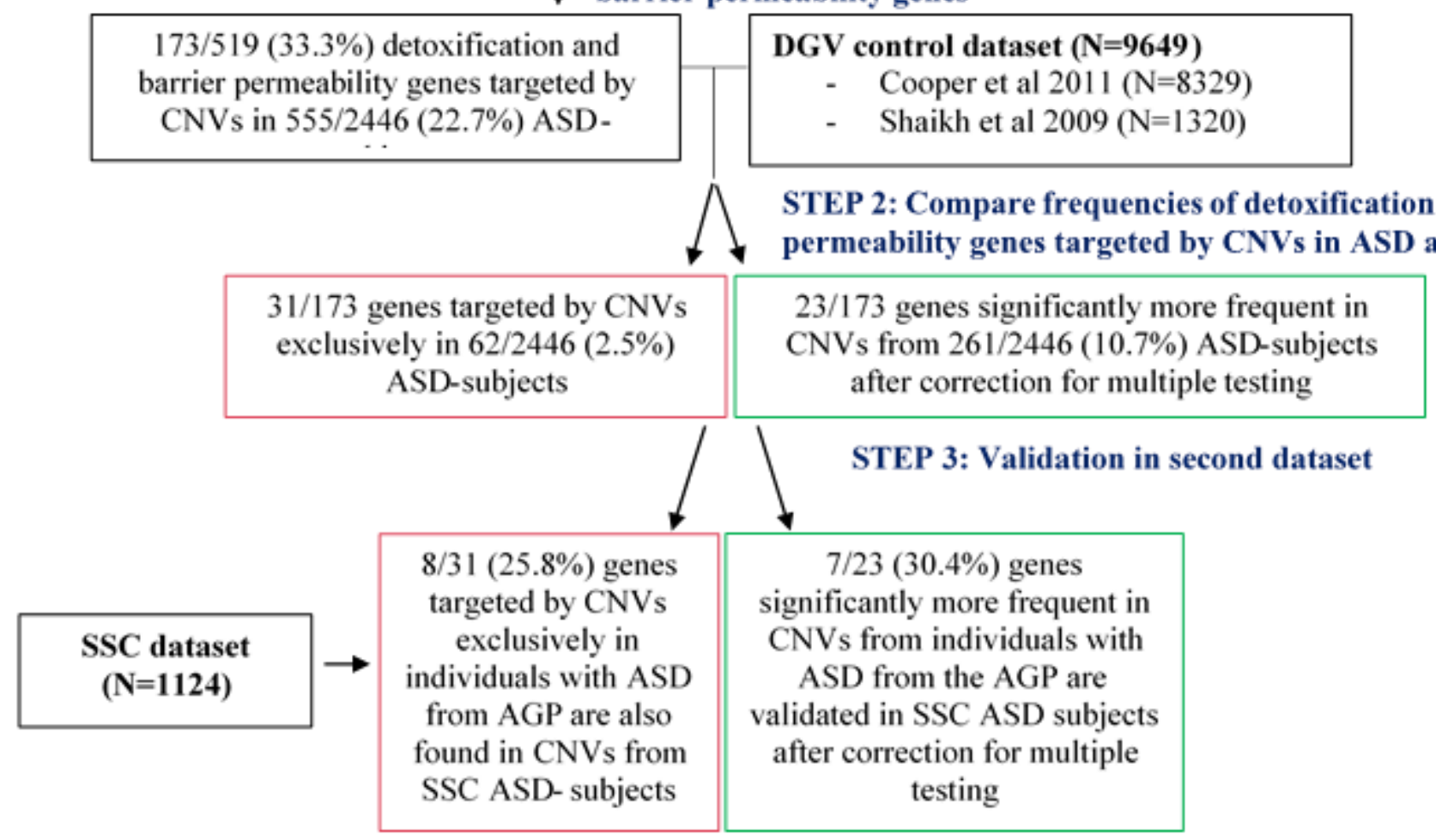

Figure S2: Main results regarding the numbers and percentages of detoxification and barrier genes targeted by CNVs in individuals from the AGP dataset and the validation results using the SSC dataset. 